\title{
Prototype Data Models and Data Dictionaries for Hanford Sediment Physical and Hydraulic Properties
}

\author{
ML Rockhold LA Middleton
}

GV Last

September 2010

\section{Pacific Northwest}

NATIONAL LABORATORY

Proudly Operated by Battelle Since 1965 


\title{
DISCLAIMER
}

This report was prepared as an account of work sponsored by an agency of the United States Government. Neither the United States Government nor any agency thereof, nor Battelle Memorial Institute, nor any of their employees, makes any warranty, express or implied, or assumes any legal liability or responsibility for the accuracy, completeness, or usefulness of any information, apparatus, product, or process disclosed, or represents that its use would not infringe privately owned rights. Reference herein to any specific commercial product, process, or service by trade name, trademark, manufacturer, or otherwise does not necessarily constitute or imply its endorsement, recommendation, or favoring by the United States Government or any agency thereof, or Battelle Memorial Institute. The views and opinions of authors expressed herein do not necessarily state or reflect those of the United States Government or any agency thereof.

\author{
PACIFIC NORTHWEST NATIONAL LABORATORY \\ operated by \\ BATTELLE \\ for the \\ UNITED STATES DEPARTMENT OF ENERGY \\ under Contract DE-AC05-76RL01830
}

Printed in the United States of America

Available to DOE and DOE contractors from the

Office of Scientific and Technical Information,

P.O. Box 62, Oak Ridge, TN 37831-0062;

ph: (865) 576-8401

fax: $(865) 576-5728$

email: reports@adonis.osti.gov

\author{
Available to the public from the National Technical Information Service \\ 5301 Shawnee Rd., Alexandria, VA 22312 \\ ph: (800) 553-NTIS (6847) \\ email: orders $a$ ntis.gov $<$ http://www.ntis.gov/about/form.aspx $>$ \\ Online ordering: http://www.ntis.gov
}

This document was printed on recycled paper. 


\title{
Prototype Data Models and Data Dictionaries for Hanford Sediment Physical and Hydraulic Properties
}

\author{
ML Rockhold \\ LA Middleton \\ GV Last
}

September 2010

Prepared for

the U.S. Department of Energy

under Contract DE-AC05-76RL01830

Pacific Northwest National Laboratory

Richland, Washington 99352 



\begin{abstract}
The Remediation Decision Support (RDS) project, managed by the Pacific Northwest National Laboratory (PNNL) for the U.S. Department of Energy (DOE) and the CH2M HILL Plateau Remediation Company (CHPRC), has been compiling physical and hydraulic property data and parameters to support risk analyses and waste management decisions at Hanford. In FY09 the RDS project developed a strategic plan for a physical and hydraulic property database. This report documents prototype data models and dictionaries for these properties and associated parameters.
\end{abstract}





\section{Acknowledgments}

We thank Bruce Williams and William D. Webber of CHPRC for providing oversight for the RDS project and review comment on this and related works. 



\section{Acronyms and Abbreviations}

CHPRC

DOE

EDM

EMSL

HEIS

HLAN

HTAG

PNNL

PSD

RDS

SFTEL
CH2M HILL Plateau Remediation Company

U.S. Department of Energy

Environmental Data Manager

Environmental Molecular Sciences Laboratory

Hanford Environmental Information System

Hanford Local Area Network

Hanford Technical Advisory Group

Pacific Northwest National Laboratory

particle size distribution

Remediation Decision Support

Subsurface Flow and Transport Experimental Laboratory 



\section{Contents}

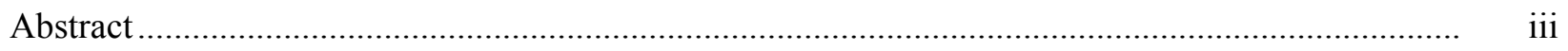

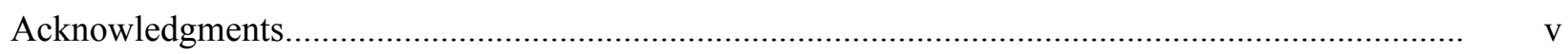

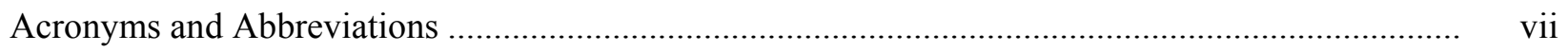

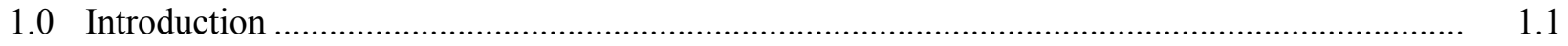

2.0 Physical Properties and Hydraulic Parameters .................................................................. 2.1

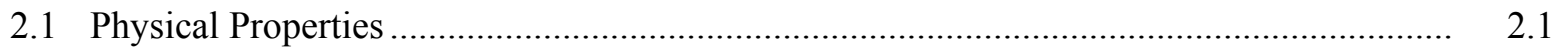

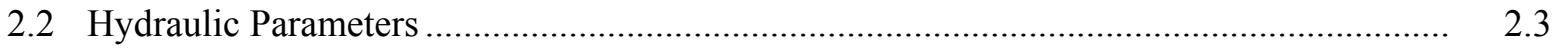

3.0 Prototype Data Models and Data Dictionaries ................................................................

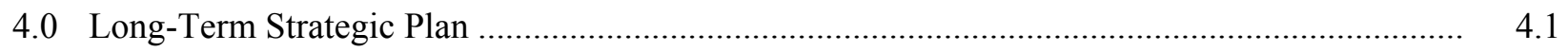

5.0 Summary and Conclusions …...................................................................................... 5.1

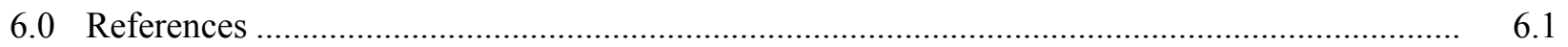

Appendix A - Water Retention Data, Parameters, and Plots of Fitted Retention Functions for Core Samples from Boreholes S-1, S-2, and S-3 at the Sisson and Lu Field Experimental Site in the Hanford 200 East Area. 


\section{Figures}

2.1 Example of Grain-Size Distribution Data and Metrics for a Sediment Sample from the Hanford 300 Area

2.2 Measured and Fitted Water Retention Characteristics for Sample S1-24 from the Sisson and $\mathrm{Lu}$ Site.

2.3 Unsaturated Hydraulic Conductivity Functions for Sample S1-24 from the Sisson and Lu Site

A.1. Water retention data, fitted parameters, and plots showing fits of the van Genuchten (1980), Brooks and Corey (1964) and Campbell (1974) functions for sample S-1/24 from the Sisson and $\mathrm{Lu}$ (1980) field experimental site in the Hanford 200 East Area.

A.2. Water retention data, fitted parameters, and plots showing fits of the van Genuchten (1980), Brooks and Corey (1964) and Campbell (1974) functions for sample S-1/25 from the Sisson and $\mathrm{Lu}$ (1980) field experimental site in the Hanford 200 East Area.

A.3. Water retention data, fitted parameters, and plots showing fits of the van Genuchten (1980), Brooks and Corey (1964) and Campbell (1974) functions for sample S-1/26B from the Sisson and $\mathrm{Lu}$ (1980) field experimental site in the Hanford 200 East Area.

A.4. Water retention data, fitted parameters, and plots showing fits of the van Genuchten (1980), Brooks and Corey (1964) and Campbell (1974) functions for sample S-1/26C from the Sisson and $\mathrm{Lu}$ (1980) field experimental site in the Hanford 200 East Area.

A.5. Water retention data, fitted parameters, and plots showing fits of the van Genuchten (1980), Brooks and Corey (1964) and Campbell (1974) functions for sample S-1/26D from the Sisson and $\mathrm{Lu}(1980)$ field experimental site in the Hanford 200 East Area.

A.6. Water retention data, fitted parameters, and plots showing fits of the van Genuchten (1980), Brooks and Corey (1964) and Campbell (1974) functions for sample S-1/27B from the Sisson and $\mathrm{Lu}$ (1980) field experimental site in the Hanford 200 East Area.

A.7. Water retention data, fitted parameters, and plots showing fits of the van Genuchten (1980), Brooks and Corey (1964) and Campbell (1974) functions for sample S-1/27D from the Sisson and $\mathrm{Lu}$ (1980) field experimental site in the Hanford 200 East Area.

A.8. Water retention data, fitted parameters, and plots showing fits of the van Genuchten (1980), Brooks and Corey (1964) and Campbell (1974) functions for sample S-1/29 from the Sisson and Lu (1980) field experimental site in the Hanford 200 East Area.

A.9. Water retention data, fitted parameters, and plots showing fits of the van Genuchten (1980), Brooks and Corey (1964) and Campbell (1974) functions for sample S-1/32B from the Sisson and $\mathrm{Lu}$ (1980) field experimental site in the Hanford 200 East Area.

A.10. Water retention data, fitted parameters, and plots showing fits of the van Genuchten (1980), Brooks and Corey (1964) and Campbell (1974) functions for sample S-1/32C from the Sisson and $\mathrm{Lu}$ (1980) field experimental site in the Hanford 200 East Area.

A.11. Water retention data, fitted parameters, and plots showing fits of the van Genuchten (1980), Brooks and Corey (1964) and Campbell (1974) functions for sample S-1/34B from the Sisson and $\mathrm{Lu}$ (1980) field experimental site in the Hanford 200 East Area.

A.12. Water retention data, fitted parameters, and plots showing fits of the van Genuchten (1980), Brooks and Corey (1964) and Campbell (1974) functions for sample S-1/34C from the Sisson and $\mathrm{Lu}$ (1980) field experimental site in the Hanford 200 East Area. 
A.13. Water retention data, fitted parameters, and plots showing fits of the van Genuchten (1980), Brooks and Corey (1964) and Campbell (1974) functions for sample S-1/34D from the Sisson and $\mathrm{Lu}$ (1980) field experimental site in the Hanford 200 East Area.

A.14. Water retention data, fitted parameters, and plots showing fits of the van Genuchten (1980), Brooks and Corey (1964) and Campbell (1974) functions for sample S-1/36B from the Sisson and $\mathrm{Lu}$ (1980) field experimental site in the Hanford 200 East Area.

A.15. Water retention data, fitted parameters, and plots showing fits of the van Genuchten (1980), Brooks and Corey (1964) and Campbell (1974) functions for sample S-1/36C from the Sisson and $\mathrm{Lu}$ (1980) field experimental site in the Hanford 200 East Area.

A.16. Water retention data, fitted parameters, and plots showing fits of the van Genuchten (1980), Brooks and Corey (1964) and Campbell (1974) functions for sample S-1/36D from the Sisson and $\mathrm{Lu}(1980)$ field experimental site in the Hanford 200 East Area.

A.17. Water retention data, fitted parameters, and plots showing fits of the van Genuchten (1980), Brooks and Corey (1964) and Campbell (1974) functions for sample S-1/38B from the Sisson and $\mathrm{Lu}$ (1980) field experimental site in the Hanford 200 East Area.

A.18. Water retention data, fitted parameters, and plots showing fits of the van Genuchten (1980), Brooks and Corey (1964) and Campbell (1974) functions for sample S-1/38C from the Sisson and $\mathrm{Lu}$ (1980) field experimental site in the Hanford 200 East Area.

A.19. Water retention data, fitted parameters, and plots showing fits of the van Genuchten (1980), Brooks and Corey (1964) and Campbell (1974) functions for sample S-1/38D from the Sisson and Lu (1980) field experimental site in the Hanford 200 East Area.

A.20. Water retention data, fitted parameters, and plots showing fits of the van Genuchten (1980), Brooks and Corey (1964) and Campbell (1974) functions for sample S-1/40B from the Sisson and $\mathrm{Lu}$ (1980) field experimental site in the Hanford 200 East Area.

A.21. Water retention data, fitted parameters, and plots showing fits of the van Genuchten (1980), Brooks and Corey (1964) and Campbell (1974) functions for sample S-1/40C from the Sisson and $\mathrm{Lu}$ (1980) field experimental site in the Hanford 200 East Area.

A.22. Water retention data, fitted parameters, and plots showing fits of the van Genuchten (1980), Brooks and Corey (1964) and Campbell (1974) functions for sample S-1/40D from the Sisson and Lu (1980) field experimental site in the Hanford 200 East Area.

A.23. Water retention data, fitted parameters, and plots showing fits of the van Genuchten (1980), Brooks and Corey (1964) and Campbell (1974) functions for sample S-1/42B from the Sisson and $\mathrm{Lu}$ (1980) field experimental site in the Hanford 200 East Area.

A.24. Water retention data, fitted parameters, and plots showing fits of the van Genuchten (1980), Brooks and Corey (1964) and Campbell (1974) functions for sample S-1/42D from the Sisson and $\mathrm{Lu}(1980)$ field experimental site in the Hanford 200 East Area.

A.25. Water retention data, fitted parameters, and plots showing fits of the van Genuchten (1980), Brooks and Corey (1964) and Campbell (1974) functions for sample S-1/43C from the Sisson and $\mathrm{Lu}$ (1980) field experimental site in the Hanford 200 East Area.

A.26. Water retention data, fitted parameters, and plots showing fits of the van Genuchten (1980), Brooks and Corey (1964) and Campbell (1974) functions for sample S-1/45B from the Sisson and $\mathrm{Lu}$ (1980) field experimental site in the Hanford 200 East Area.

A.27. Water retention data, fitted parameters, and plots showing fits of the van Genuchten (1980), Brooks and Corey (1964) and Campbell (1974) functions for sample S-1/45C from the Sisson and Lu (1980) field experimental site in the Hanford 200 East Area. 
A.28. Water retention data, fitted parameters, and plots showing fits of the van Genuchten (1980), Brooks and Corey (1964) and Campbell (1974) functions for sample S-1/45D from the Sisson and $\mathrm{Lu}(1980)$ field experimental site in the Hanford 200 East Area.

A.29. Water retention data, fitted parameters, and plots showing fits of the van Genuchten (1980), Brooks and Corey (1964) and Campbell (1974) functions for sample S-2/1B from the Sisson and $\mathrm{Lu}$ (1980) field experimental site in the Hanford 200 East Area.

A.30. Water retention data, fitted parameters, and plots showing fits of the van Genuchten (1980), Brooks and Corey (1964) and Campbell (1974) functions for sample S-2/5C from the Sisson and $\mathrm{Lu}$ (1980) field experimental site in the Hanford 200 East Area.

A.31. Water retention data, fitted parameters, and plots showing fits of the van Genuchten (1980), Brooks and Corey (1964) and Campbell (1974) functions for sample S-2/9B from the Sisson and $\mathrm{Lu}$ (1980) field experimental site in the Hanford 200 East Area.

A.32. Water retention data, fitted parameters, and plots showing fits of the van Genuchten (1980), Brooks and Corey (1964) and Campbell (1974) functions for sample S-2/13C from the Sisson and $\mathrm{Lu}$ (1980) field experimental site in the Hanford 200 East Area.

A.33. Water retention data, fitted parameters, and plots showing fits of the van Genuchten (1980), Brooks and Corey (1964) and Campbell (1974) functions for sample S-2/15B from the Sisson and $\mathrm{Lu}$ (1980) field experimental site in the Hanford 200 East Area.

A.34. Water retention data, fitted parameters, and plots showing fits of the van Genuchten (1980), Brooks and Corey (1964) and Campbell (1974) functions for sample S-2/19B from the Sisson and Lu (1980) field experimental site in the Hanford 200 East Area.

A.35. Water retention data, fitted parameters, and plots showing fits of the van Genuchten (1980), Brooks and Corey (1964) and Campbell (1974) functions for sample S-2/21B from the Sisson and $\mathrm{Lu}$ (1980) field experimental site in the Hanford 200 East Area.

A.36. Water retention data, fitted parameters, and plots showing fits of the van Genuchten (1980), Brooks and Corey (1964) and Campbell (1974) functions for sample S-2/23B from the Sisson and $\mathrm{Lu}$ (1980) field experimental site in the Hanford 200 East Area.

A.37. Water retention data, fitted parameters, and plots showing fits of the van Genuchten (1980), Brooks and Corey (1964) and Campbell (1974) functions for sample S-2/25C from the Sisson and $\mathrm{Lu}$ (1980) field experimental site in the Hanford 200 East Area.

A.38. Water retention data, fitted parameters, and plots showing fits of the van Genuchten (1980), Brooks and Corey (1964) and Campbell (1974) functions for sample S-2/24B from the Sisson and $\mathrm{Lu}$ (1980) field experimental site in the Hanford 200 East Area.

A.39. Water retention data, fitted parameters, and plots showing fits of the van Genuchten (1980), Brooks and Corey (1964) and Campbell (1974) functions for sample S-2/30C from the Sisson and $\mathrm{Lu}$ (1980) field experimental site in the Hanford 200 East Area.

A.40. Water retention data, fitted parameters, and plots showing fits of the van Genuchten (1980), Brooks and Corey (1964) and Campbell (1974) functions for sample S-3/NO1 from the Sisson and Lu (1980) field experimental site in the Hanford 200 East Area.

A.41. Water retention data, fitted parameters, and plots showing fits of the van Genuchten (1980), Brooks and Corey (1964) and Campbell (1974) functions for sample S-3/NO2 from the Sisson and $\mathrm{Lu}(1980)$ field experimental site in the Hanford 200 East Area.

A.42. Water retention data, fitted parameters, and plots showing fits of the van Genuchten (1980), Brooks and Corey (1964) and Campbell (1974) functions for sample S-3/8C from the Sisson and Lu (1980) field experimental site in the Hanford 200 East Area. 
A.43. Water retention data, fitted parameters, and plots showing fits of the van Genuchten (1980), Brooks and Corey (1964) and Campbell (1974) functions for sample S-3/8B from the Sisson and $\mathrm{Lu}$ (1980) field experimental site in the Hanford 200 East Area.

A.44. Water retention data, fitted parameters, and plots showing fits of the van Genuchten (1980), Brooks and Corey (1964) and Campbell (1974) functions for sample S-3/10B from the Sisson and $\mathrm{Lu}$ (1980) field experimental site in the Hanford 200 East Area.

A.45. Water retention data, fitted parameters, and plots showing fits of the van Genuchten (1980), Brooks and Corey (1964) and Campbell (1974) functions for sample S-3/12C from the Sisson and $\mathrm{Lu}$ (1980) field experimental site in the Hanford 200 East Area.

A.46. Water retention data, fitted parameters, and plots showing fits of the van Genuchten (1980), Brooks and Corey (1964) and Campbell (1974) functions for sample S-3/14C from the Sisson and $\mathrm{Lu}$ (1980) field experimental site in the Hanford 200 East Area.

A.47. Water retention data, fitted parameters, and plots showing fits of the van Genuchten (1980), Brooks and Corey (1964) and Campbell (1974) functions for sample S-3/16B from the Sisson and $\mathrm{Lu}$ (1980) field experimental site in the Hanford 200 East Area.

A.48. Water retention data, fitted parameters, and plots showing fits of the van Genuchten (1980), Brooks and Corey (1964) and Campbell (1974) functions for sample S-3/20C from the Sisson and $\mathrm{Lu}$ (1980) field experimental site in the Hanford 200 East Area.

A.49. Water retention data, fitted parameters, and plots showing fits of the van Genuchten (1980), Brooks and Corey (1964) and Campbell (1974) functions for sample S-3/NO3 from the Sisson and Lu (1980) field experimental site in the Hanford 200 East Area.

A.50. Water retention data, fitted parameters, and plots showing fits of the van Genuchten (1980), Brooks and Corey (1964) and Campbell (1974) functions for sample S-3/22C from the Sisson and $\mathrm{Lu}$ (1980) field experimental site in the Hanford 200 East Area.

A.51. Water retention data, fitted parameters, and plots showing fits of the van Genuchten (1980), Brooks and Corey (1964) and Campbell (1974) functions for sample S-3/NO6 from the Sisson and $\mathrm{Lu}(1980)$ field experimental site in the Hanford 200 East Area.

A.52. Water retention data, fitted parameters, and plots showing fits of the van Genuchten (1980), Brooks and Corey (1964) and Campbell (1974) functions for sample S-3/NO7 from the Sisson and Lu (1980) field experimental site in the Hanford 200 East Area.

A.53. Water retention data, fitted parameters, and plots showing fits of the van Genuchten (1980), Brooks and Corey (1964) and Campbell (1974) functions for sample S-3/NO4 from the Sisson and Lu (1980) field experimental site in the Hanford 200 East Area. 


\section{Tables}

3.1 Suggested Data Fields for Master Site and HEIS Sample Number Table ............................... 3.3

3.2 Suggested Data Fields for Physical Properties and Hydraulic Parameters............................. 3.4

3.3 Suggested Data Fields for Water Retention Data ............................................................ 3.6

3.4 Suggested Data Fields for Grain Size Data ...................................................................... 3.7 


\subsection{Introduction}

Physical and hydraulic property data are needed to support numerical modeling of contaminant transport and fate, risk analyses, and remediation decisions for waste sites at Hanford. Physical property data of interest include bulk and particle densities and grain-size distributions. Hydraulic property data include saturated hydraulic conductivity, and relative permeability-saturation-capillary pressure (k-S-p) relations. The latter properties are needed for modeling flow in unsaturated or variably saturated porous media. In Hanford's central plateau, where most of the legacy waste sites are located, the unsaturated sediments are up to $100-\mathrm{m}$ thick, so these sediments and their properties have a dominant influence on the transport and fate of contaminants that have been released into the subsurface.

Physical property data are much less expensive to generate than are hydraulic property data. Hence, grain-size distribution data have been generated for more than 40,000 sediment samples collected during well drilling operations at Hanford. In contrast, direct measurements of unsaturated hydraulic properties on intact or repacked cores are available for just a few hundred samples. High-resolution borehole geophysical logging has also been performed during drilling of most Hanford wells, using primarily total gamma (historical) or spectral gamma (recent), and neutron moisture logging tools. Consequently, recent efforts have focused on using the more prevalent grain-size distribution data in conjunction with borehole geophysical logs to develop property transfer functions that relate the geophysical log data to grain-size distribution metrics, and then correlating the computed grain-size distribution metrics with other properties or parameters of interest including saturated hydraulic conductivity, porosity, water retention parameters, surface area, cation-exchange capacity, etc. These efforts all require the availability of reliable, high-quality, and traceable datasets.

The Remediation Decision Support (RDS) project, managed by Pacific Northwest National Laboratory (PNNL) for the U.S. Department of Energy (DOE) and the CH2M HILL Plateau Remediation Company (CHPRC), has been developing databases of physical and geochemical properties, and hydraulic and sorption parameters to support site assessments at Hanford (Last et al. 2009). One of the goals of this project is to compile high-quality, traceable datasets and parameters that can be used by operable unit managers to support remedial decisions. Efforts have also been initiated to transfer some of the datasets and parameters to CHPRC for inclusion in the Hanford Environmental Information System (HEIS) or equivalent databases. Making these data and parameter estimates available to anyone with access to HEIS should allow for maximum beneficial use of this information.

In FY09, the RDS project presented a long-term strategic plan for development and maintenance of a physical and hydraulic property database for Hanford sediments, and for making this database available to a larger group of potential users on the Hanford local area network (HLAN) via HEIS (Rockhold et al. 2009). Efforts to establish data traceability and to check quality, consistency, and parameter reproducibility for historical data sets prior to transferring data to HEIS were also described. Two initial database schemas, or data models, were proposed - one for physical property data and one for hydraulic parameters. The current report documents revisions to the two earlier data models and proposes two additional data models for 1) water retention data that are needed for reproducibility of some water retention parameter datasets, and 2) a master site and HEIS sample number identification table that links samples to their spatial coordinates. Some version of the latter already exists within the current HEIS framework, but is included here for clarity. 
This report is organized as follows. Section 2 provides a brief review of the primary physical properties and hydraulic parameters that are of interest for transferring to HEIS. Section 3 outlines the steps that will be needed to accomplish the transfer of physical property data and hydraulic parameters to HEIS, and presents the modified and newly proposed data models and data dictionaries. Section 4 reiterates a proposed long-term strategic plan for continued updating, improvement, and expansion of the physical and hydraulic property databases. Sections 5 and 6 present conclusions and references, respectively. Note that portions of this document are taken from Rockhold et al. (2009).

Appendix A contains water retention data, parameters, and plots of fitted water retention functions for core samples from boreholes S-1, S-2, and S-3 at the Sisson and Lu field experimental site located in the Hanford 200 East Area. Hydraulic parameters for these samples were reported previously by Schaap et al. (2003), but the water retention data for these samples were refit using different assumptions to initiate the development of a database of hydraulic parameters. These parameters are all generated in a consistent manner such that more meaningful statistical distributions of the parameters can be generated for Hanford Site-wide applications. 


\subsection{Physical Properties and Hydraulic Parameters}

The two primary types of information that are of interest to this task for transferring to HEIS are physical properties, including bulk and particle densities and grain-size distributions, and hydraulic parameters. Reproducibility of hydraulic parameter datasets also requires that some water retention data be included, so a new schema for these data is proposed. A master site table is also required to link sediment or core samples identified by their HEIS sample numbers (SAMP_NUM) with their spatial coordinates. These database models and dictionaries are described in detail in Section 3.

Additional properties and associated parameters of interest for modeling subsurface flow and reactive transport in Hanford sediments include geochemical properties (e.g. mineralogy, carbonate content, etc.), sorption or transport-related parameters (e.g. cation-exchange capacity, surface area, equilibrium sorption coefficients, etc.), and thermal and electrical properties (e.g. thermal conductivity, specific heat capacity, dielectric permittivity). Separate RDS tasks are responsible for compiling these types of data and associated parameters and these efforts are reported elsewhere (Mackley et al. 2008; Cantrell et al. 2003).

\subsection{Physical Properties}

Physical properties of interest include bulk and particle densities and grain-size distributions. Densities are determined routinely by standard methods, so they will not be discussed further here. Grainsize distribution data have started to be used more quantitatively to estimate other properties, so some further discussion on these data is warranted. Figure 2.1 shows an example of grain size data for a sediment sample from Hanford's 300 Area. Although there can be exceptions, grain size data are typically limited to less than 30 data pairs, each representing the mass fraction of the sediment that is less than a given diameter. These data can be interpolated, or continuous functions can be fit to the data as shown by the pink curve in Figure 2.1, to estimate various grain- or particle-size-distribution (PSD) metrics. Since the number of size metrics that may be of interest could be close to or even exceed the number of actual grain-size distribution data points, it makes more sense to put the fractions passing the different sizes into HEIS rather than the size metrics. This will allow for maximum flexibility in using the data.

Grain-size distributions are fundamental properties of sediments that can be used to estimate many other hydraulic and transport- or sorption-related parameters (e.g. geometric surface area, cationexchange capacity, etc.). The fitted function shown as the pink curve in Figure 2.1 and the various grain size distribution metrics that are reported in the figure were generated using Microsoft ${ }^{\circledR}$ Office $^{\text {Excel }}{ }^{\circledR}$ 2003 with its add-in solver package and custom-built Visual Basic for Applications (VBA) macros ${ }^{1}$. This type of curve fitting and estimation of grain size distribution metrics can also be performed using specialized commercial software packages such as SoilVision ${ }^{\circledR 2}$, or other general purpose scientific software such as Matlab ${ }^{\mathbb{3} 3}$. The types of grain-size distribution metrics shown in Figure 2.1 have proven to be useful for estimating both hydraulic and sorption parameters using empirical correlation functions (Oostrom et al. 2005, Ward et al. 2006, Williams et al. 2008).

\footnotetext{
${ }^{1}$ Excel $^{\circledR}$ is a product of Microsoft ${ }^{\circledR}$ Corp., Redmond, Washington, U.S.A.

${ }^{2}$ SoilVision ${ }^{\circledR}$ is a product of SoilVision ${ }^{\mathbb{B}}$ Systems, Ltd., Saskatoon, SK, Canada.

${ }^{3}$ Matlab $^{\circledR}$ is a product of The Mathworks ${ }^{\circledR}$ Inc., Natick, Massachusetts, U.S.A.
} 


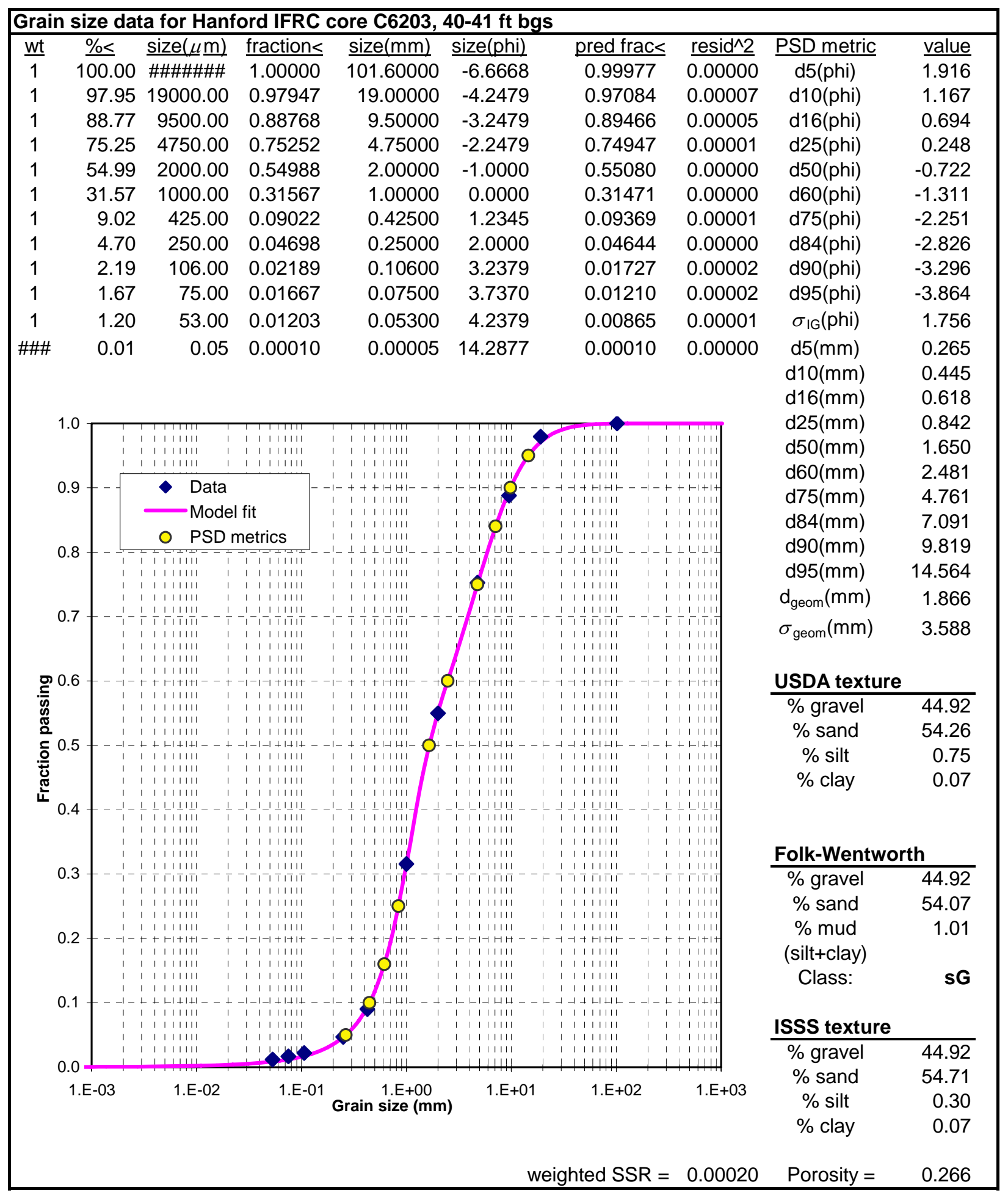

Figure 2.1. Example of Grain-Size Distribution Data and Metrics for a Sediment Sample from the Hanford 300 Area 


\subsection{Hydraulic Parameters}

The governing equations for water or multi-fluid flow in variably saturated porous media require the use of constitutive functions that relate the relative permeability or unsaturated hydraulic conductivity to fluid saturations or water contents and pressures. Although multi-fluid flow is of concern at Hanford (owing to the release of carbon tetrachloride and co-contaminants), our primary interest here is in water flow and associated solute transport. Readers interested in constitutive relative permeability, saturation, and capillary pressure (k-S-p) relations for multi-fluid flow problems, and in particular carbon tetrachloride, are referred to Oostrom et al. (2006).

Water retention characteristics represent the volumes of water held in the porous medium by capillary and adsorptive forces at given energy states or pressures. The unsaturated hydraulic conductivity is the rate at which the porous medium will transmit water for a given saturation and hydraulic gradient. The hydraulic properties of variably saturated porous media are hysteretic, or non-unique, and depend on the wetting and drying history. Hysteresis in these properties is potentially important but is typically neglected because modeling hysteresis requires additional characterization data that are not typically available. Modeling hysteresis also requires significantly more computational effort in subsurface flow and transport simulators.

Various functions have been developed to represent water retention and unsaturated hydraulic conductivity relationships. For example, the van Genuchten (1980) water retention function can be written as

$$
S_{e}(h)=\left[1+(\alpha h)^{n}\right]^{-m}
$$

where:

$S_{e}=$ effective saturation $=\frac{\theta-\theta_{r}}{\theta_{s}-\theta_{r}}, 0 \leq S_{e} \leq 1$

$h=$ soil-moisture tension [L]

$\theta=$ volumetric water content [-]

$\alpha=$ curve-fitting parameter related to the air-entry pressure $\left[\mathrm{L}^{-1}\right]$

$n, m=$ curve-fitting parameters related to pore size distribution; the relationship $m=1-1 / n$ is often assumed [-]

$\theta_{\mathrm{r}}=$ residual water content $[-]$

$\theta_{s}=$ saturated water content $[-]$.

The van Genuchten hydraulic conductivity relationship, based on the Mualem (1976) hydraulic conductivity model, can be written as

$$
K\left(S_{e}\right)=K_{s} S_{e}^{\ell}\left[1-\left(1-S_{e}^{1 / m}\right)^{m}\right]^{2}
$$

where $K_{s}$ is the saturated hydraulic conductivity and $\ell$ is a pore-interaction term that is equal to $1 / 2$ for the Mualem model with $m=1-1 / \mathrm{n}$. The Brooks and Corey (1964) water retention relationship can be written as 


$$
\begin{gathered}
S_{e}(h)=\left(\frac{h_{b}}{h}\right)^{\lambda} \text { for } h \geq h_{b} \\
S_{e}(h)=1 \text { otherwise. }
\end{gathered}
$$

where $h_{b}$ is the air-entry pressure and $\lambda$ is a pore-size distribution index. The Brooks-Corey function can be combined with the Burdine (1953) or Mualem (1976) relative permeability model to yield

$$
K\left(S_{e}\right)=K_{s} S_{e}^{2+\ell+2 / \lambda}
$$

where $\ell=1 / 2$ for the Mualem model and $\ell=1$ for the Burdine model.

The Campbell (1974) water retention function is written as

$$
\begin{gathered}
\frac{\theta}{\theta_{s}}=\left(\frac{h_{b}}{h}\right)^{1 / b} \text { for } h \geq h_{b} \\
\frac{\theta}{\theta_{s}}=1 \text { otherwise, }
\end{gathered}
$$

where $b$ is also a pore-size distribution index. The corresponding hydraulic conductivity relationship for the Campbell (1974) model is

$$
K(\theta)=K_{s}\left(\frac{\theta}{\theta_{s}}\right)^{2 b+3}
$$

Note that all of the single-valued water retention and hydraulic conductivity relationships given above assume that hysteresis is not important.

Using the so-called Mualem-based restriction, $m=1-1 / n$, the van Genuchten water retention function plots as an $S$-shaped curve that is symmetric in the dry and wet ends (van Genuchten, 1980). If $m$ and $n$ are both allowed to be free parameters, such that $m \neq 1-1 / n$, the curve can be asymmetric and even mimic the shape of a Brooks-Corey or Campbell type water retention function that has a sharp air-entry pressure. However, in this case the unsaturated hydraulic conductivity function becomes more complicated than that given by Eq. (2.2) and requires the use of complete and incomplete beta functions that have to be evaluated numerically. Some further discussion about alternative models developed to represent conditions ranging from fully water-saturated to air-dry is given in Section 3.0.

For the Campbell and Brooks-Corey water retention models, the parameter $\lambda=1 / b$, and the two models are equivalent when $\theta_{r}=0$. In this case the Campbell hydraulic conductivity function is also equivalent to the combined Brooks-Corey and Burdine models, with $\ell=1.0$. Although the exponent $\ell$ representing pore-interaction terms in Eq. (2.2) and (2.4) takes on certain values for specific models, it can also be treated as an unknown parameter to be estimated. Data for estimating parameters such as $\ell$ usually come from so-called multistep outflow experiments (Tuli et al. 2001). 
Because of their additional parameters, the van Genuchten and Brooks-Corey models usually fit water retention data somewhat better than the Campbell model. The Campbell functions are included here primarily because they are used in the RESRAD model (Yu et al. 1993) that is used for some risk assessments at Hanford and elsewhere. The RESRAD manual contains a list of default values of the $b$ parameter for different soil types. These default parameters (from Clapp and Hornberger, 1978) are applicable to soil types that have much finer textures than are typical for Hanford sediments. The default RESRAD $b$ values are generally larger than what should be expected for most Hanford sediments.

Meyer et al. (1997) derived an expression for $b$ in terms of $\theta_{s}, \theta_{r}$, and $\lambda$, assuming that the BrooksCorey and Campbell models predict the same hydraulic conductivity for a given value of water content. The water content used is that corresponding to an effective saturation of 0.5 . This yields the following equation that can be solved for $b$

$$
b=0.5\left\{\frac{\ln (0.5)(3+2 / \lambda)}{\ln \left[0.5\left(1+\theta_{r} / \theta_{s}\right)\right]}-3\right\} .
$$

If Brooks-Corey model parameters are available but the water retention data are not, Eq. (2.7) can be used to estimate the $b$ parameter. Another alternative for estimating the Campbell $b$ parameter that was used by Last et al. (2009) is to use van Genuchten or Brooks-Corey model parameters to generate discrete water retention data points and then to refit these generated values using the Campbell model.

Figure 2.2 shows water retention data for a sample collected from the Sisson and $\mathrm{Lu}$ (1980) site in the 200 East Area of the Hanford Site, generated from a multistep outflow experiment. The methods used for measuring physical properties and estimating hydraulic parameter for samples from this site are described by Schaap et al. (2003). The general procedures for performing multistep outflow experiments and for estimating hydraulic parameters using inverse modeling are described by Tuli et al. (2001). The fits of various water retention functions to the data using different procedures are also shown.

As discussed previously by Rockhold et al. (2009), Figure 2.2 illustrates some interesting points. The porosity of each of the samples described by Schaap et al. (2003) was calculated in the conventional way from

$$
\phi=1-\frac{\rho_{b}}{\rho_{s}}
$$

where $\rho_{b}$ and $\rho_{s}$ are the measured bulk density and the assumed particle density $\left(2.65 \mathrm{~g} \mathrm{~cm}^{-3}\right)$, respectively. The multistep outflow experiment that was performed on this sample started with an equivalent tension of $12.5 \mathrm{~cm}$ of water. Given the relatively coarse nature of these sediments, this tension resulted in nearly $30 \%$ of the available water in the sample draining during the first pressure step. For hydraulic parameter estimation, Schapp et al. (2003) report that the $\theta_{s}$ values were fit using an optimization procedure and the calculated values of porosity were simply used as upper bound constraints on the fitted values of $\theta_{s}$. Consequently, almost all of the fitted values of $\theta_{s}$ are significantly lower than the calculated values of porosity, as shown in Figure 2.2. This result is in part a consequence of the first pressure step being too large relative to the texture of the porous media such that too much water drained from the sample leaving no data points to represent the wet end of the water retention curves. 


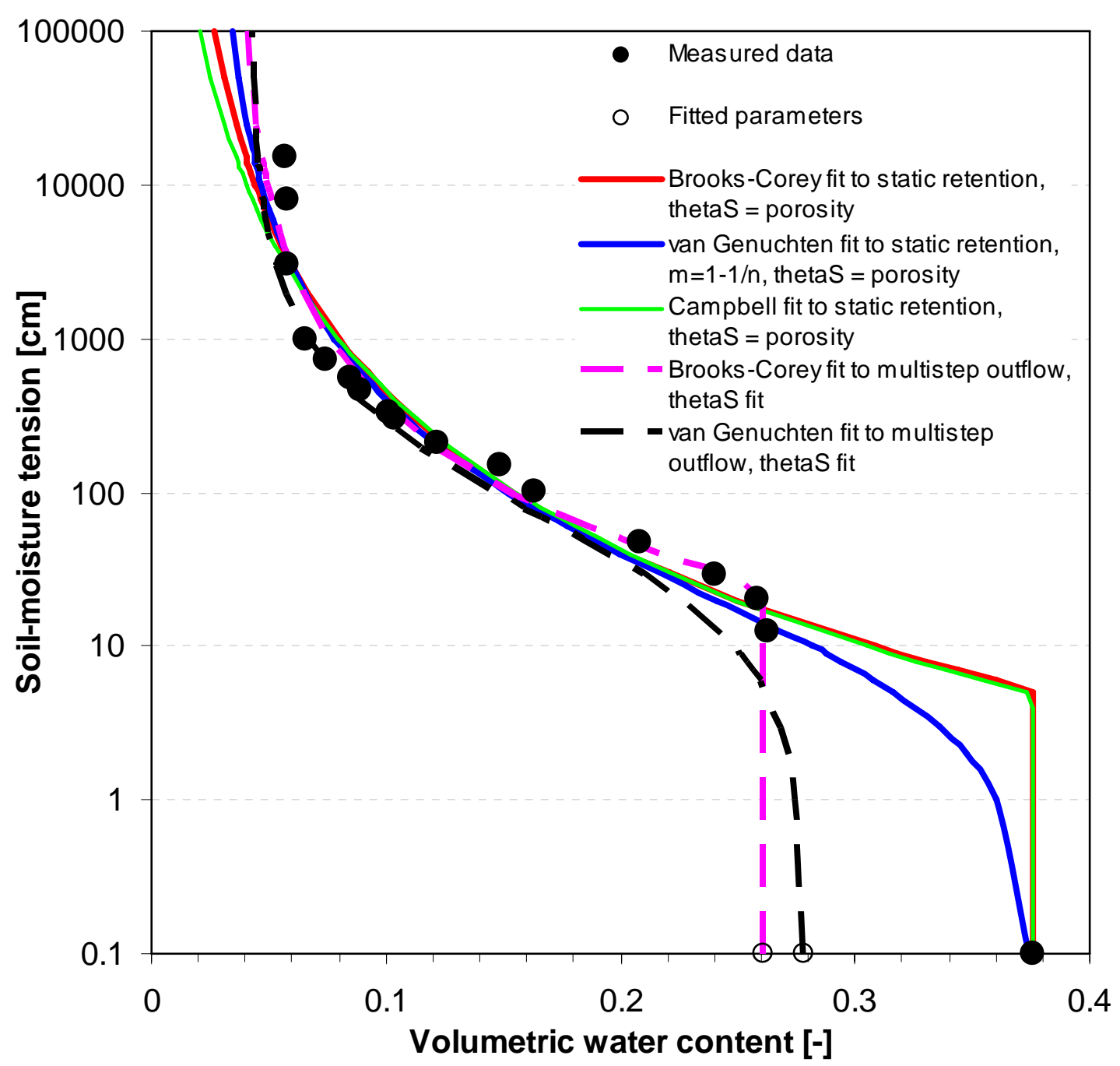

Figure 2.2. Measured and Fitted Water Retention Characteristics for Sample S1-24 from the Sisson and Lu Site (data and inverse model fits from Schaap et al. 2003)

The fitting approach used by Schaap et al. (2003) is problematic from the standpoint that in previous analyses of samples from other sites by other analysts, $\theta_{s}$ has been assumed to be equivalent to porosity and was treated as a fixed parameter rather than being fitted. When groups of parameters that have been estimated in different ways like this are combined to estimate statistical distributions, the apparent variability reflects a combination of real differences due to actual physical characteristics and their spatial variability, as well as apparent differences arising from inconsistencies in analysis procedures. As clearly shown in Figure 2.2, measured or calculated values of porosity and fitted values of $\theta_{s}$ can be significantly different.

Figure 2.3 shows the unsaturated hydraulic conductivity functions corresponding to the water retention functions shown in Figure 2.2. Similar to their treatment of $\theta_{s}$, Schaap et al. (2003) also fitted values of the apparent saturated hydraulic conductivities, that we will refer to as $K_{o}$, and used the measured values of $K_{s}$ as upper bound constraints in the fitting process. 


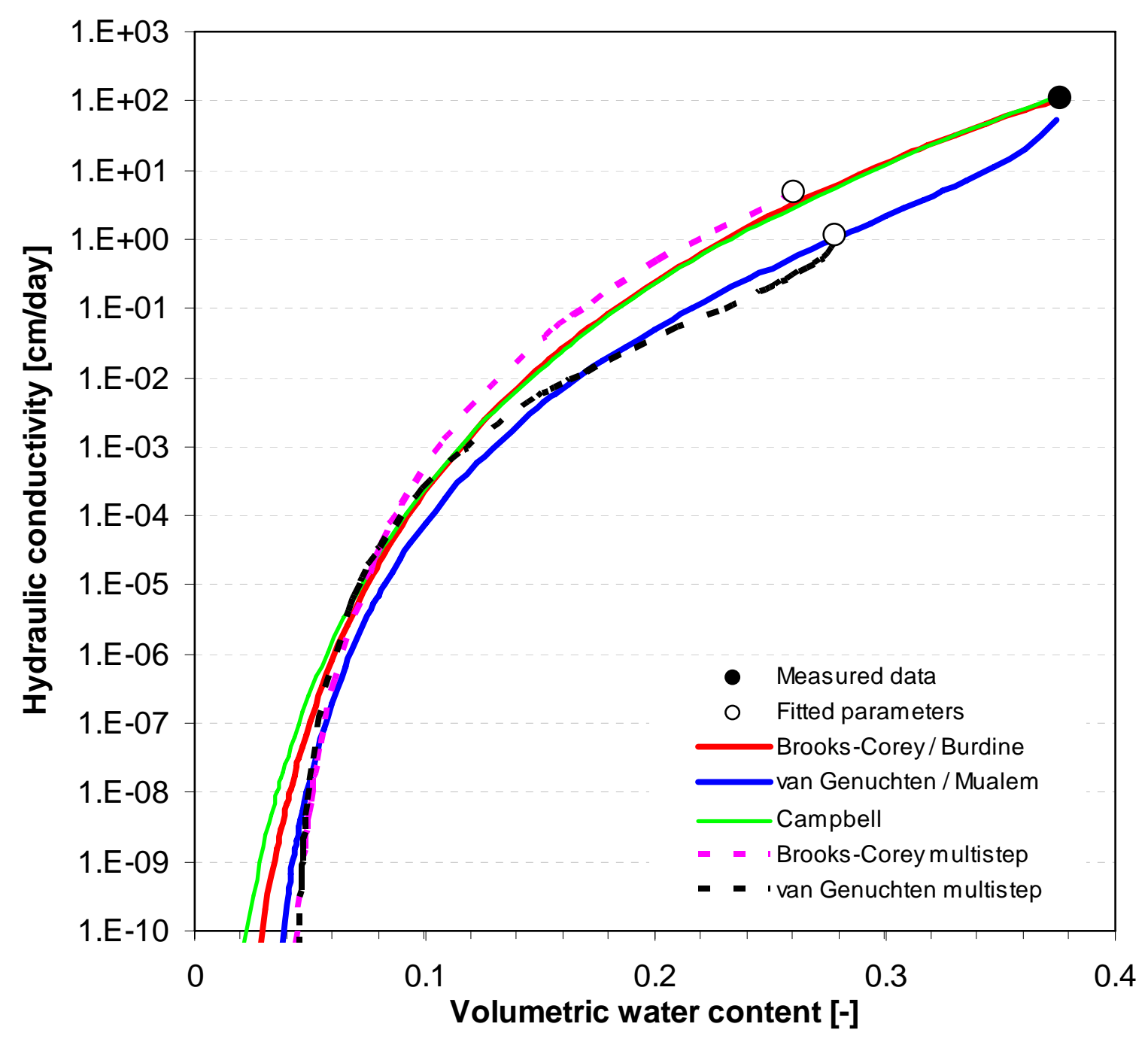

Figure 2.3. Unsaturated Hydraulic Conductivity Functions for Sample S1-24 from the Sisson and Lu Site (data and inverse model fits from Schaap et al. 2003)

Consequently, the fitted values of $K_{o}$, that have been used as surrogates for the actual saturated hydraulic conductivity, are up to two orders of magnitude lower than the measured value of $K_{s}$ for this particular sample. A difference in the fitted $K_{o}$ values also occurs due to the use of different hydraulic functions, but this difference is less than one order of magnitude. Similar to $\theta_{s}$ and porosity, when fitted values of $K_{o}$ are mixed with measured values of $K_{s}$ to generate parameter distributions, the apparent variability is not due solely to real differences in actual sediment properties, but is also due in part to inconsistencies in the analysis procedures.

Similar effects can be seen in parameters reported by Khaleel et al. (2000; 2001; 2002), summarized in Last et al. (2009; Appendix A), in which measured values of unsaturated hydraulic conductivity were used as match points and apparent values of the saturated hydraulic conductivity were fitted rather than being fixed at their measured values. In this case they assumed fixed values for the $\ell$ parameter (which was implicit in their choice of hydraulic functions) and allowed $K_{o}$ to be fitted in order to get their chosen 
unsaturated hydraulic conductivity function to pass through the measured unsaturated $K$ match points. However, if they had allowed values of $\ell$ to be fit, they could have fixed $K_{s}$ at the measured values and still had their functions pass through their match points. Their chosen fitting process resulted in fitted values of the saturated hydraulic conductivity of very dissimilar geologic units, such as the fine-grained and semi-consolidated Plio-Pleistocene silts and caliche units and the much coarser overlying Hanford Fm sand and gravel units, having fitted values of saturated hydraulic conductivity that are very similar (within a factor of 3) when they should actually differ by orders of magnitude, as evidenced by measured values of $K_{s}$. These authors did not anticipate that their fitted parameters would be combined with other parameter sets to estimate statistical distributions, but this is in fact what has happened. Issues like this are pervasive in the hydraulic parameter datasets that have been compiled for Hanford sediments.

It should be noted that Schaap et al. (2003) argue that fitting $\theta_{s}$ and $K_{o}$, instead of using measured values of porosity and $K_{s}$, may be justified because of macropore flow. Macropore flow is a preferential flow phenomenon that can occur at high liquid saturations when multiple pore domains are present in the porous media that have significantly different characteristic length scales. In the field, features such as open fractures, worm holes, or animal burrows within a finer-grained and lower permeability matrix may preferentially conduct water during saturated conditions. During unsaturated conditions, such features tend to drain rapidly and then become more-or-less inactive for aqueous-phase flow, with liquid water then flowing primarily through the finer-grained matrix. In a laboratory setting, preferential flow may occur along the walls of a flow cell or column when the porous media is saturated, owing to the slightly increased porosity and permeability along the walls that result from the discontinuity at the edge of the porous media. Macropore flow may be significant in some cases, but only two of the samples evaluated by Schaap et al. (2003) show compelling evidence for this (see later discussion and Appendix A). It should also be noted that fitting $\theta_{s}$ and $K_{o}$ instead of using measured or calculated values of porosity and $K_{s}$ generally results in improved fits to data from multistep outflow experiments, owing to the two additional degrees of freedom.

Counter arguments to fitting values of $\theta_{s}$ and $K_{o}$ are that 1) macropore flow effects may or may not be significant, depending on the porous media and on the core sampling method and/or sediment repacking process, 2) if macropore flow does appear to be significant, then it should perhaps be explicitly considered by using dual-porosity and dual-permeability models, 3 ) fitting the $\theta_{s}$ and $K_{o}$ parameters generally requires data from multistep outflow experiments that are typically less prevalent and that may be more expensive to generate and analyze, 4) most of the historical data for unsaturated hydraulic properties at Hanford consist of static water retention measurements obtained using hanging water column and pressure-plate methods, bulk and particle density measurements that are used to calculate porosity, and calculated $K_{s}$ values determined using classical methods (e.g. falling head and constant head), and these data are not amenable to fitting separate values of $\theta_{s}$ and $K_{o}$, and, 5) as noted previously, when fitted values of $\theta_{s}$ and $K_{o}$ are combined with measured or calculated values of porosity and $K_{s}$ to generate statistical distributions, the resulting statistics reflect both real variability resulting from natural heterogeneity, and variability resulting from inconsistent analysis procedures.

We have initiated a reanalysis of selected Hanford sediment physical and hydraulic property datasets to develop a more consistent and hopefully more reliable set of parameters and parameter distributions that are applicable to Hanford site-wide applications, and that can be transferred to HEIS for general use. 
The initial dataset selected for this reanalysis is from Schaap et al. (2003), representing 60 core samples collected from three boreholes (referred to as S-1, S-2, and S-3) at the Sisson and Lu (1980) site, located in the 200 East Area of the Hanford Site. The drilling of these boreholes and core sampling is described by Last and Caldwell (2001). Measurements of physical properties, including bulk density and grain size distributions, and previous estimates of hydraulic parameters are described in detail by Schaap et al. (2003).

The Brooks and Corey (1964), Campbell (1974), and van Genuchten (1980) models were fit to the data for each sample from this site, assuming $\theta_{s}$ is equal to porosity. In our opinion, this is the best and most consistent approach for estimating water retention parameters from laboratory measurements on sediment samples that have been completely saturated and then subjected to drying. For the van Genuchten model, the Mualem-based restriction ( $\mathrm{m}=1-1 / \mathrm{n}$ ) was used to avoid the later use of complete and incomplete beta functions for numerical evaluation of the unsaturated hydraulic conductivity function. Measured values of $K_{s}$ are assumed to represent the saturated hydraulic conductivity rather than fitted values of $K_{o}$.

Water retention data, hydraulic parameters, and plots of refitted water retention functions are given on Appendix A. In general, all model fits are very good. The van Genuchten (1980) model fits the data for most of the samples somewhat better than either the Brooks-Corey (1964) or Campbell (1974) models. The Brooks-Corey model generally fits the data better than the Campbell model, owing to one additional degree of freedom. The sum-of-squared residual values for observed and fitted results are reported in the figures shown in Appendix A. Only two of the samples (S-1/42D and S-2/24B) have water retention characteristics at high water contents that could arguably be interpreted as evidence for macropore flow. Several other samples (e.g. S-1/38C, S-2/13C, and S-3/10B) have water retention characteristics at low water contents that indicate using independent values of $n$ and $m$ in the van Genuchten model could lead to improved fits. Otherwise, the fits of these models with the constraints and assumptions that were used are considered to be very good overall. Electronic copies of these data and parameters will be delivered to the HTAG lead and EDM at CHPRC in FY11.

Additional datasets will be reanalyzed, and data will be refit where appropriate, to ensure that parameter estimation is performed in a consistent manner. The various hydraulic parameter datasets that have been evaluated and reanalyzed will then be transmitted to CHPRC in batches for inclusion in HEIS in FY11. Prototype data models and data dictionaries for physical and hydraulic properties and parameters are described in the following section. 



\subsection{Prototype Data Models and Data Dictionaries}

HEIS-Geo is a new instance of HEIS that is under development to better accommodate borehole geologic data. The data fields for physical and hydraulic properties and parameters that we suggest be added initially to HEIS-Geo are listed in Tables 3.1 - 3.4.

Table 3.1 contains suggested data fields for a Master Site and HEIS Sample Number Table. Some version of this already exists within the HEIS framework, but is included here for completeness. This table simply links the HEIS sample numbers, SAMP_NUM, to the spatial coordinates of the locations where the samples were collected. The SAMP_NUM is a unique alpha-numeric character string.

Table 3.2 contains suggested data fields for Physical Properties and Hydraulic Parameters. The physical properties in this table are currently limited to bulk and particle densities, and porosity. Bulk and particle densities are typically used to calculate porosity. Suggested data fields also include Grav_Correct, and Grav_Correct_Meth, to indicate whether or not the parameters represent data that were measured on a finer fraction of the sediments and corrected for the coarser (e.g. gravel) fraction, and if so, what methods were used for these corrections (e.g. Bouwer and Rice, 1983). Hydraulic parameters are primarily those described in Section 2 for the van Genuchten (1980), Campbell (1974), and Brooks and Corey (1964) models combined with the Mualem (1976) and Burdine (1953) relative permeability models. Also included in Table 3.2 are entries for experimental methods, sample specifications (e.g. bulk, intact core; subsampled core; and repacked core), maximum grain (or core) diameter, and metadata fields for data and parameter references.

As an aside, one of the remediation alternatives that is being evaluated for waste sites in the Hanford 200 Areas is soil desiccation. Modeling of the soil desiccation process requires that hydraulic properties be represented for conditions ranging from fully water saturated, to air dry, at which point the water content is effectively zero. The van Genuchten (1980) and Brooks and Corey (1964) water retention functions contain a residual or irreducible water content parameter, $\theta_{r}$, that is typically greater than zero, so modifications to these standard functions may be required to model air-dry conditions. Fayer and Simmons (1995) presented an extension to these functions that is applicable to modeling the full range of conditions that may be encountered in soil desiccation problems. However, their extension requires that some modifications be made to existing parameters to account for the dry end of the curve. Webb (2000) proposed a simple extension to commonly used retention functions that allows for the full range of conditions from water saturated to air dry to be modeled, without affecting existing parameters. Thus the use of the Webb model would allow existing databases of parameters to be used as is, without further modification. Capillary conduction models upon which Eqs. (2.4) and (2.6) are based assume that water flow in the aqueous phase ceases for water contents below $\theta_{r}$ because the aqueous phase is no longer continuous. For water contents below $\theta_{r}$ further movement of water would be via film flow and/or vapor transport, and not by capillary conduction. In other words, the relative permeability of the porous media to water in the aqueous phase, or the unsaturated hydraulic conductivity, is zero for water contents below $\theta_{r}$. The relative permeability of the porous media to air, in which water vapor is contained, is a function of air saturation and the water retention parameters that implicitly define the pore size distribution. Although no specific changes to existing relative permeability models are obviously needed to model capillary conduction below the residual water content, it is possible that in the future, combining multiple functions in the manner of Fayer and Simmons (1995) could require new data fields to be added to the physical and hydraulic parameter database. A separate RDS task is currently evaluating alternative functions for 
representing water retention and relative permeability from water-saturated to air-dry conditions, so it possible that the data fields in Table 3.2 may have to expand to accommodate these functions, if they are adopted for general use.

Table 3.3 contains suggested data fields for Water Retention Data. These data represent matric potential (a.k.a. soil-moisture tension) and water content data pairs that can be used to generate the parameters for fitting the van Genuchten (1980), Campbell (1974), Brooks and Corey (1964), or other functions. Also included in this table is a field for MassFrac_Greater_WRC that specifies the mass fraction of the bulk sediment that is greater than the size fraction used for the water retention measurements, if applicable, and Grav_Correct_WRC that indicates whether or not "gravel corrected" water content values are included.

Table 3.4 contains suggested data fields for Grain Size Distribution Data. The primary data in this table are the grain size and fraction or percent passing data pairs. Data fields are also included for MassFrac_Greater_PSD and Grav_Correct_PSD to specify the mass fraction of bulk sediment that is greater than the size fraction for which grain size distribution measurements were made, and to indicate whether or not the data also includes fraction or percent passing values that have been scaled or gravel corrected to represent the bulk sample. 
Table 3.1. Suggested Data Fields for Master Site and HEIS Sample Number Table

\begin{tabular}{|c|c|c|}
\hline Data Field & Type & Description \\
\hline SAMP_NUM & Character & A unique alpha-numeric HEIS identifier for the sample \\
\hline Site_ID & Character & $\begin{array}{l}\text { Identifier for the site (e.g. operable unit designation, tank farm, } \\
\text { experimental field site name, etc.) }\end{array}$ \\
\hline Site_ID_Qual & Character & $\begin{array}{l}\text { B, W, or E (for borehole, well, or excavation) } \\
\text { Note: Wells usually start with a borehole, but not all boreholes are } \\
\text { completed with well casing. If this field = "B", the entry for Well_ID } \\
\text { should be empty. If this field = "W", then the entry for Well_ID should be } \\
\text { a valid well identification number. If this field = "E" then Borehole and } \\
\text { Well IDs are not applicable. }\end{array}$ \\
\hline Borehole_ID & Character & $\begin{array}{l}\text { Temporary identification number for borehole used in standard Hanford } \\
\text { drilling practice (e.g. C6186) }\end{array}$ \\
\hline Well_ID & Character & Final well identification number (eg. 399-2-9) \\
\hline Easting & Real & Easting coordinate \\
\hline Northing & Real & Northing coordinate \\
\hline HorizCoord_Units & Character & [L] \\
\hline HorizCoord_Ref & Character & Reference for horizontal coordinate system (e.g. NAD29 or NAD83) \\
\hline Samp_ID & Character & Local identifier for sample \\
\hline SampDepth_Top & Real & Depth to top of sample \\
\hline SampDepth_Bot & Real & Depth to bottom of sample \\
\hline Depth_Units & Character & {$[\mathrm{L}]$} \\
\hline SurfaceElev & Real & Surface elevation at site \\
\hline SurfaceElev_Units & Character & [L] (e.g. $\mathrm{m}$ or $\mathrm{ft}$ above mean sea level) \\
\hline VertCoord_Ref & Character & Reference for vertical coordinates (e.g. NAVD88) \\
\hline
\end{tabular}


Table 3.2. Suggested Data Fields for Physical Properties and Hydraulic Parameters

\begin{tabular}{|c|c|c|}
\hline Data Field & Type & Description \\
\hline SAMP_NUM & Character & A unique alpha-numeric HEIS identifier for the sample \\
\hline BulkDen & Real & Bulk density \\
\hline BulkDen_Units & Character & {$\left[\mathrm{M} \mathrm{L}^{-3}\right]$} \\
\hline BulkDen_Meth & Character & Reference for method used to determine bulk density \\
\hline PartDen & Real & Particle (a.k.a. grain) density \\
\hline PartDen_Units & Character & {$\left[\mathrm{M} \mathrm{L}^{-3}\right]$} \\
\hline PartDen_Meth & Character & Reference for method used to determine bulk density \\
\hline Porosity & Real & {$[-]$} \\
\hline Ks_Sample_Specs & Character & $\begin{array}{l}\text { Specification about whether saturated hydraulic conductivity }(\mathrm{Ks}) \\
\text { was measured on: } \mathrm{B}=\text { bulk, intact core, } \mathrm{S}=\text { subsampled core, or } \mathrm{R} \\
=\text { repacked core }\end{array}$ \\
\hline Ks_Meth & Character & $\begin{array}{l}\text { Reference for method used to determine Ks (e.g. constant or } \\
\text { falling head methods) }\end{array}$ \\
\hline Max_Diam_Ks & Real & $\begin{array}{l}\text { Maximum possible grain diameter used for Ks measurement. If } \\
\text { hydraulic property measurements were performed on a bulk, intact } \\
\text { core or a sub-sampled core, the theoretical maximum possible } \\
\text { grain diameter would be the inside diameter of the core. If the } \\
\text { sample is a repacked core of the }<2 \mathrm{~mm} \text { size fraction only, then the } \\
\text { maximum grain diameter would be } 2 \mathrm{~mm} \text {. This information is } \\
\text { needed in case hydraulic properties are measured on a subsample } \\
\text { that may not be representative of the bulk sample, and subsequent } \\
\text { "corrections" are applied to the data or in parameter estimation to } \\
\text { account for gravel, etc. }\end{array}$ \\
\hline Max_Diam_Ks_Units & Character & Units for Max_Diam_Ks (e.g. mm) \\
\hline MassFrac_Greater_Ks & Real & Mass fraction of sample that is greater than Max_Diam_Ks \\
\hline Ks_Z & Real & Saturated hydraulic conductivity in $\mathrm{z}$ (vertical)-direction \\
\hline Ks_Z_Unit & Character & {$\left[\mathrm{L} \mathrm{T}^{-1}\right]$} \\
\hline Grav_Correct_Ks & Character & $\begin{array}{l}\text { This entry should be either "Y" or "N" to indicate if an additional } \\
\text { Ks value is provided that accounts for gravel correction }(\mathrm{Y}) \text {, or if } \\
\text { there is only one Ks value }(\mathrm{N}) \text {. }\end{array}$ \\
\hline Grav_Correct_WRC_Method & Character & $\begin{array}{l}\text { Description or citation for method used for gravel corrections, if } \\
\text { applicable. }\end{array}$ \\
\hline Ks_Z_gravC & Real & $\begin{array}{l}\text { "Gravel-corrected" value of saturated hydraulic conductivity in z } \\
\text { (vertical)-direction }\end{array}$ \\
\hline Ks_Z_Unit_gravC & Character & {$\left[\mathrm{L} \mathrm{T}^{-1}\right]$} \\
\hline
\end{tabular}


Table 3.2. ( cont'd)

\begin{tabular}{|c|c|c|}
\hline Data Field & Type & Description \\
\hline WRC_Param_Specs & Character & $\begin{array}{l}\text { Specification about whether WRC parameters are based on } \\
\text { measurements from: } \mathrm{B}=\text { bulk, intact core, } \mathrm{S}=\text { subsampled core, } \mathrm{R} \\
=\text { repacked core, or } \mathrm{C}=\text { "corrected" data, where the latter refers to } \\
\text { the use of data that were measured on a smaller size fraction of the } \\
\text { sediments, but that were scaled to the bulk sediment (a.k.a. gravel } \\
\text { corrections). More than one specification is allowable (e.g. } \\
\text { WRC_Param_Specs = "R, C". Additional details are given in the } \\
\text { Water Retention Data table. }\end{array}$ \\
\hline Theta_S & Real & $\begin{array}{l}\text { Saturated water content [dimensionless]; could be equal to } \\
\text { porosity }\end{array}$ \\
\hline Theta_R & Real & Residual or irreducible water content [dimensionless] \\
\hline vG_Alp & Real & vanGenuchten model alpha parameter \\
\hline vG_Alp_Units & Character & {$\left[\mathrm{L}^{-1}\right]$} \\
\hline vG_N & Real & vanGenuchten model $n$ parameter [dimensionless] \\
\hline vG_M & Real & $\begin{array}{l}\text { vanGenuchten model } \mathrm{m} \text { parameter, default } \mathrm{m}=1-1 / \mathrm{n} \\
\text { [dimensionless] }\end{array}$ \\
\hline Ks_vG & Real & $\begin{array}{l}\text { Ks value used with vG retention model. This could be either the } \\
\text { measured value of Ks, a "gravel-corrected" value, or a value } \\
\text { determined by inverse modeling. }\end{array}$ \\
\hline Ks_vG_Unit & Character & {$\left[\mathrm{L} \mathrm{T}^{-1}\right]$} \\
\hline Lz_vG & Real & $\begin{array}{l}\text { Pore interaction term (z-direction) for relative permeability model } \\
\text { when used with van Genuchten water retention model } \\
\text { [dimensionless]. If the Mualem relative permeability model is } \\
\text { assumed, then Lz_vG }=0.5 \text { (default value). }\end{array}$ \\
\hline BC_Hd & Real & Brooks-Corey model air-entry pressure. \\
\hline BC_Hd_Unit & Character & {$[\mathrm{L}]$} \\
\hline BC_Lam & Real & Brooks-Corey model lambda parameter [dimensionless] \\
\hline Ks_BC & Real & $\begin{array}{l}\text { Ks value used with Brooks-Corey retention model. This could be } \\
\text { either the measured value of Ks, a "gravel-corrected" value, or a } \\
\text { value determined by inverse modeling. }\end{array}$ \\
\hline Ks_BC_Unit & Character & {$\left[\mathrm{L} \mathrm{T}^{-1}\right]$} \\
\hline Lz_BC & Real & $\begin{array}{l}\text { Pore interaction term (z-direction) for relative permeability model } \\
\text { when used with the Brooks-Corey water retention model } \\
\text { [dimensionless]. If the Burdine relative permeability model is } \\
\text { assumed, then Lz_BC }=1 \text {. }\end{array}$ \\
\hline Camp_Hd & Real & Campbell model air-entry pressure. \\
\hline Camp_Hd_Units & Character & {$[\mathrm{L}]$} \\
\hline Camp_B & Real & Campbell model b parameter [dimensionless] \\
\hline Data_Ref & Character & $\begin{array}{l}\text { General information or citation(s) for original reference } \\
\text { document(s) in which data and procedures are described in more } \\
\text { detail. }\end{array}$ \\
\hline
\end{tabular}


Table 3.2. ( cont'd)

\begin{tabular}{|c|c|c|}
\hline Data Field & Type & Description \\
\hline Param_Ref & Character & $\begin{array}{l}\text { References to software (e.g. SoilVision), spreadsheet file name, or } \\
\text { equations used for parameter estimation. For example, SoilVision } \\
\text { or the Excel solver might be used to fit an analytic function to } \\
\text { static water retention data, or a flow and transport simulator might } \\
\text { be used with inverse parameter estimate code to estimate } \\
\text { parameters from dynamic data obtained in multistep outflow } \\
\text { experiments. This field is a place for this documentation. }\end{array}$ \\
\hline
\end{tabular}

Table 3.3. Suggested Data Fields for Water Retention Data

\begin{tabular}{|c|c|c|}
\hline Data Field & Type & Description \\
\hline SAMP_NUM & Character & A unique alpha-numeric HEIS identifier for the sample \\
\hline WRC_Methods & Character & Methods used for generating water retention data \\
\hline WRC_Ref_Info & Character & Reference to documents describing experimental methods \\
\hline Max_Diam_WRC & Real & $\begin{array}{l}\text { Maximum possible grain diameter in samples used for water } \\
\text { retention measurements. If measurements were performed on } \\
\text { bulk, intact core or sub-sampled core, the theoretical maximum } \\
\text { grain diameter would be the inside diameter of the core. If sample } \\
\text { is repacked core of }<2 \mathrm{~mm} \text { size fraction, then max. grain diameter } \\
\text { would be } 2 \mathrm{~mm} \text {. }\end{array}$ \\
\hline Max_Diam_WRC_Units & Character & Units for Max_Diam_WRC (e.g. mm). \\
\hline MassFrac_Greater_WRC & Real & $\begin{array}{l}\text { Mass fraction of sample that is greater than Max_Diam_WRC. If } \\
\text { measurements were performed on the }<2 \mathrm{~mm} \text { size fraction, then } \\
\text { this entry should be the gravel }(>2 \mathrm{~mm}) \text { size fraction. If } \\
\text { measurements were performed on the bulk sediments, then this } \\
\text { entry should be zero. }\end{array}$ \\
\hline Grav_Correct_WRC & Character & $\begin{array}{l}\text { This entry should be either "Y" or "N" to indicate that the water } \\
\text { retention data to follow in this table represent both tension-water } \\
\text { content data pairs representing both a finer size fraction as well as } \\
\text { "corrected" water content values that account for gravel }(\mathrm{Y}) \text {, or if } \\
\text { there is only one set of water content data }(\mathrm{N}) \text {. }\end{array}$ \\
\hline Grav_Correct_WRC_Method & Character & $\begin{array}{l}\text { Description or citation for method used for gravel corrections, if } \\
\text { applicable. }\end{array}$ \\
\hline Tension_Units & Character & Units for tension (e.g. cm). \\
\hline WaterContent_Units & Character & Water content units. Typically "Volumetric" or "\%". \\
\hline N_WRC_Tuples & Integer & Number of tension - water content data pairs. \\
\hline Tension_01 & Real & Tension value 1 \\
\hline Tension_02 & Real & Tension value 2 \\
\hline$\cdots$ & Real & $\cdots$ \\
\hline Tension_N & Real & Tension value $\mathrm{N}$ \\
\hline
\end{tabular}


Table 3.3. (cont'd)

\begin{tabular}{|c|c|c|}
\hline Data Field & Type & Description \\
\hline WaterContent_01 & Real & Water content value 1 \\
\hline WaterContent_02 & Real & Water content value 2 \\
\hline$\cdots$ & Real & $\ldots$ \\
\hline WaterContent_N & Real & Water content value $\mathrm{N}$ \\
\hline WaterContent_01_gravC & Real & $\begin{array}{l}\text { If Grav_Correct }=\text { "Y" then this entry is WaterContent_01 } \\
\text { corrected for gravel content of bulk sample. }\end{array}$ \\
\hline WaterContent_02_gravC & Real & $\begin{array}{l}\text { If Grav_Correct }=\text { "Y" then this entry is WaterContent_02 } \\
\text { corrected for gravel content of bulk sample. }\end{array}$ \\
\hline$\ldots$ & Real & $\ldots$ \\
\hline WaterContent_N_gravC & Real & $\begin{array}{l}\text { If Grav_Correct = "Y" then this entry is WaterContent_N } \\
\text { corrected for gravel content of bulk sample. }\end{array}$ \\
\hline
\end{tabular}

Table 3.4. Suggested Data Fields for Grain Size Data

\begin{tabular}{|c|c|c|}
\hline Data Field & Type & Description \\
\hline SAMP_NUM & Character & Unique alpha-numeric HEIS identification number for the sample. \\
\hline PSD_Methods & Character & $\begin{array}{l}\text { Reference to methods used for grain size analyses. Different } \\
\text { methods are typically used to determine the fractionation of } \\
\text { different size classes (e.g. wet or dry sieve for }>2 \mathrm{~mm} \text { size fraction; } \\
\text { sedimentation [via hydrometer method] for }<2 \mathrm{~mm} \text { size fraction), } \\
\text { so these methods and the grain size ranges to which they were } \\
\text { applied are to be specified here. }\end{array}$ \\
\hline Max_Diam_PSD & Real & $\begin{array}{l}\text { Maximum grain diameter represented by the data. If } \\
\text { measurements were performed on }<2 \mathrm{~mm} \text { size fraction only, then } \\
\text { max. grain diameter would be } 2 \mathrm{~mm} \text {. If measurements were } \\
\text { performed on the bulk sample, then this value would be the inside } \\
\text { diameter of the core, representing a theoretical maximum size. }\end{array}$ \\
\hline Max_Diam_PSD_Units & Character & Units for Max_Diam_PSD (e.g. mm). \\
\hline MassFrac_Greater_PSD & Real & $\begin{array}{l}\text { Mass fraction of sample that is greater than Max_Diam_PSD. If } \\
\text { the particle-size distribution data represents just the }<2 \mathrm{~mm} \text { size } \\
\text { fraction, then this entry should be the gravel }(>2 \mathrm{~mm}) \text { size fraction. } \\
\text { If the particle-size distribution represents the bulk sediments, then } \\
\text { this entry should be zero. }\end{array}$ \\
\hline Grav_Correct_PSD & Character & $\begin{array}{l}\text { This entry should be "Y" or "N" to indicate that if grain size and } \\
\text { fraction passing data pairs represent a smaller size fraction of the } \\
\text { bulk sediment (e.g. }<2 \mathrm{~mm}) \text {, then the fraction or \% passing data } \\
\text { from the finer fraction are followed by "corrected" values } \\
\text { representing the fraction passing scaled to represent the bulk } \\
\text { sample. }\end{array}$ \\
\hline PSD_Ref_Info & Character & $\begin{array}{l}\text { General reference information for any publication(s) in which data } \\
\text { and procedures are described in more detail. }\end{array}$ \\
\hline
\end{tabular}


Table 3.4. (cont'd)

\begin{tabular}{|c|c|c|}
\hline Data Field & Type & Description \\
\hline GrainSize_Units & Character & [L] (e.g. mm or $\mu \mathrm{m})$ \\
\hline Passing_Units & Character & "Fraction" or "\%" \\
\hline N_PSD_tuples & Integer & Number of grain size - fraction passing tuples (data pairs) \\
\hline GrainSize_01 & Real & {$[\mathrm{L}]$} \\
\hline GrainSize_02 & Real & {$[\mathrm{L}]$} \\
\hline$\ldots$ & Real & {$[\mathrm{L}]$} \\
\hline GrainSize_N & Real & {$[\mathrm{L}]$} \\
\hline Passing_01 & Real & Fraction or $\%$ of sample less than GrainSize_ 01 \\
\hline Passing_02 & Real & Fraction or $\%$ of sample less than GrainSize_02 \\
\hline$\ldots$ & Real & $\ldots$ \\
\hline Passing_N & Real & Fraction or $\%$ of sample less than GrainSize_N \\
\hline Passing_01_gravC & Real & $\begin{array}{l}\text { If Scaled_PSD }=\text { "Y" then this entry is the value of Passing_01 } \\
\text { scaled by MassFrac_Greater_PSD to represent the bulk sample. }\end{array}$ \\
\hline Passing_02_gravC & Real & $\begin{array}{l}\text { If Scaled_PSD }=\text { "Y" then this entry is the value of Passing_02 } \\
\text { scaled by MassFrac_Greater_PSD to represent the bulk sample. }\end{array}$ \\
\hline$\ldots$ & Real & $\ldots$ \\
\hline Passing_N_gravC & Real & $\begin{array}{l}\text { If Scaled_PSD = "Y" then this entry is the value of Passing_N } \\
\text { scaled by MassFrac_Greater_PSD to represent the bulk sample. }\end{array}$ \\
\hline
\end{tabular}




\subsection{Long-Term Strategic Plan}

Development of a long-term strategic plan for continual improvement and updating of the physical properties and hydraulic parameter datasets for the Hanford Site that will eventually be contained in HEIS database is contingent upon first approving and then implementing new data schemas or data models in HEIS. The approval process requires the involvement of HTAG, currently managed by JoAnne Rieger (CHPRC), who is responsible for reviewing and approving any changes to HEIS. Implementation of new data schemas or data models in HEIS is the responsibility of the Hanford Environmental Data Manager, who is currently Bill Webber (CHPRC). Compiling, analyzing, and transferring relevant physical and hydraulic property data and parameters to CHPRC is the responsibility of the RDS Project, whose delegates will also ensure that data consistency, quality, and documentation needs are met. Guidance will also be provided by the RDS project to rank different datasets for relative quality.

The prototype datasets representing the samples described by Schaap et al. (2003) will be transferred to CHPRC. After the prototype datasets have been successfully loaded into HEIS-Geo or an equivalent repository, we envision that existing physical property data and hydraulic parameters that are currently maintained by PNNL will be transferred in batches to CHPRC in a standardized format (e.g., CSV, or Excel spreadsheets). Periodic transfer of these datasets will continue until all of the desired datasets have been incorporated into HEIS-Geo. New datasets will be documented and then transferred in the same way.

New measurements of physical and hydraulic properties and estimation of hydraulic parameters are ongoing and we expect the data and associated parameters for these new datasets to also be added to HEIS-Geo. For example, multistep outflow experiments have recently been performed on a number of intact core samples of gravel-dominated sediments from both the 300 Area and the 100-N Area at Hanford. Determination of unsaturated hydraulic properties and parameters using data from multistep outflow experiments can involve the use of thousands or even tens of thousands of voltages from multiple (typically 3) pressure transducers (Tuli, 2001). The transducer voltages are converted to pressures and outflow volumes using calibration equations. The pressure and outflow data are then used with a flow simulator that is coupled with an inverse parameter estimation algorithm to optimize hydraulic parameters such that the differences between observed and simulated pressures and outflow volumes are minimized.

Storing thousands or tens of thousands of voltage or pressure and outflow volume data points from a multistep outflow experiment representing a single sample would not be a good use of HEIS. Another option would be to post-process the data to generate a smaller number of average water content and pressure head values corresponding to steady state outflow for each pressure step, and to store those data. However, these may not be the data that are actually used with the simulator and inverse parameter estimation code to estimate model parameters. Alternatively, for multistep outflow experiments, only the estimated hydraulic parameters could be stored, as long as sufficient metadata is also provided that contains information on reference documents in which the data have been published (e.g. laboratory record book numbers, technical reports, and journal articles), the methods or procedures that were used, and other pertinent information about parameter estimation from which the raw data could potentially be obtained if needed.

Some further refinements to the suggested data models, and/or data standardization, may be required to accommodate the wide variety of physical and hydraulic property data that have been generated. The 
prototype datasets described in the previous section will be transmitted to both Bill Webber and JoAnne Rieger of CHPRC. They have agreed to review the data models and to make whatever revisions are needed to incorporate data conforming to these specifications into HEIS-Geo or an equivalent.

As noted previously by Rockhold et al. (2009), one issue that has hampered efforts to consolidate physical and hydraulic property data in the past is the fact that these data are generated for different projects, by different groups that use different methods for measurements and analyses. Just knowing who is doing or has done what is one of the biggest challenges. We recommend that all ongoing projects that involve sediment sampling and characterization at Hanford be notified of this effort to consolidate data and to make it readily accessible for mutual benefit. Then when data are generated, PNNL staff working as points of contact for this task should be notified and the data transferred to them with complete documentation as soon as it is available. The Laboratory will provide quality checks, reformatting, and will perform curve-fitting or inverse modeling of the datasets, as needed. The data and associated parameter sets will then be transferred to CHPRC in an agreed upon, standardized format. The EDM or his delegate will then upload the data to HEIS-Geo. We also recommend that a user list be established so that anyone who expresses an interest in using the data or parameters will be notified periodically when new datasets become available. 


\subsection{Summary and Conclusions}

Physical properties and hydraulic parameters and their distributions are required for any type of quantitative assessment of risk and uncertainty associated with predictions of contaminant transport and fate in the subsurface. The central plateau of the Hanford Site in southeastern Washington State contains most of the contamination at the Site and has up to $\sim 100 \mathrm{~m}$ of unsaturated and unconsolidated or semiconsolidated sediments overlying the unconfined aquifer. These sediments contain a wide variety of contaminants ranging from organic compounds, such as carbon tetrachloride, to numerous radionuclides including technetium, plutonium, and uranium. Knowledge of the physical and hydraulic properties of the sediments and their distributions is critical for quantitative assessment of the transport of these contaminants in the subsurface, for evaluation of long-term risks and uncertainty associated with model predictions of contaminant transport and fate, and for evaluating, designing, and operating remediation alternatives.

One of the goals of PNNL's RDS project is to work with the Hanford Environmental Data Manager (currently with CHPRC) to develop a protocol and schedule for incorporation of physical property and hydraulic parameter datasets currently maintained by PNNL into HEIS. This requires that the data first be reviewed to ensure quality and consistency. New data models must then be developed for HEIS that are approved by the HTAG that oversees HEIS development. After approval, these new data models then need to be implemented in HEIS by the EDM before there is an actual repository for the data. This document summarizes modifications to previously developed data models, and new data models and data dictionaries for physical and hydraulic property data and parameters to be transferred to HEIS.

A prototype dataset that conforms to the specifications of these recommended data models has been identified and processed, and is ready for transfer to CHPRC for inclusion in HEIS. Additional datasets are planned for transfer from PNNL to CHPRC in FY11. 



\subsection{References}

Bouwer H and RC Rice. 1983. "Effects of Stones on Hydraulic Properties of Vadose Zones.” In Proceedings of the Characterization and Monitoring of the Vadose (Unsaturated) Zone. National Water Well Association, Worthington, Ohio.

Brooks RH and AT Corey. 1964. Hydraulic Properties of Porous Media. Hydrology Paper No. 3, Colorado State University, Fort Collins, Colorado.

Burdine NT. 1953. "Relative permeability calculations from pore-size distribution data." Petr. Trans. Am. Inst. Mining Metall. Eng. 198:71-78.

Campbell GS. 1974. "A simple model for determining unsaturated conductivity from moisture retention data." Soil Sci. 117(6):311-314.

Cantrell KJ, RJ Serne, and GV Last. 2003. Hanford Contaminant Distribution Coefficient Database and Users Guide. PNNL-13895, Rev. 1, Pacific Northwest National Laboratory, Richland, Washington.

Clapp RB and GM Hornberger. 1978. "Empirical equations for some soil hydraulic properties." Water Resour. Res. 14(4):601-604.

Doherty J. 2004. PEST - Model-Independent Parameter Estimation, User's Manual: 5th Edition, Watermark Numerical Computing, Australia.

Fayer MJ and CS Simmons. 1995. "Modified soil-water retention functions for all matric suctions." Water Resour. Res. 31:1233-1238.

Freeman EJ and GV Last. 2003. Vadose Zone Hydraulic Property Letter Report. WMP-17524, Rev. 0, Fluor Hanford, Richland, Washington.

Khaleel R, TE Jones, AJ Knepp, FM Mann, DA Myers, PM Rogers, RJ Serne, and MI Wood. 2000. Modeling Data Package for S-SX Field Investigation Report (FIR). RPP-6296, Rev. 0, CH2M HILL Hanford Group, Richland, Washington.

Khaleel R, TE Jones, AJ Knepp, FM Mann, DA Myers, and MI Wood. 2001. Modeling Data Package for B-BX-BY Field Investigation Report (FIR). CH2M HILL Hanford Group, Richland, Washington.

Khaleel R, MP Connelly, D Crumpler, TE Jones, AJ Knepp, FM Mann, B McMahion, CW Miller, and MI Wood. 2002. Modeling Data Package for an Initial Assessment of Closure of C Tank Farm.

RPP-13310, Rev. 0, CH2M HILL Hanford Group, Richland, Washington.

Last GV and TG Caldwell. 2001. Core Sampling in Support of the Vadose Zone Transport Field Study. PNNL-13454, Pacific Northwest National Laboratory, Richland, Washington.

Last GV, ML Rockhold, CJ Murray, and KJ Cantrell. 2009. Selection and Traceability of Parameters to Support Hanford-Specific RESRAD Analyses. PNNL-18564, Pacific Northwest National Laboratory, Richland, Washington. 
Mackley RD, JA Serkowski, and GV Last. 2008. Status Report on the Creation of a Preliminary Data Model and Dictionary for a New Petrologic Database. PNNL-17663, Pacific Northwest National Laboratory, Richland, WA.

Meyer PD, ML Rockhold, and GW Gee. 1997. Uncertainty Analyses of Infiltration and Subsurface Flow and Transport for SDMP Sites. NUREG/CR-6565, US Nuclear Regulatory Commission, Washington, DC.

Mualem Y. 1976. "A new model for predicting the hydraulic conductivity of unsaturated porous media." Water Resour. Res. 12(3):513-522.

Oostrom M, ML Rockhold, PD Thorne, GV Last, and MJ Truex. 2006. Carbon Tetrachloride Flow and Transport in the Subsurface of the 216-Z-9 Trench at the Hanford Site: Heterogeneous Model Development and Soil Vapor Extraction Modeling. PNNL-15914, Pacific Northwest National Laboratory, Richland, Washington.

Raats PA, ZF Zhang, AL Ward, and GW Gee. 2004. "The relative connectivity-tortuosity tensor for conduction of water in anisotropic unsaturated soils." Vadose Zone J. 3:1471-1478.

Rockhold, ML, LA Middleton, and GV Last. 2009. A Long-Term Strategic Plan for Hanford Sediment Physical Property and Hydraulic Parameter Databases. PNNL-18836, Pacific Northwest National Laboratory, Richland, Washington.

Schaap MG, PJ Shouse, and PD Meyer. 2003. Laboratory Measurements of the Unsaturated Hydraulic Properties at the Vadose Zone Transport Field Study Site. PNNL-14284, Pacific Northwest National Laboratory, Richland, Washington.

Sisson JB, and AH Lu. 1984. Field Calibration of Computer Models for Application to Buried Liquid Discharges: A Status Report. Tech. Rep. RHO-ST-46-P, Rockwell Hanford Operations, Richland, Washington.

Tuli A, MA Denton, JW Hopmans, T Harter, and JL MacIntyre. 2001. Multi-Step Outflow Experiment: From Soil Preparation to Parameter Estimation. Report 100037, University of California, Dept. of Land, Air, and Water Resources, Davis, California.

van Genuchten M Th. 1980. "A closed-form equation for predicting the unsaturated hydraulic conductivity of unsaturated soils." Soil Sci Soc Am J 44:892-898.

Ward AL, ME Conrad, WD Daily, JB Fink, VL Freedman, GW Gee, GM Halvorston, MJ Keller, EL Majer, CJ Murray, MD White, SB Yabusaki, ZF Zhang. 2006. Vadose Zone Transport Field Study Summary Report. PNNL-15443, Pacific Northwest National Laboratory, Richland, Washington.

Webb SW. 2000. "A simple extension of two-phase characteristic curves to include the dry region." Water Resour. Res. 36:1425-1430.

White MD and M Oostrom. 2006. STOMP - Subsurface Transport Over Multiple Phases, Version 4.0 User's Guide. PNNL-15782, Pacific Northwest National Laboratory, Richland, Washington. 
Williams MD, ML Rockhold, PD Thorne, and Y Chen. 2008. Three-Dimensional Groundwater Models of the 300 Area at the Hanford Site, Washington State. PNNL-17708. Pacific Northwest National Laboratory, Richland, Washington.

Yu C, AJ Zielen, J-J Cheng, YC Yuan, LG Jones, DJ LePoire, YY Wang, CO Loureiro, E Gnanapraggasam, E Faillace, A Wallo III, WA Williams, and H Peterson. 1993. Manual for Implementing Residual Radioactive Material Guidelines Using RESRAD, Version 5.0. ANL/EAD/LD-2, Argonne National Laboratory, Argonne, Illinois. 



\section{Appendix A}

Water Retention Data, Parameters, and Plots of Fitted Retention Functions for Core Samples from Boreholes S-1, S-2, and S-3 at the Sisson and Lu Field Experimental Site in the Hanford 200 East Area 



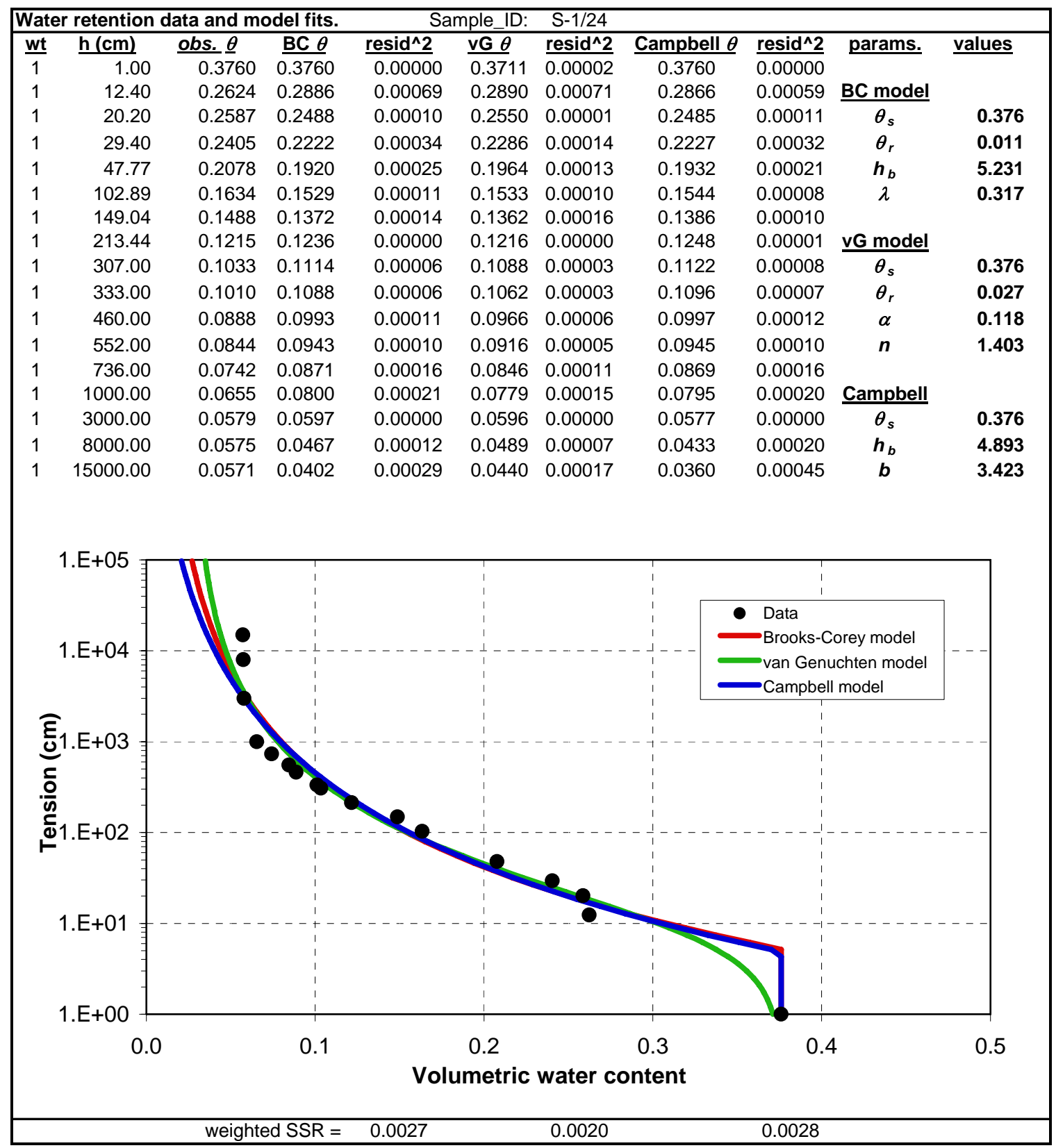

Figure A.1. Water retention data, fitted parameters, and plots showing fits of the van Genuchten (1980), Brooks and Corey (1964) and Campbell (1974) functions for sample S-1/24 from the Sisson and $\mathrm{Lu}$ (1980) field experimental site in the Hanford 200 East Area. 


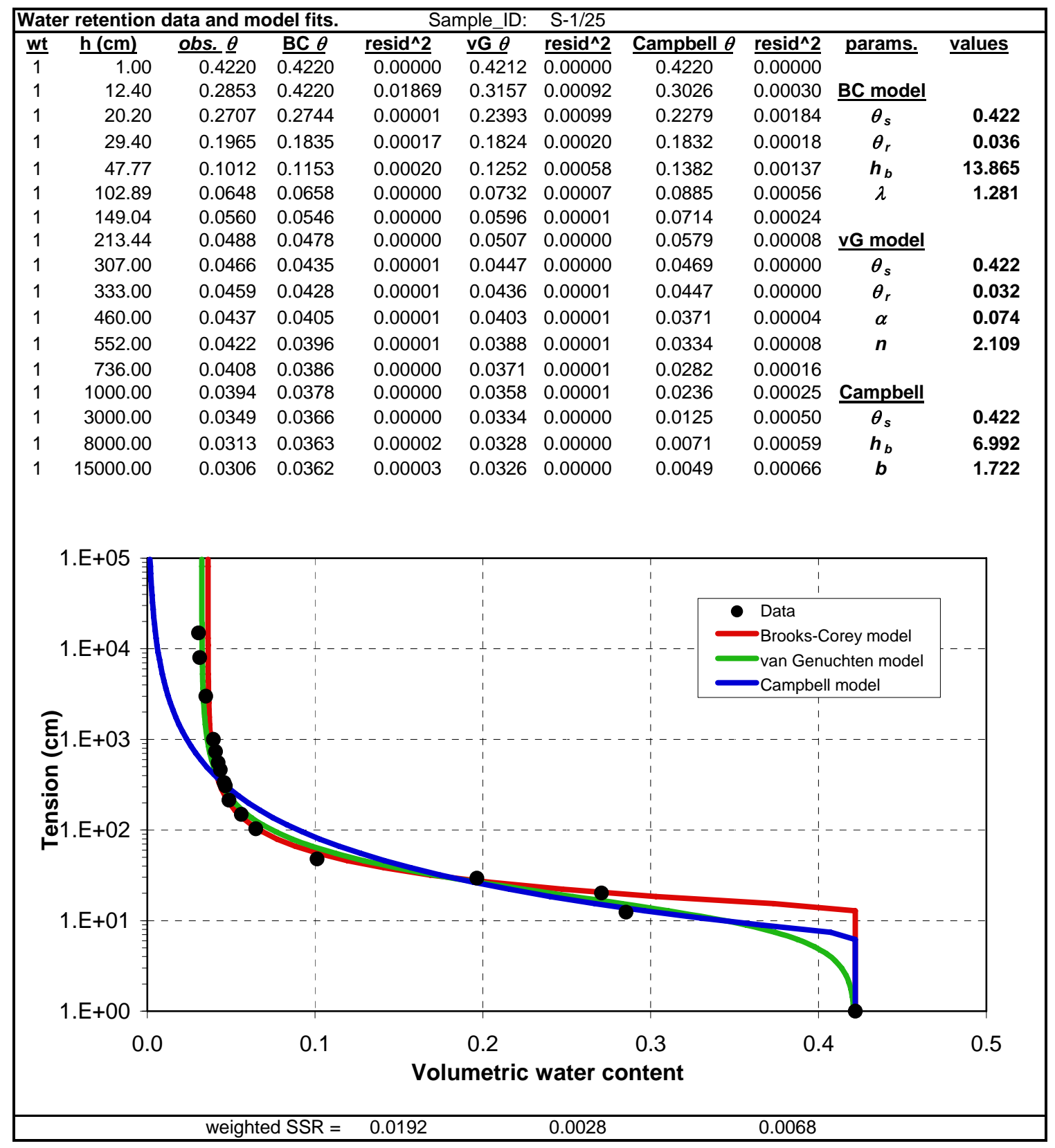

Figure A.2. Water retention data, fitted parameters, and plots showing fits of the van Genuchten (1980), Brooks and Corey (1964) and Campbell (1974) functions for sample S-1/25 from the Sisson and $\mathrm{Lu}$ (1980) field experimental site in the Hanford 200 East Area. 


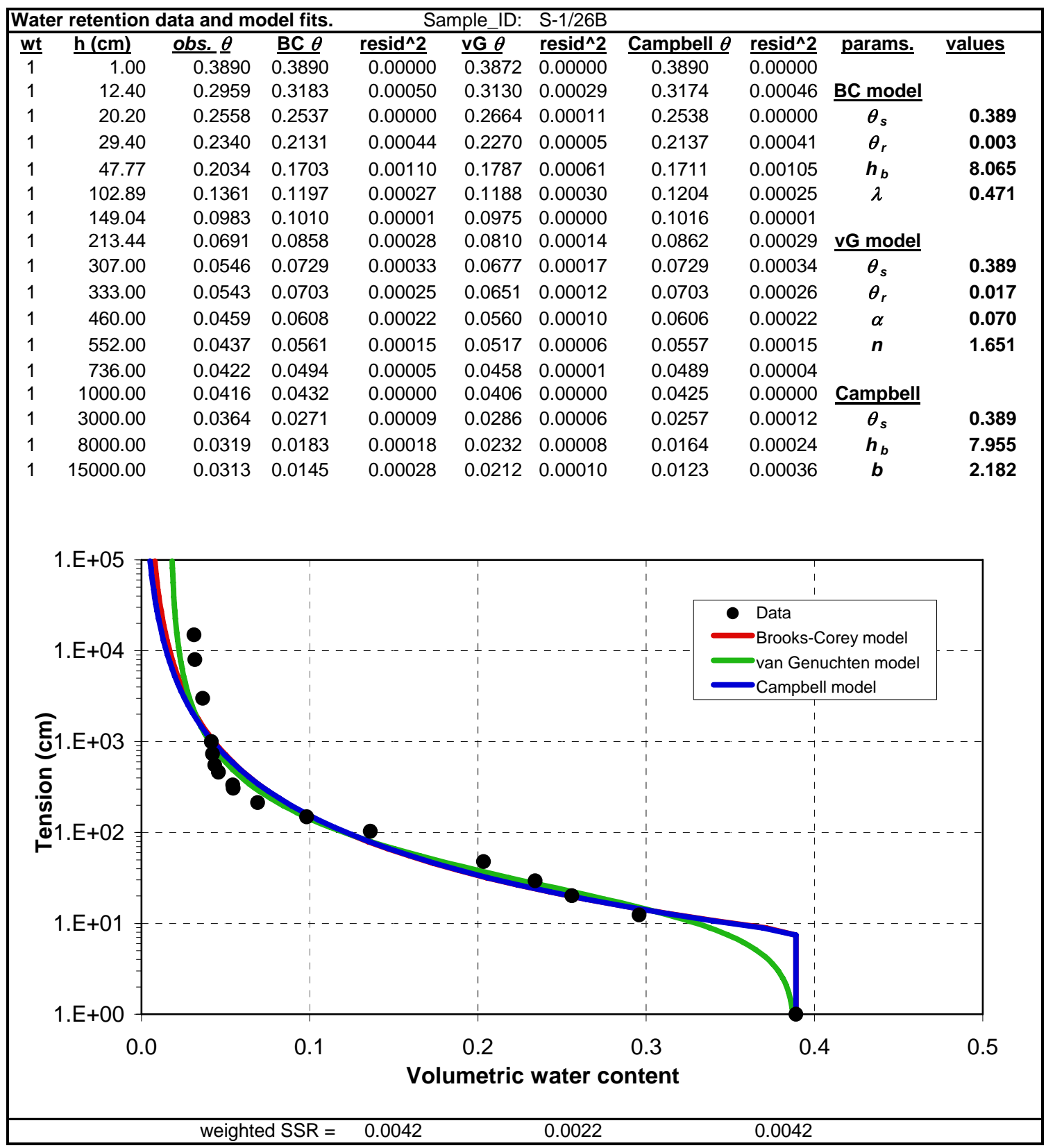

Figure A.3. Water retention data, fitted parameters, and plots showing fits of the van Genuchten (1980), Brooks and Corey (1964) and Campbell (1974) functions for sample S-1/26B from the Sisson and $\mathrm{Lu}(1980)$ field experimental site in the Hanford 200 East Area. 


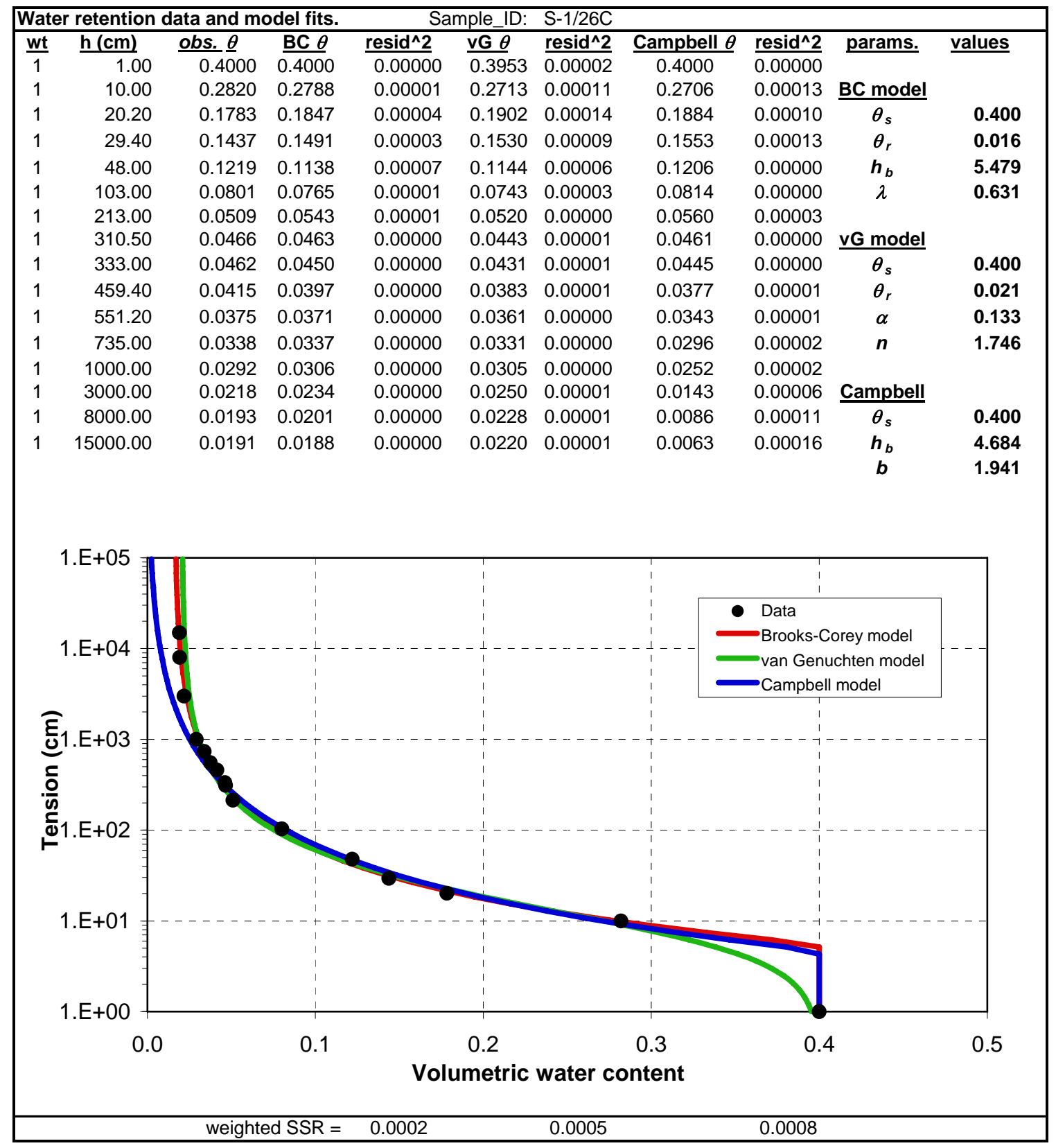

Figure A.4. Water retention data, fitted parameters, and plots showing fits of the van Genuchten (1980), Brooks and Corey (1964) and Campbell (1974) functions for sample S-1/26C from the Sisson and $\mathrm{Lu}(1980)$ field experimental site in the Hanford 200 East Area. 


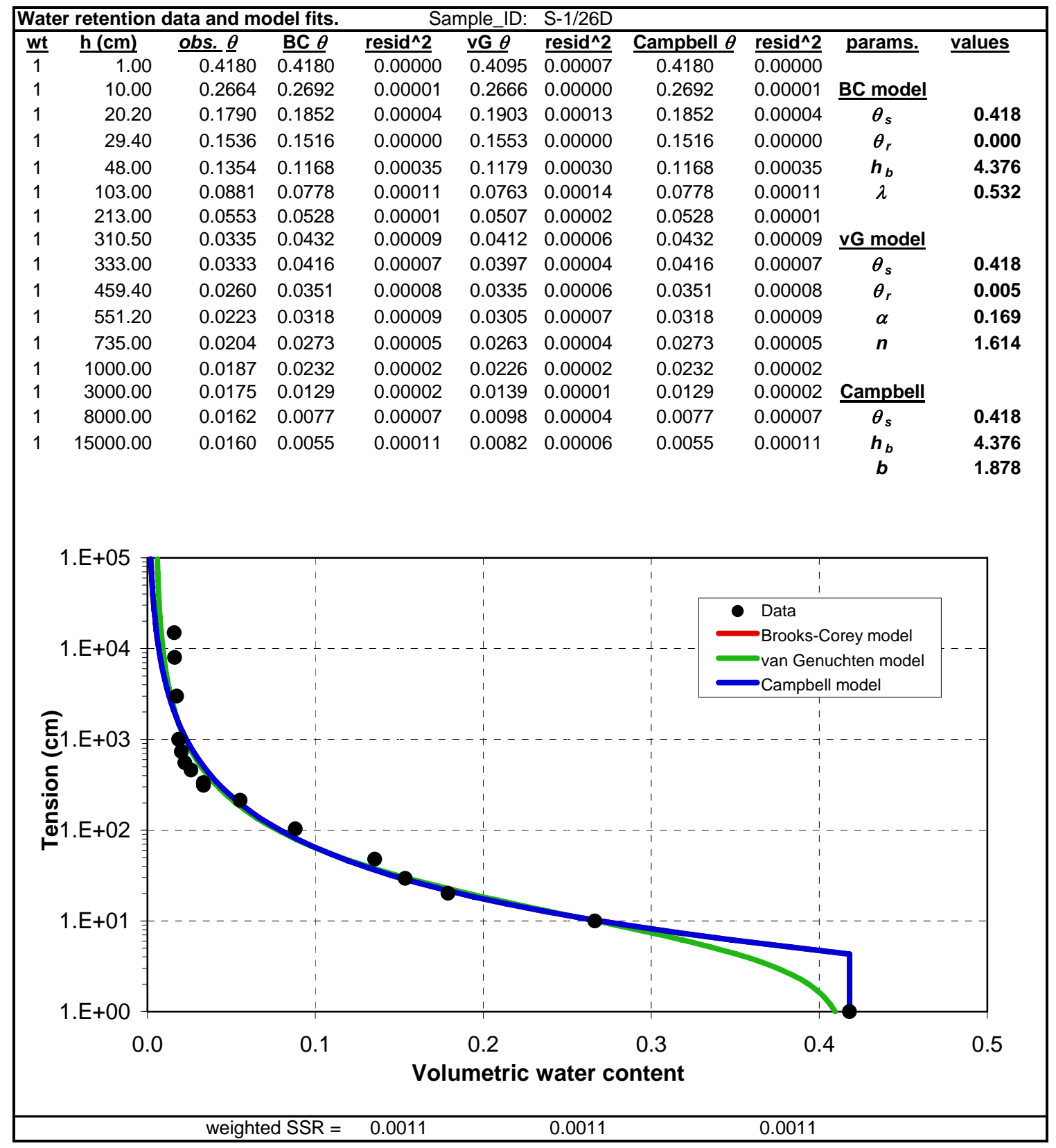

Figure A.5. Water retention data, fitted parameters, and plots showing fits of the van Genuchten (1980), Brooks and Corey (1964) and Campbell (1974) functions for sample S-1/26D from the Sisson and $\mathrm{Lu}(1980)$ field experimental site in the Hanford 200 East Area. 


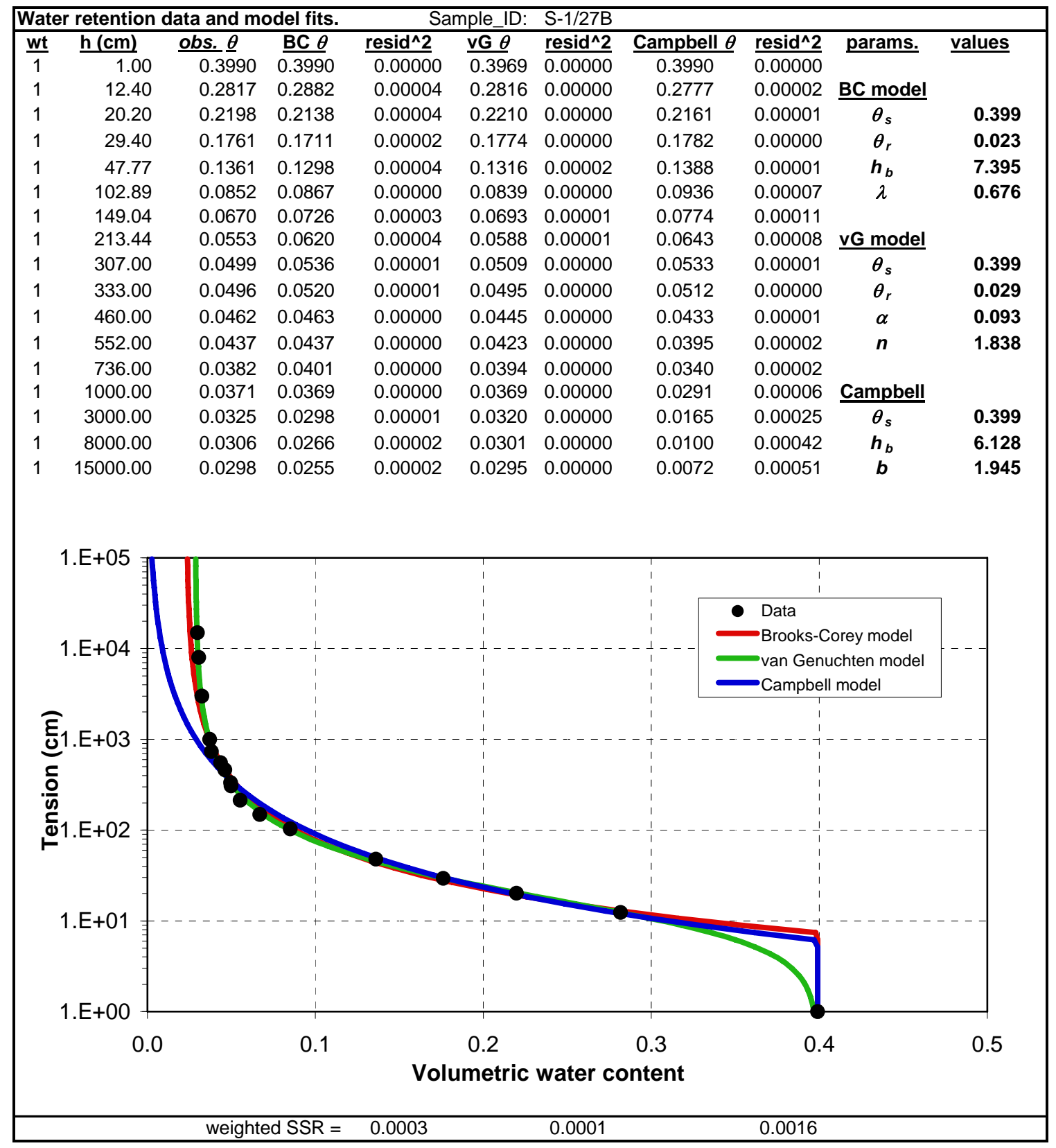

Figure A.6. Water retention data, fitted parameters, and plots showing fits of the van Genuchten (1980), Brooks and Corey (1964) and Campbell (1974) functions for sample S-1/27B from the Sisson and $\mathrm{Lu}(1980)$ field experimental site in the Hanford 200 East Area. 


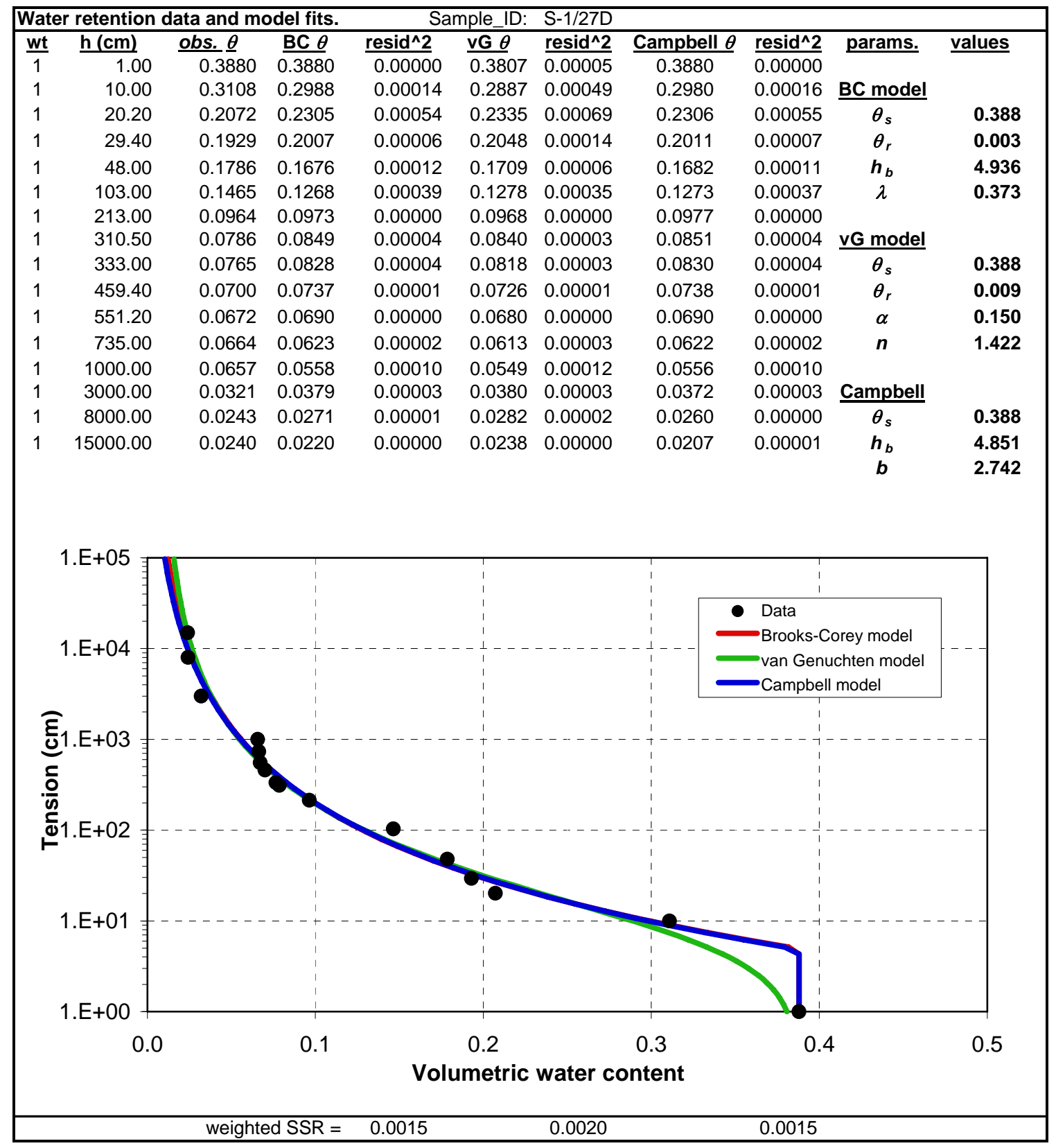

Figure A.7. Water retention data, fitted parameters, and plots showing fits of the van Genuchten (1980), Brooks and Corey (1964) and Campbell (1974) functions for sample S-1/27D from the Sisson and $\mathrm{Lu}(1980)$ field experimental site in the Hanford 200 East Area. 


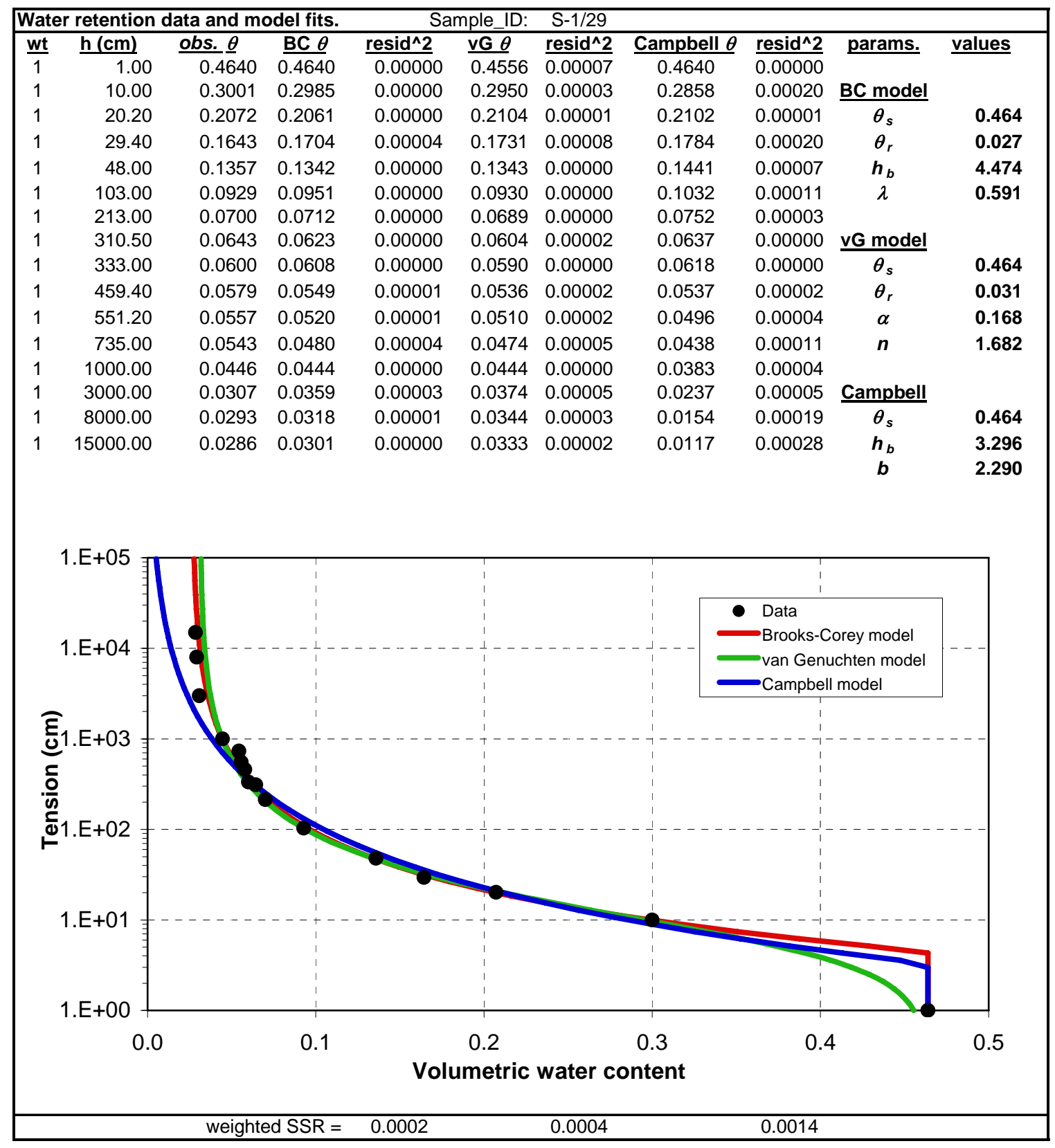

Figure A.8. Water retention data, fitted parameters, and plots showing fits of the van Genuchten (1980), Brooks and Corey (1964) and Campbell (1974) functions for sample S-1/29 from the Sisson and $\mathrm{Lu}$ (1980) field experimental site in the Hanford 200 East Area. 


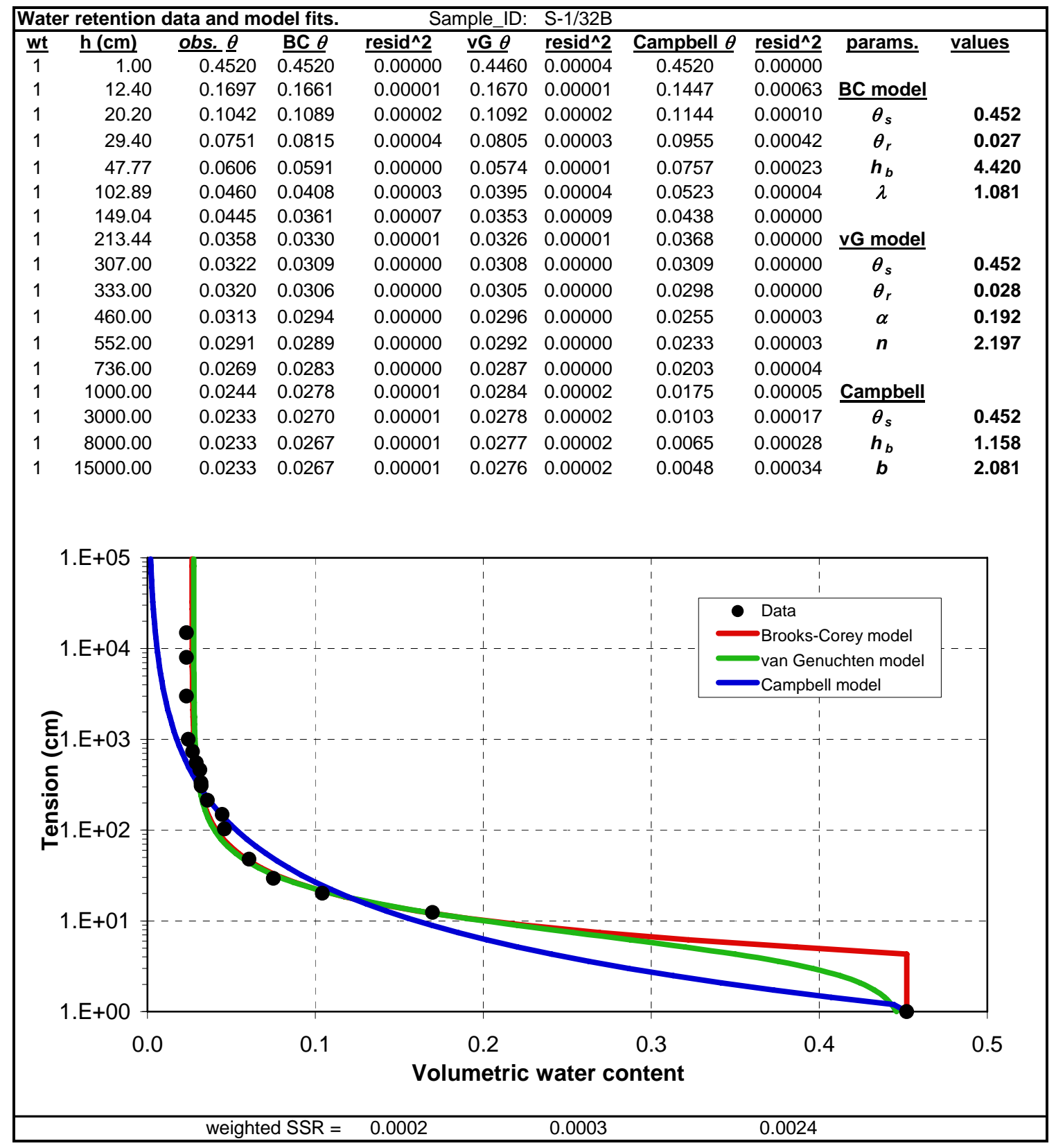

Figure A.9. Water retention data, fitted parameters, and plots showing fits of the van Genuchten (1980), Brooks and Corey (1964) and Campbell (1974) functions for sample S-1/32B from the Sisson and $\mathrm{Lu}(1980)$ field experimental site in the Hanford 200 East Area. 


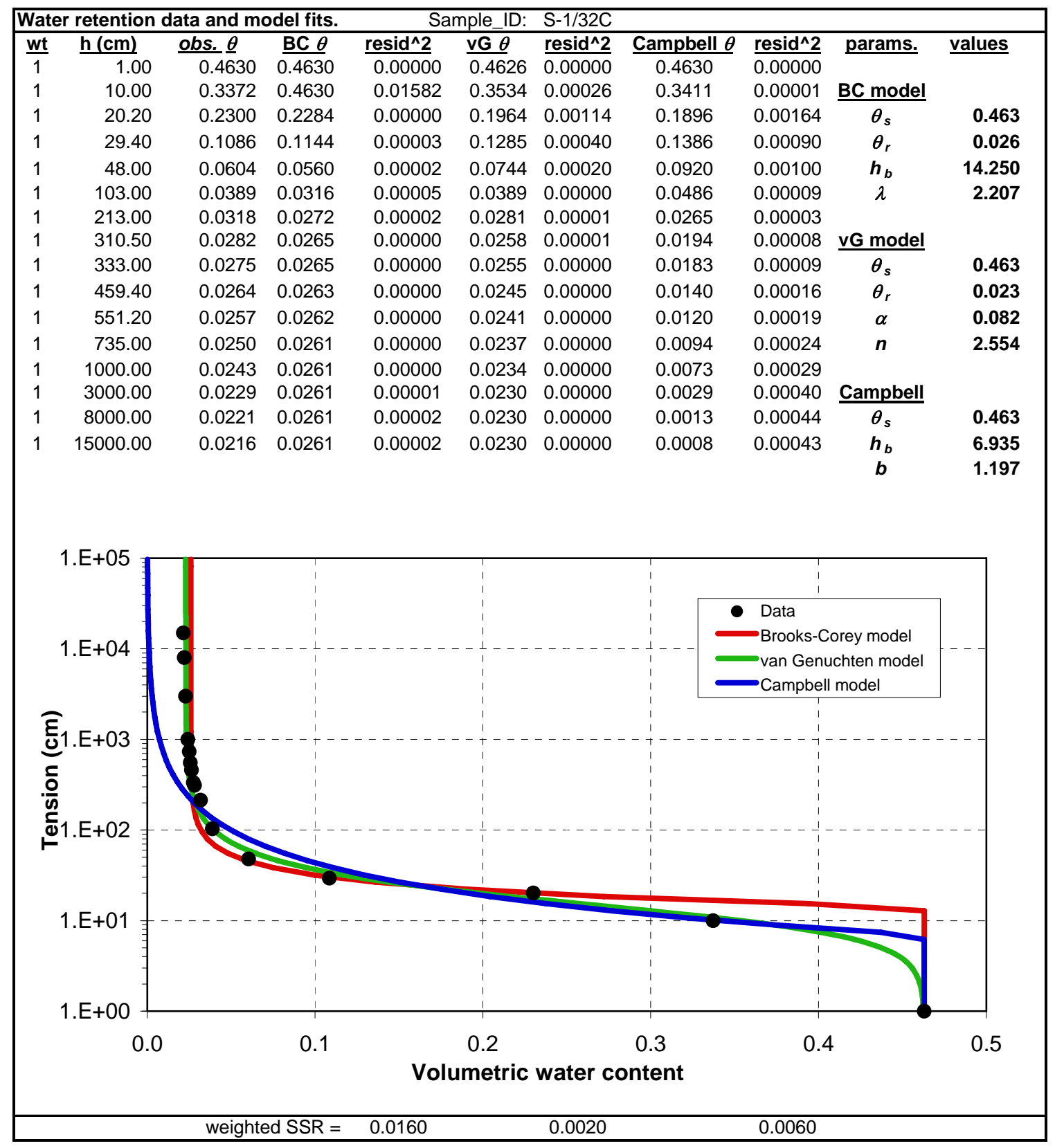

Figure A.10. Water retention data, fitted parameters, and plots showing fits of the van Genuchten (1980), Brooks and Corey (1964) and Campbell (1974) functions for sample S-1/32C from the Sisson and $\mathrm{Lu}$ (1980) field experimental site in the Hanford 200 East Area. 


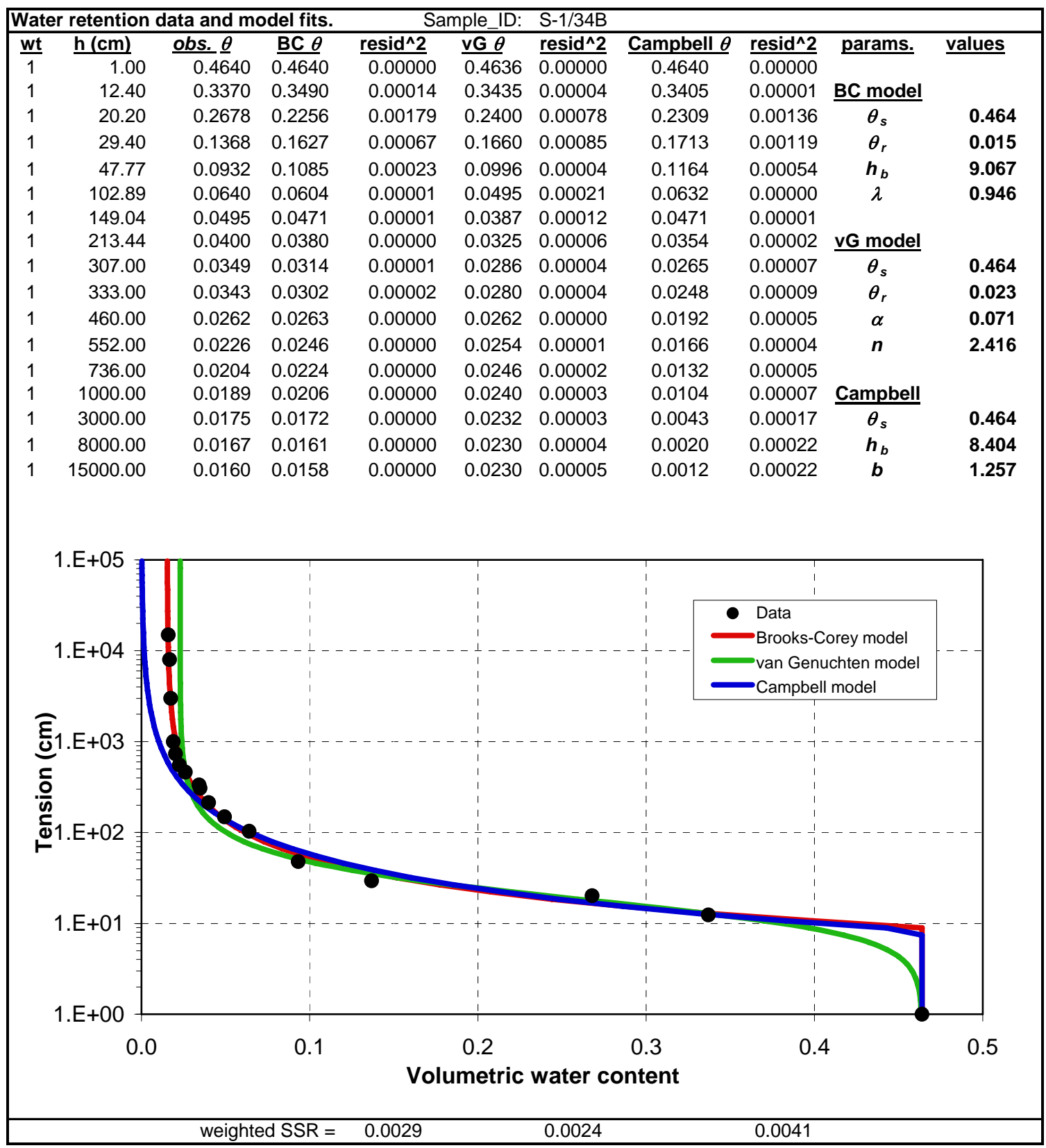

Figure A.11. Water retention data, fitted parameters, and plots showing fits of the van Genuchten (1980), Brooks and Corey (1964) and Campbell (1974) functions for sample S-1/34B from the Sisson and $\mathrm{Lu}$ (1980) field experimental site in the Hanford 200 East Area. 


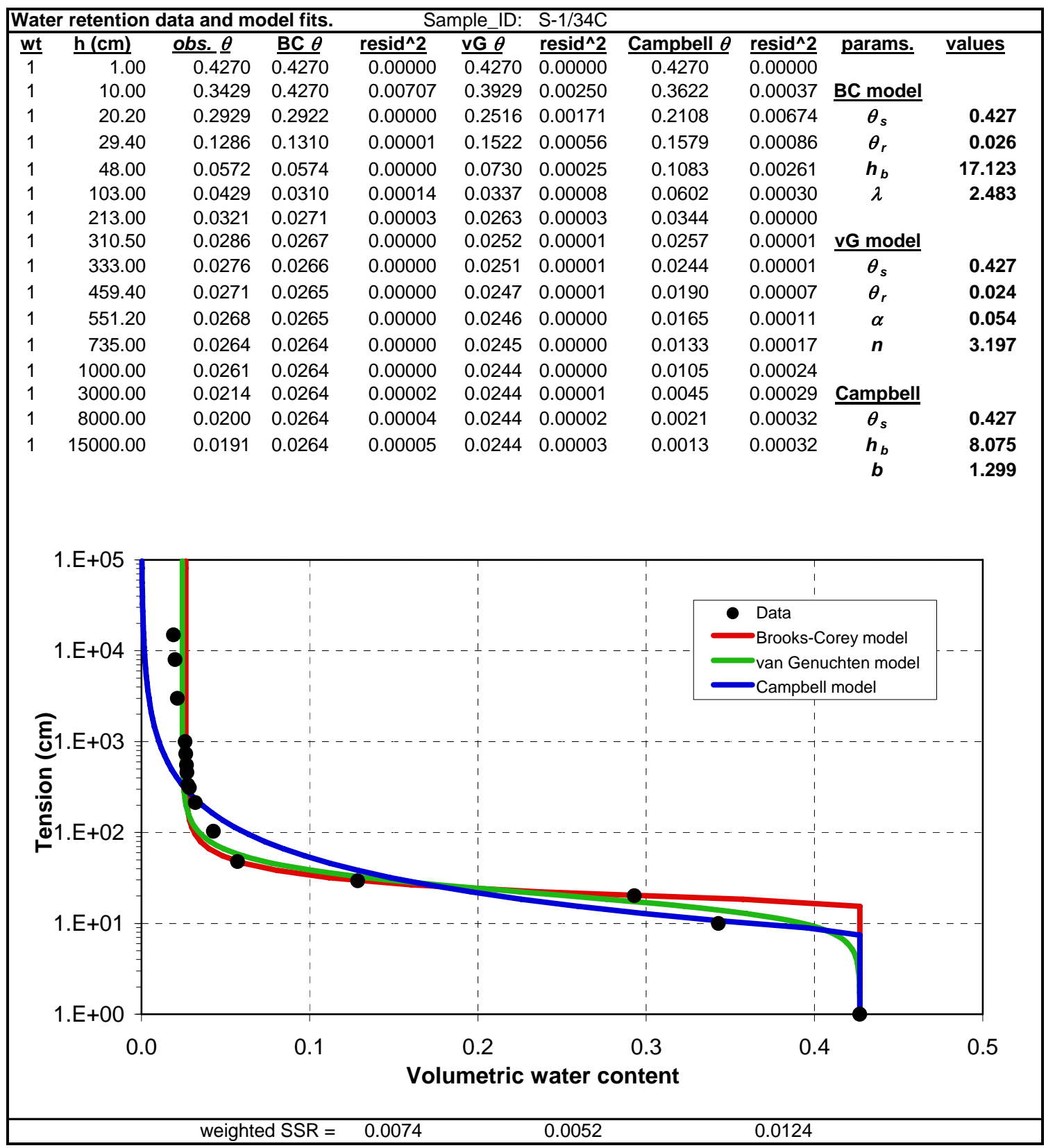

Figure A.12. Water retention data, fitted parameters, and plots showing fits of the van Genuchten (1980), Brooks and Corey (1964) and Campbell (1974) functions for sample S-1/34C from the Sisson and $\mathrm{Lu}$ (1980) field experimental site in the Hanford 200 East Area. 


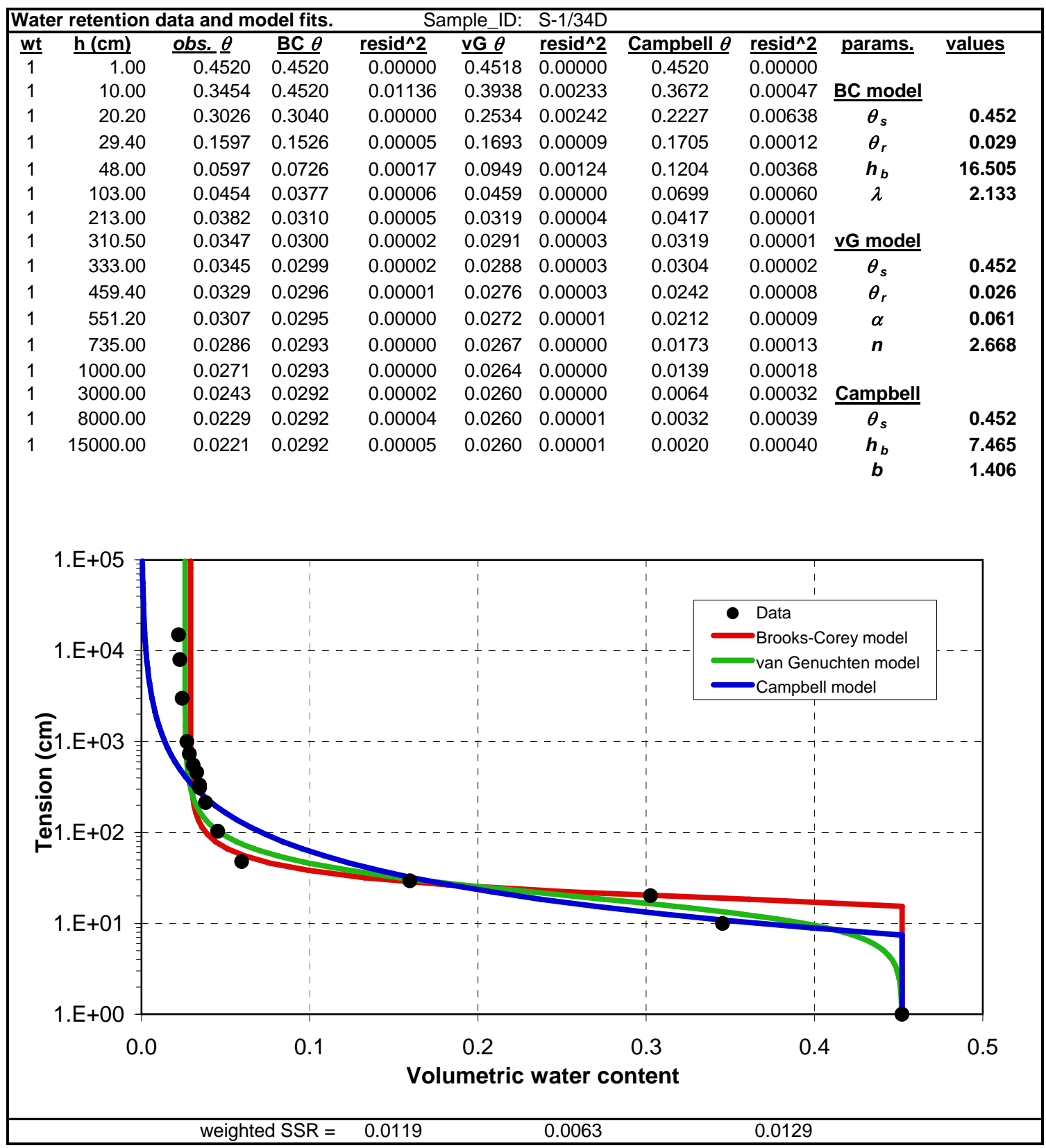

Figure A.13. Water retention data, fitted parameters, and plots showing fits of the van Genuchten (1980), Brooks and Corey (1964) and Campbell (1974) functions for sample S-1/34D from the Sisson and $\mathrm{Lu}$ (1980) field experimental site in the Hanford 200 East Area. 


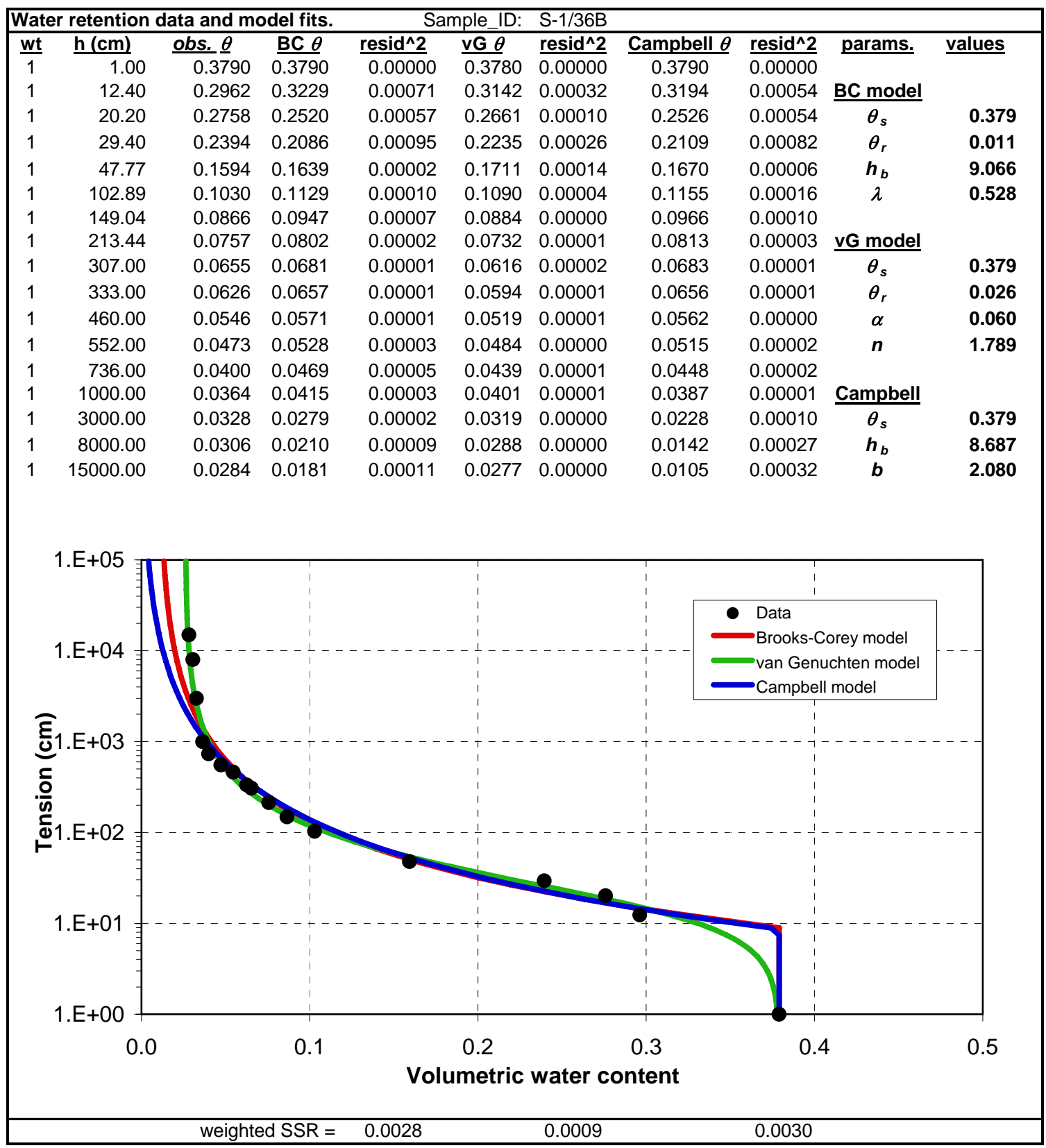

Figure A.14. Water retention data, fitted parameters, and plots showing fits of the van Genuchten (1980), Brooks and Corey (1964) and Campbell (1974) functions for sample S-1/36B from the Sisson and $\mathrm{Lu}$ (1980) field experimental site in the Hanford 200 East Area. 


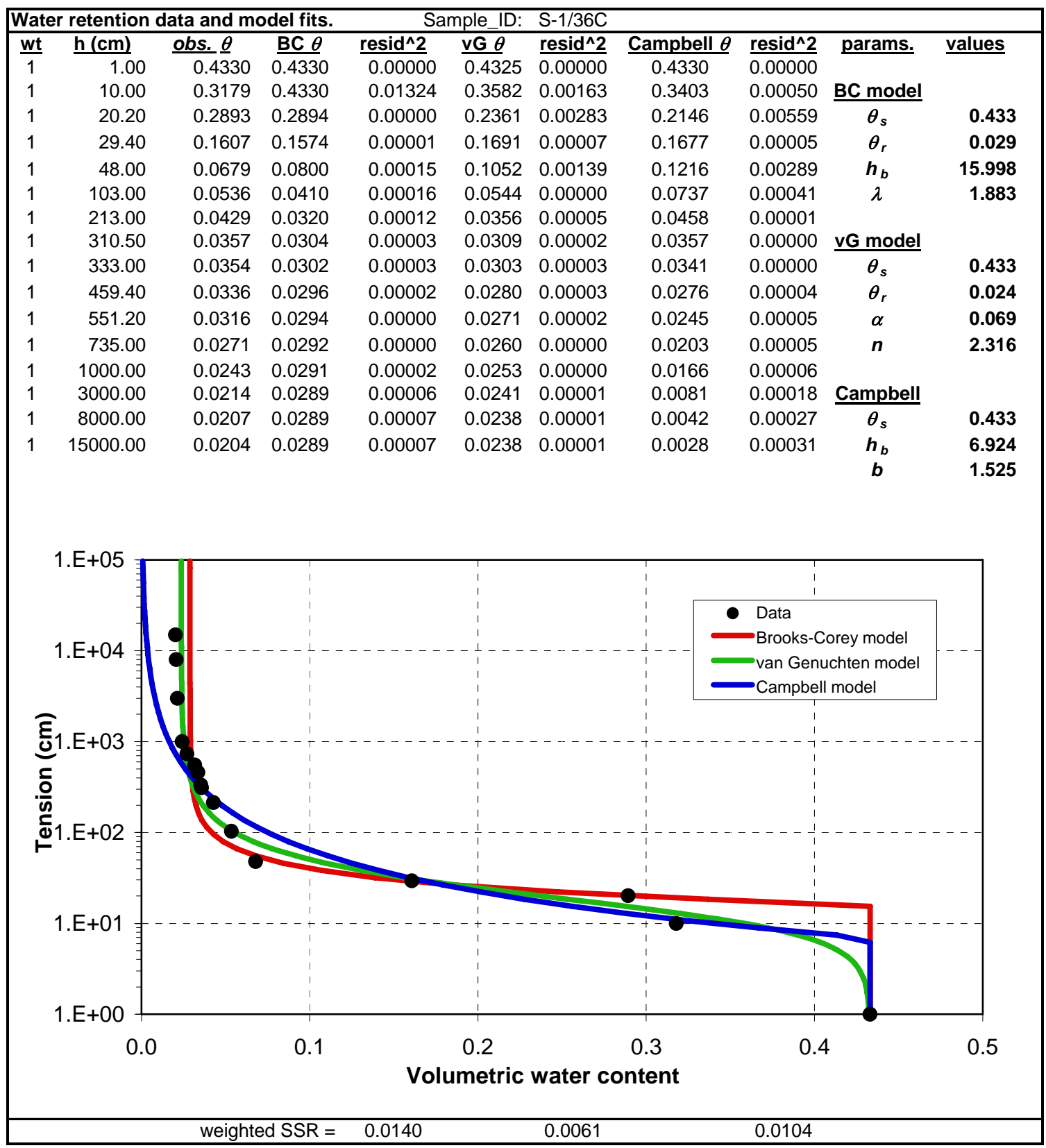

Figure A.15. Water retention data, fitted parameters, and plots showing fits of the van Genuchten (1980), Brooks and Corey (1964) and Campbell (1974) functions for sample S-1/36C from the Sisson and $\mathrm{Lu}$ (1980) field experimental site in the Hanford 200 East Area. 


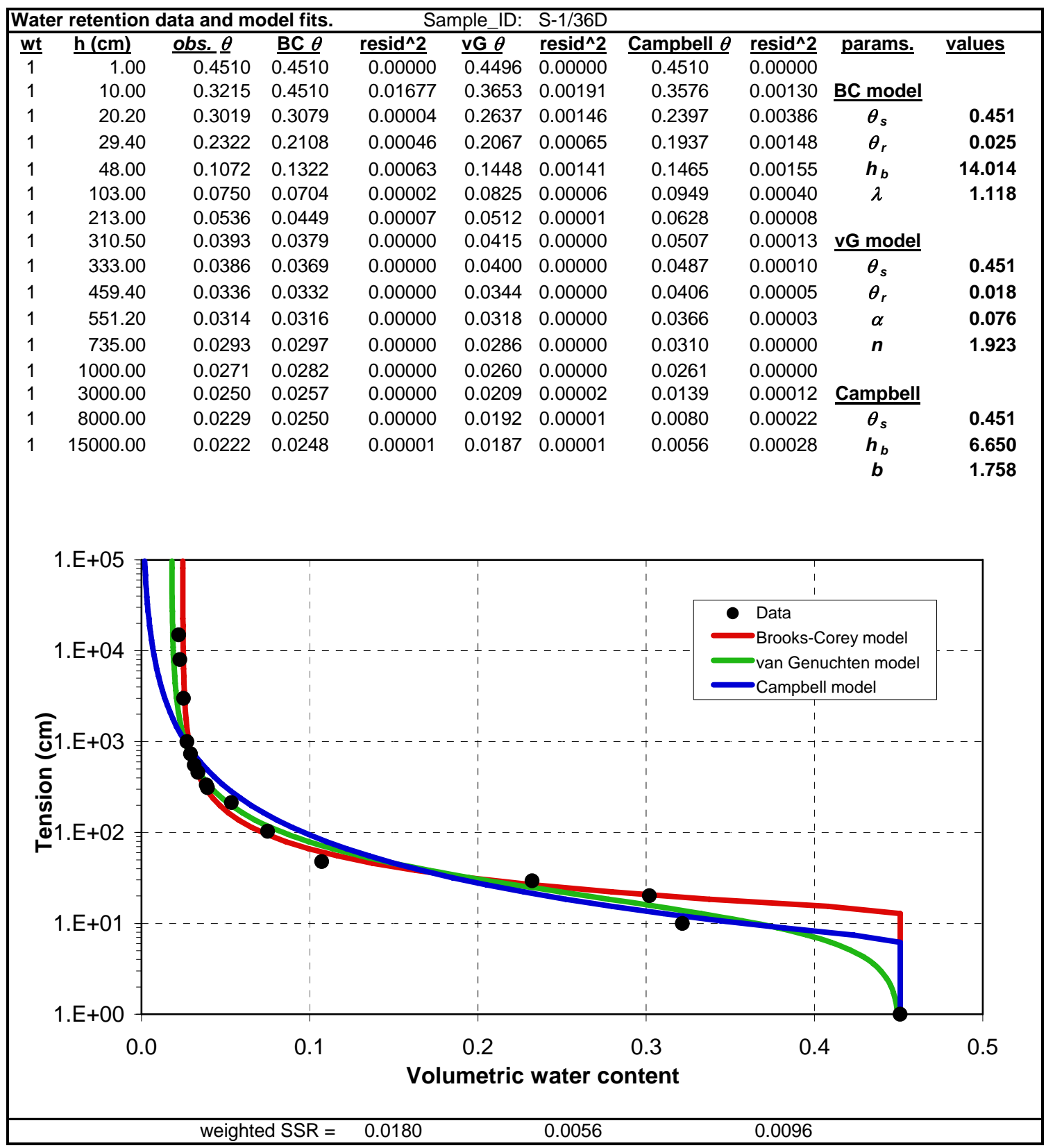

Figure A.16. Water retention data, fitted parameters, and plots showing fits of the van Genuchten (1980), Brooks and Corey (1964) and Campbell (1974) functions for sample S-1/36D from the Sisson and $\mathrm{Lu}$ (1980) field experimental site in the Hanford 200 East Area. 


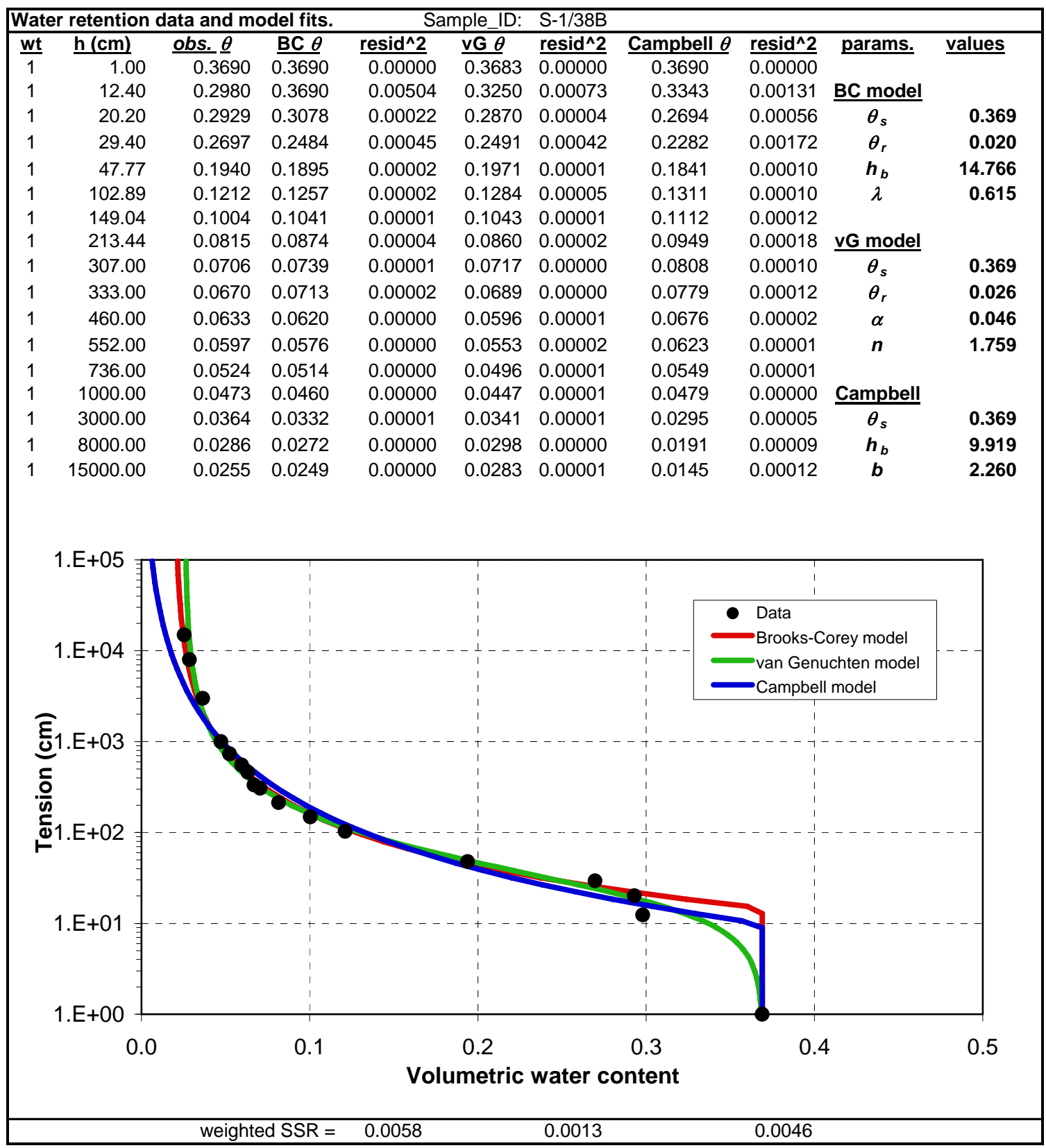

Figure A.17. Water retention data, fitted parameters, and plots showing fits of the van Genuchten (1980), Brooks and Corey (1964) and Campbell (1974) functions for sample S-1/38B from the Sisson and $\mathrm{Lu}$ (1980) field experimental site in the Hanford 200 East Area. 


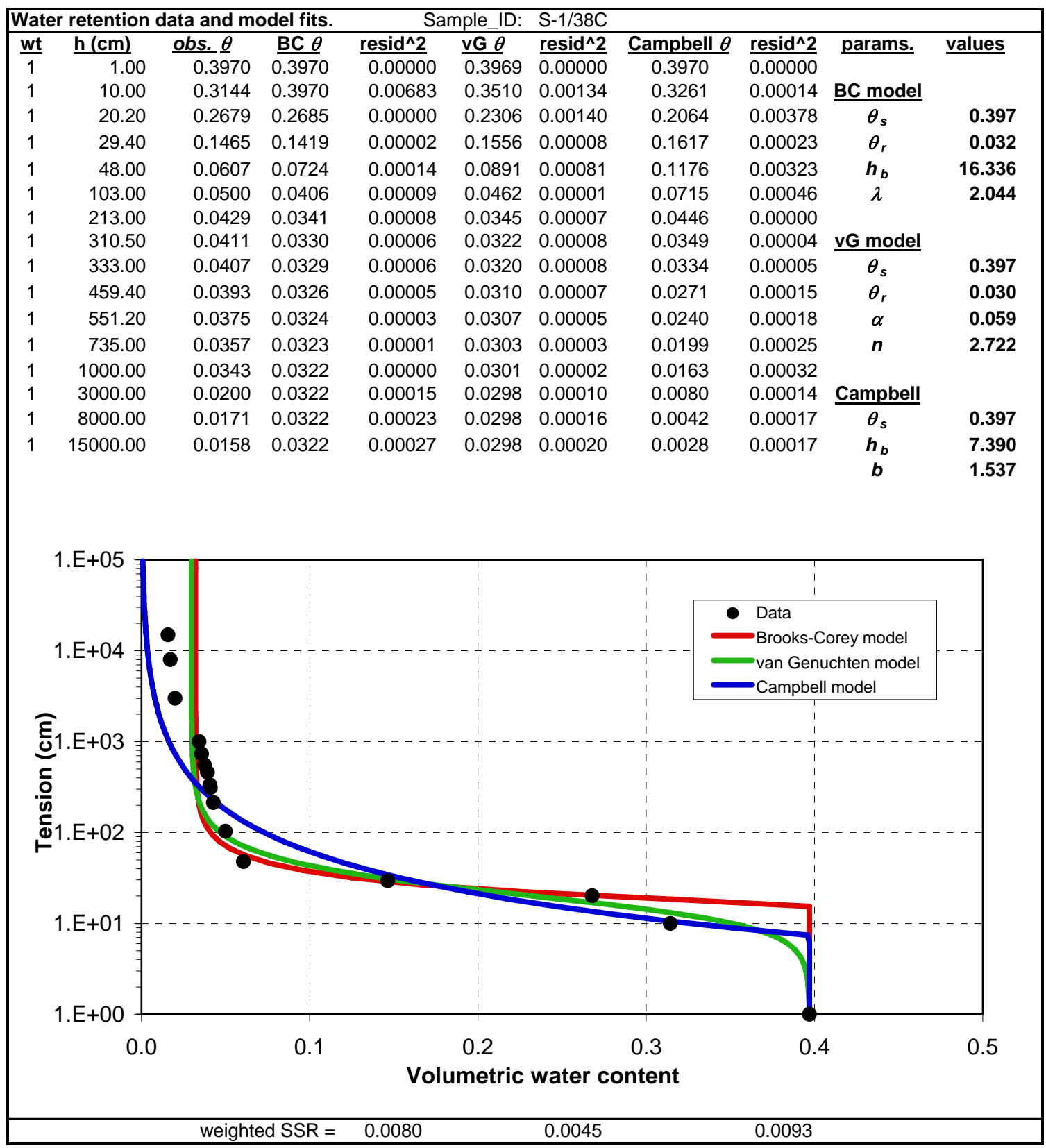

Figure A.18. Water retention data, fitted parameters, and plots showing fits of the van Genuchten (1980), Brooks and Corey (1964) and Campbell (1974) functions for sample S-1/38C from the Sisson and $\mathrm{Lu}$ (1980) field experimental site in the Hanford 200 East Area. 


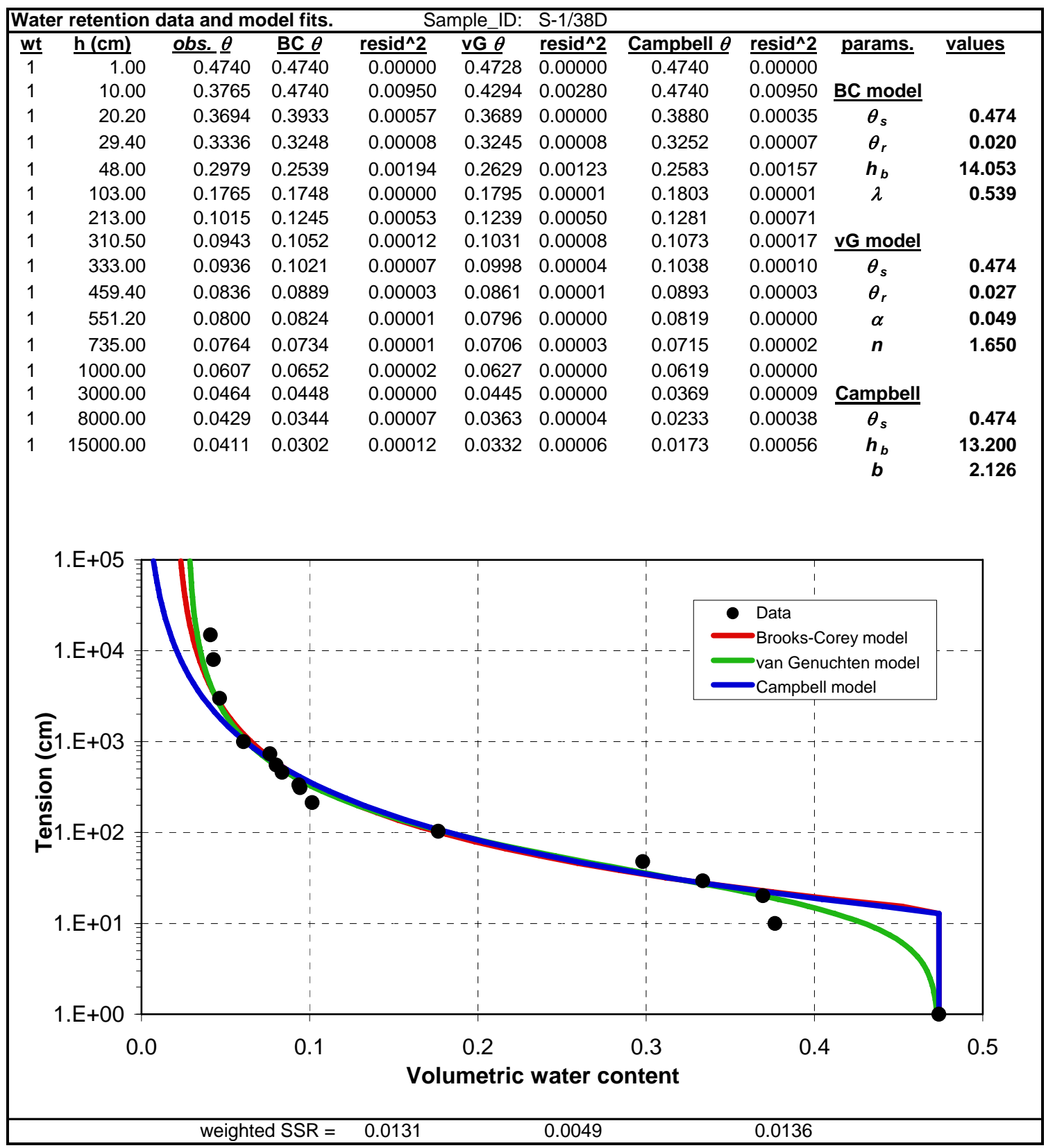

Figure A.19. Water retention data, fitted parameters, and plots showing fits of the van Genuchten (1980), Brooks and Corey (1964) and Campbell (1974) functions for sample S-1/38D from the Sisson and $\mathrm{Lu}$ (1980) field experimental site in the Hanford 200 East Area. 


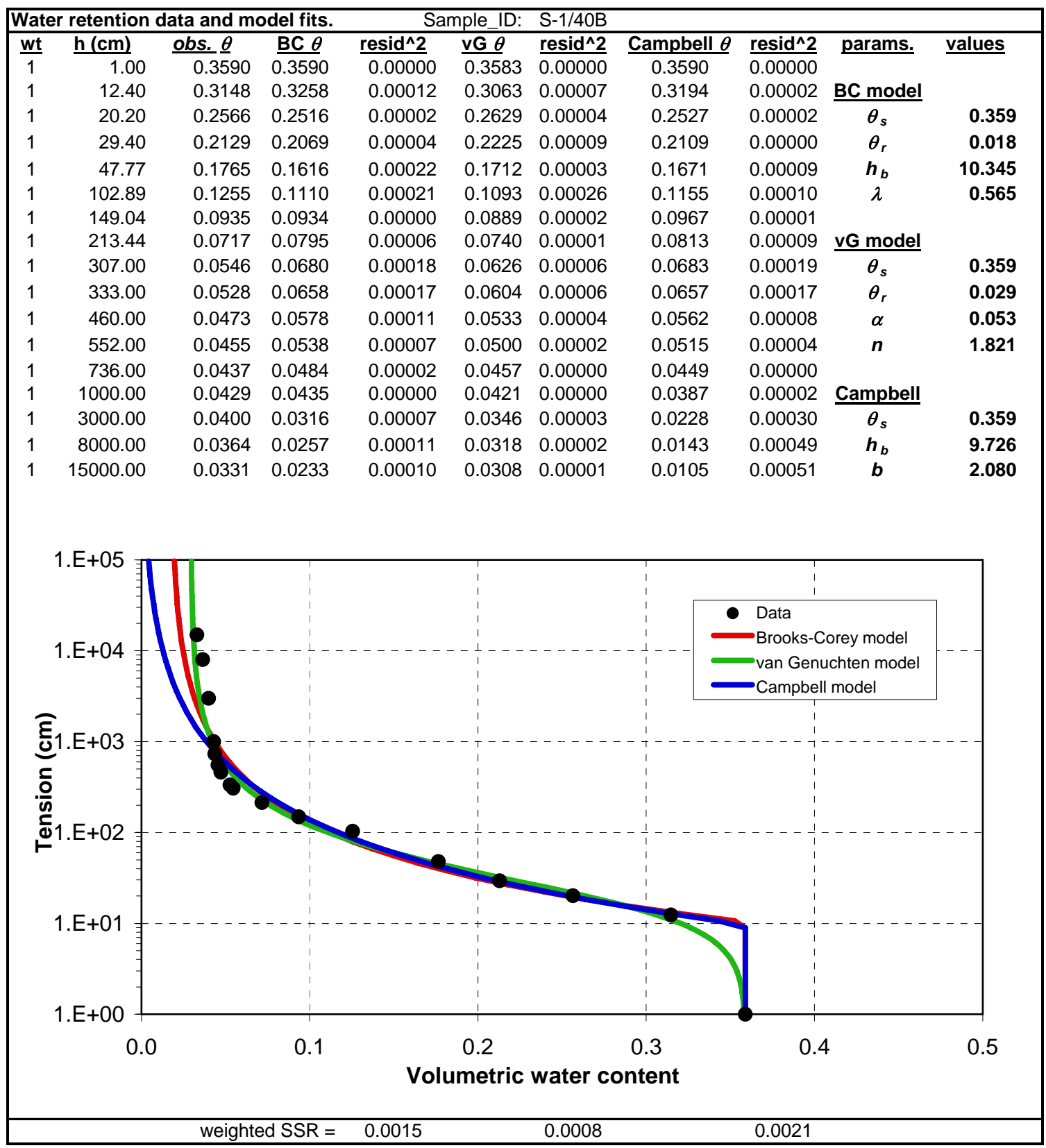

Figure A.20. Water retention data, fitted parameters, and plots showing fits of the van Genuchten (1980), Brooks and Corey (1964) and Campbell (1974) functions for sample S-1/40B from the Sisson and $\mathrm{Lu}$ (1980) field experimental site in the Hanford 200 East Area. 


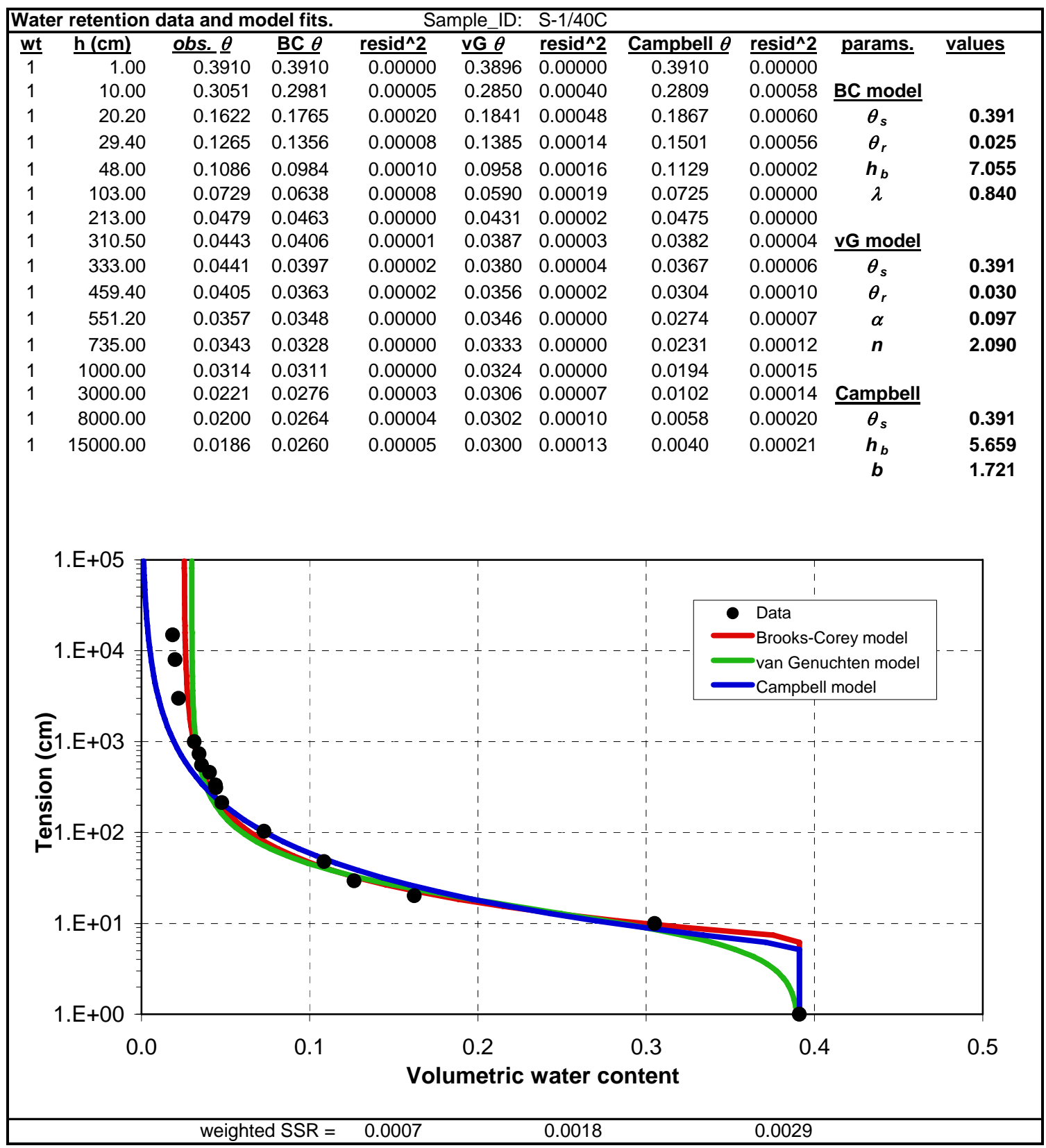

Figure A.21. Water retention data, fitted parameters, and plots showing fits of the van Genuchten (1980), Brooks and Corey (1964) and Campbell (1974) functions for sample S-1/40C from the Sisson and $\mathrm{Lu}$ (1980) field experimental site in the Hanford 200 East Area. 


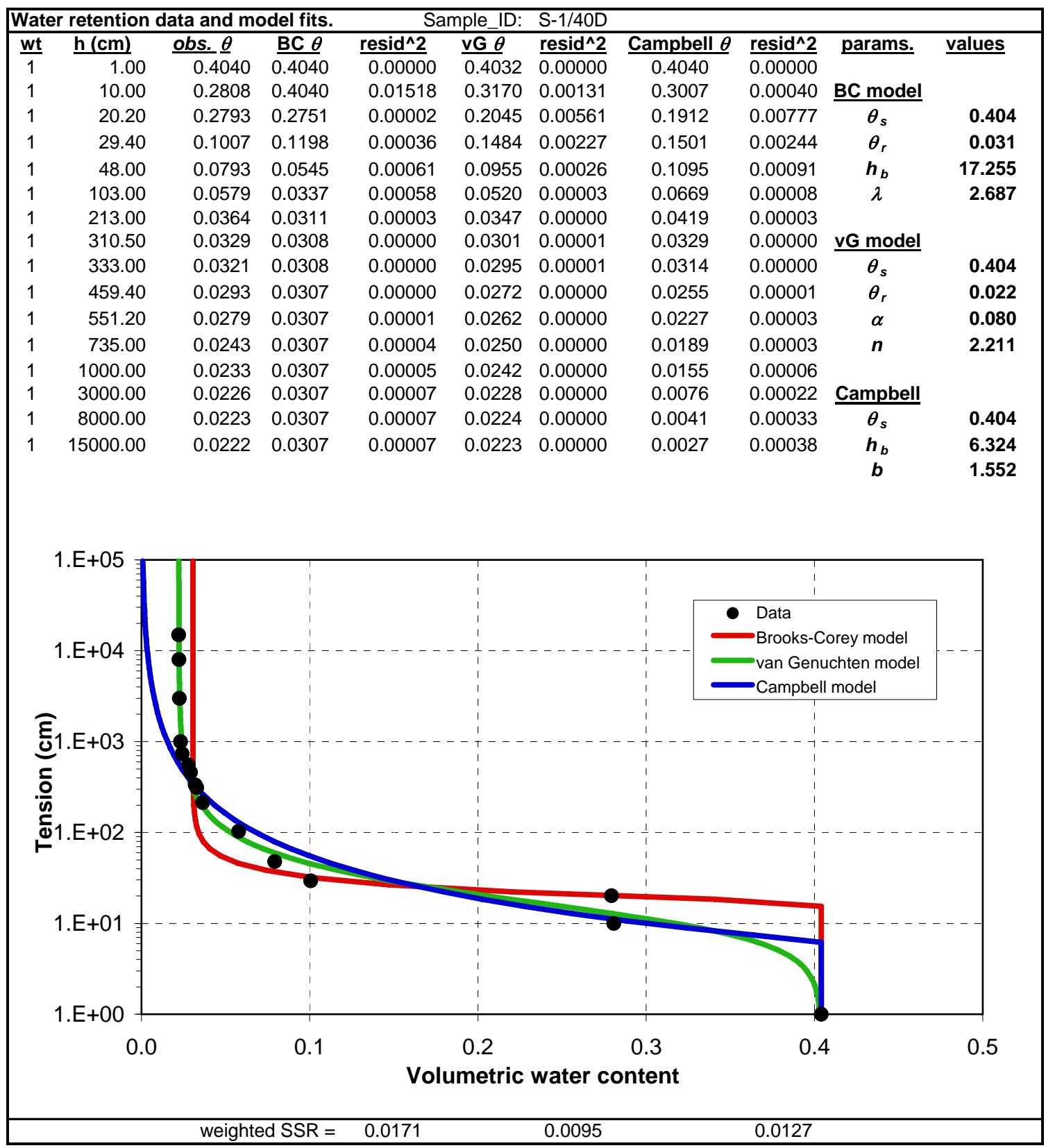

Figure A.22. Water retention data, fitted parameters, and plots showing fits of the van Genuchten (1980), Brooks and Corey (1964) and Campbell (1974) functions for sample S-1/40D from the Sisson and $\mathrm{Lu}$ (1980) field experimental site in the Hanford 200 East Area. 


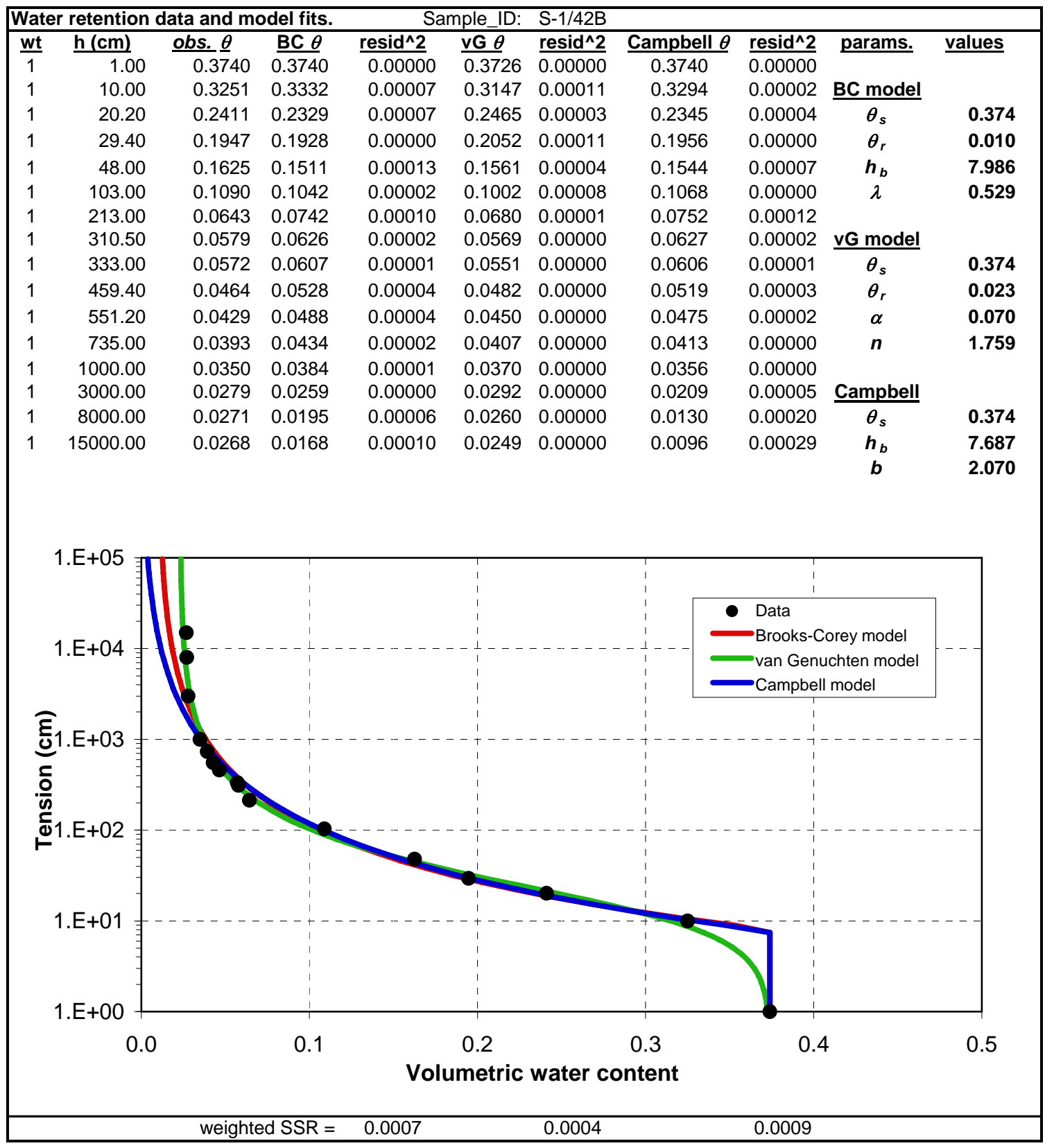

Figure A.23. Water retention data, fitted parameters, and plots showing fits of the van Genuchten (1980), Brooks and Corey (1964) and Campbell (1974) functions for sample S-1/42B from the Sisson and $\mathrm{Lu}$ (1980) field experimental site in the Hanford 200 East Area. 


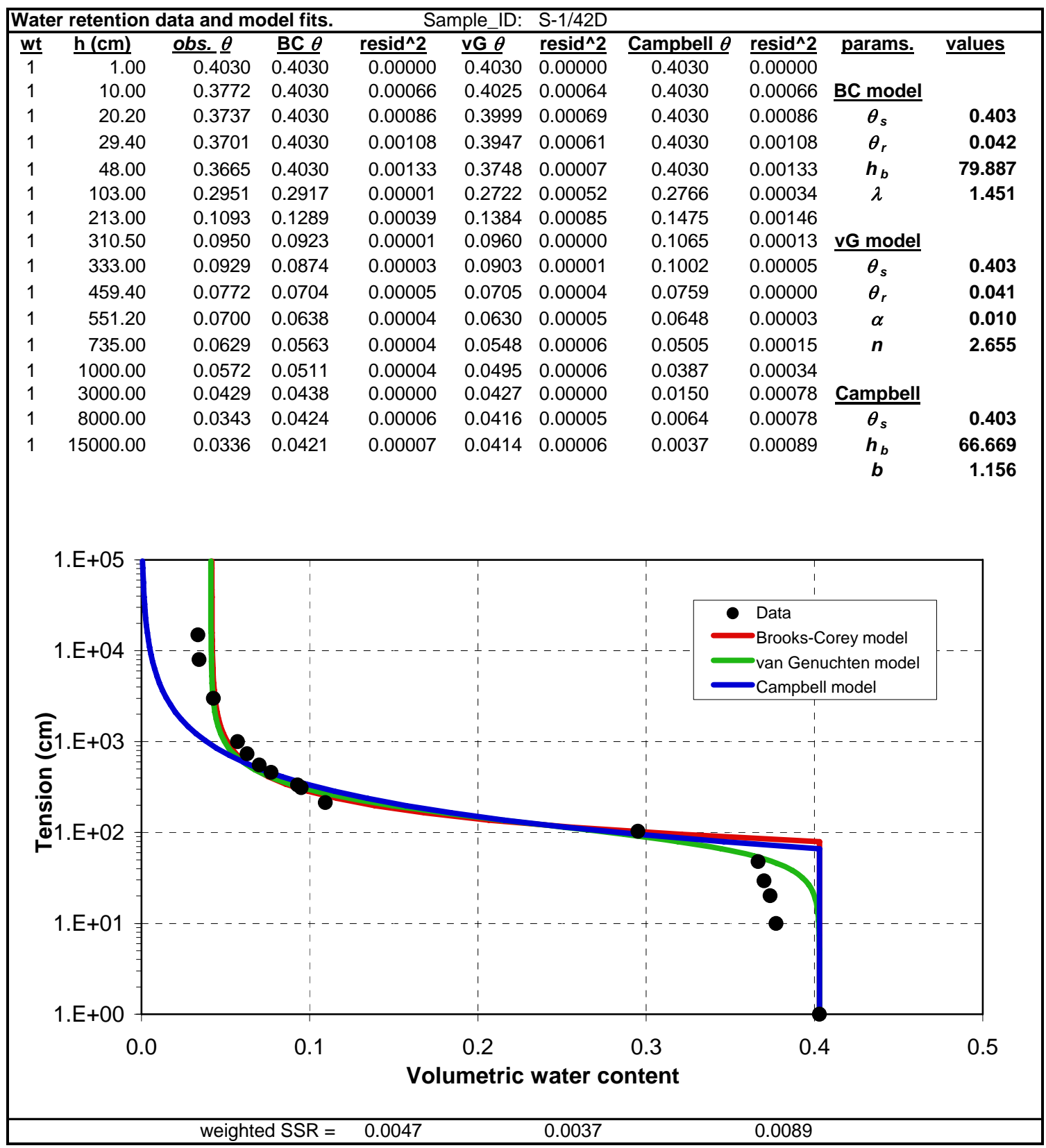

Figure A.24. Water retention data, fitted parameters, and plots showing fits of the van Genuchten (1980), Brooks and Corey (1964) and Campbell (1974) functions for sample S-1/42D from the Sisson and $\mathrm{Lu}(1980)$ field experimental site in the Hanford 200 East Area. 


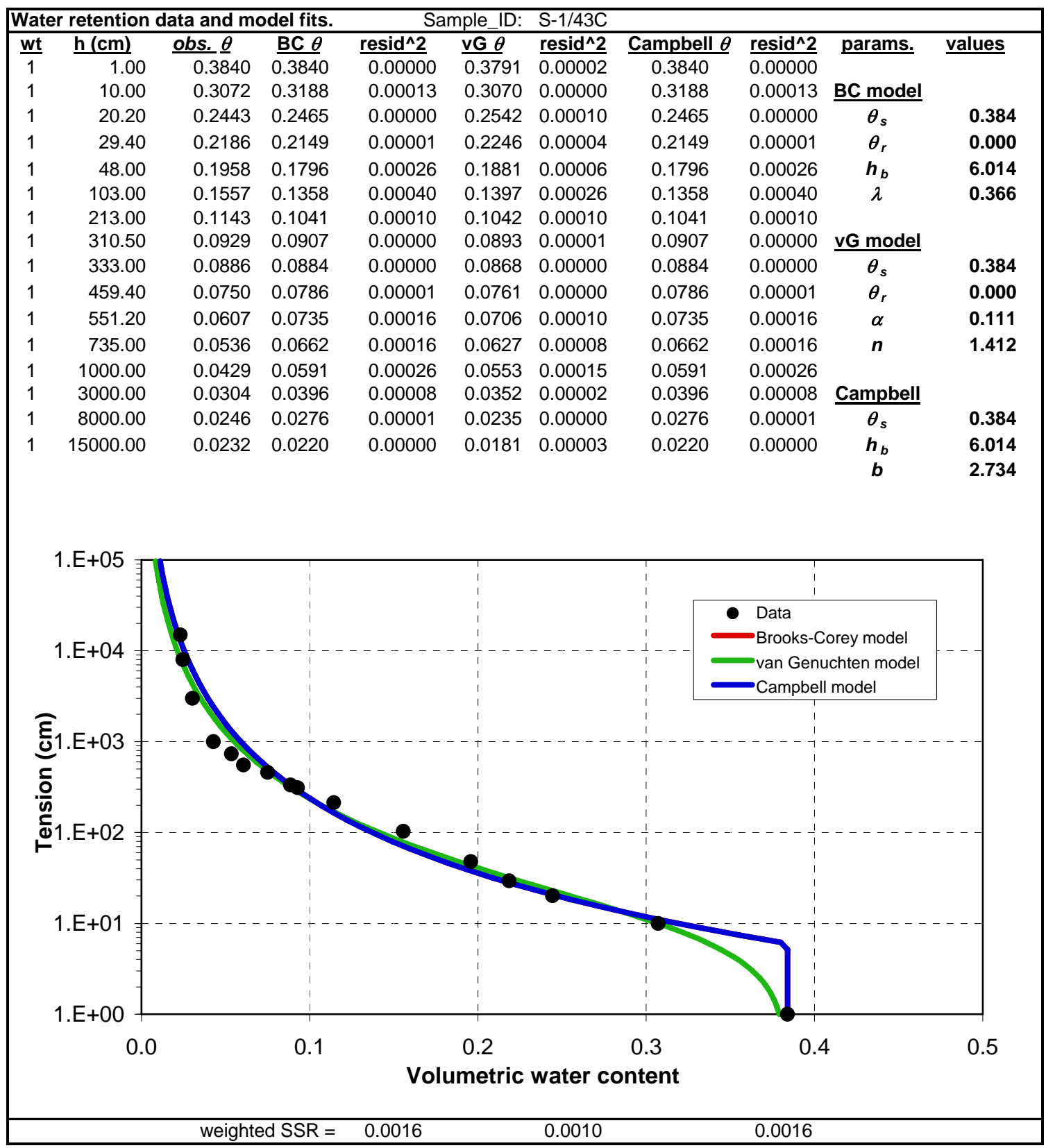

Figure A.25. Water retention data, fitted parameters, and plots showing fits of the van Genuchten (1980), Brooks and Corey (1964) and Campbell (1974) functions for sample S-1/43C from the Sisson and $\mathrm{Lu}$ (1980) field experimental site in the Hanford 200 East Area. 


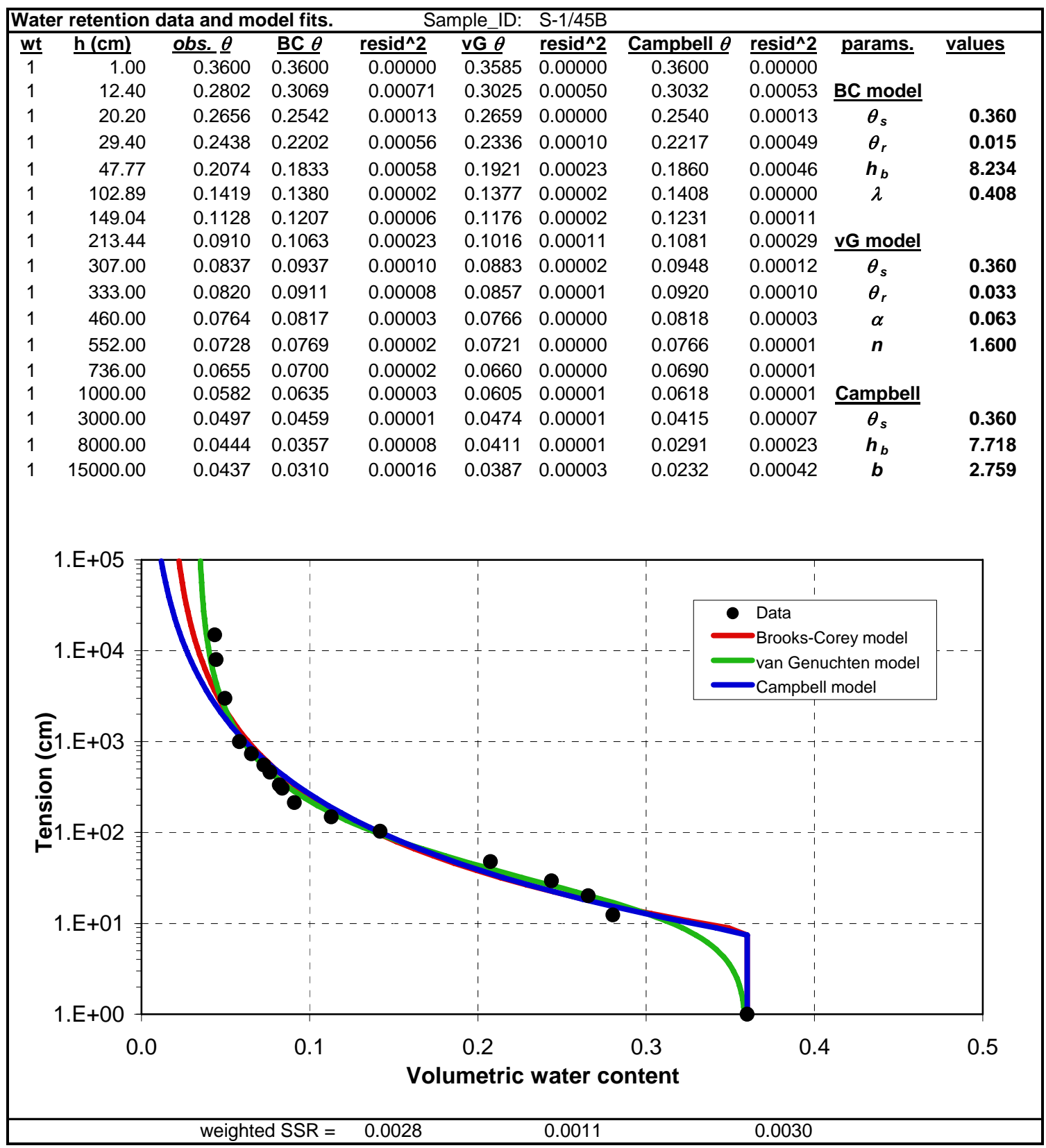

Figure A.26. Water retention data, fitted parameters, and plots showing fits of the van Genuchten (1980), Brooks and Corey (1964) and Campbell (1974) functions for sample S-1/45B from the Sisson and $\mathrm{Lu}$ (1980) field experimental site in the Hanford 200 East Area. 


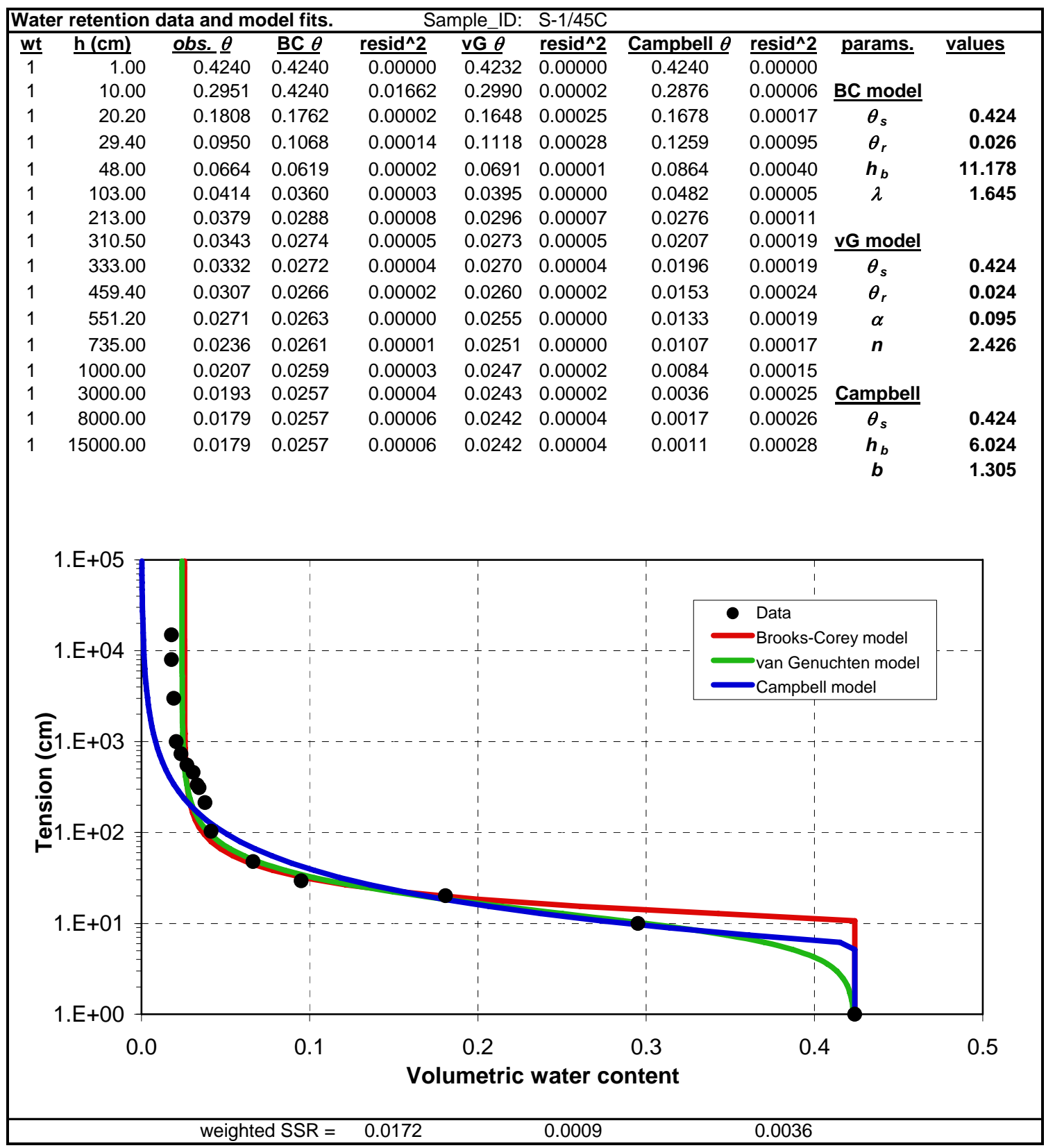

Figure A.27. Water retention data, fitted parameters, and plots showing fits of the van Genuchten (1980), Brooks and Corey (1964) and Campbell (1974) functions for sample S-1/45C from the Sisson and $\mathrm{Lu}$ (1980) field experimental site in the Hanford 200 East Area. 


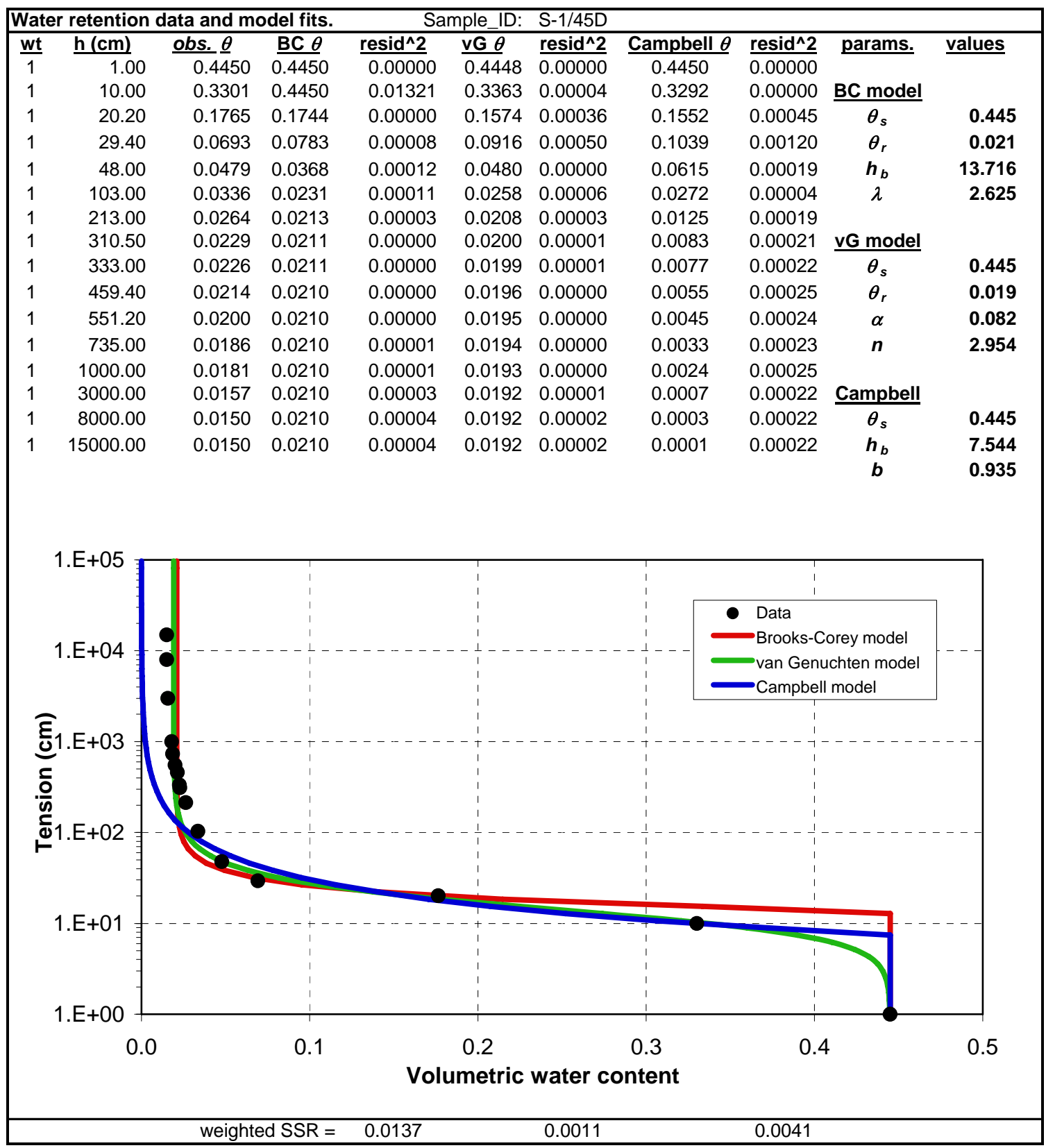

Figure A.28. Water retention data, fitted parameters, and plots showing fits of the van Genuchten (1980), Brooks and Corey (1964) and Campbell (1974) functions for sample S-1/45D from the Sisson and $\mathrm{Lu}$ (1980) field experimental site in the Hanford 200 East Area. 


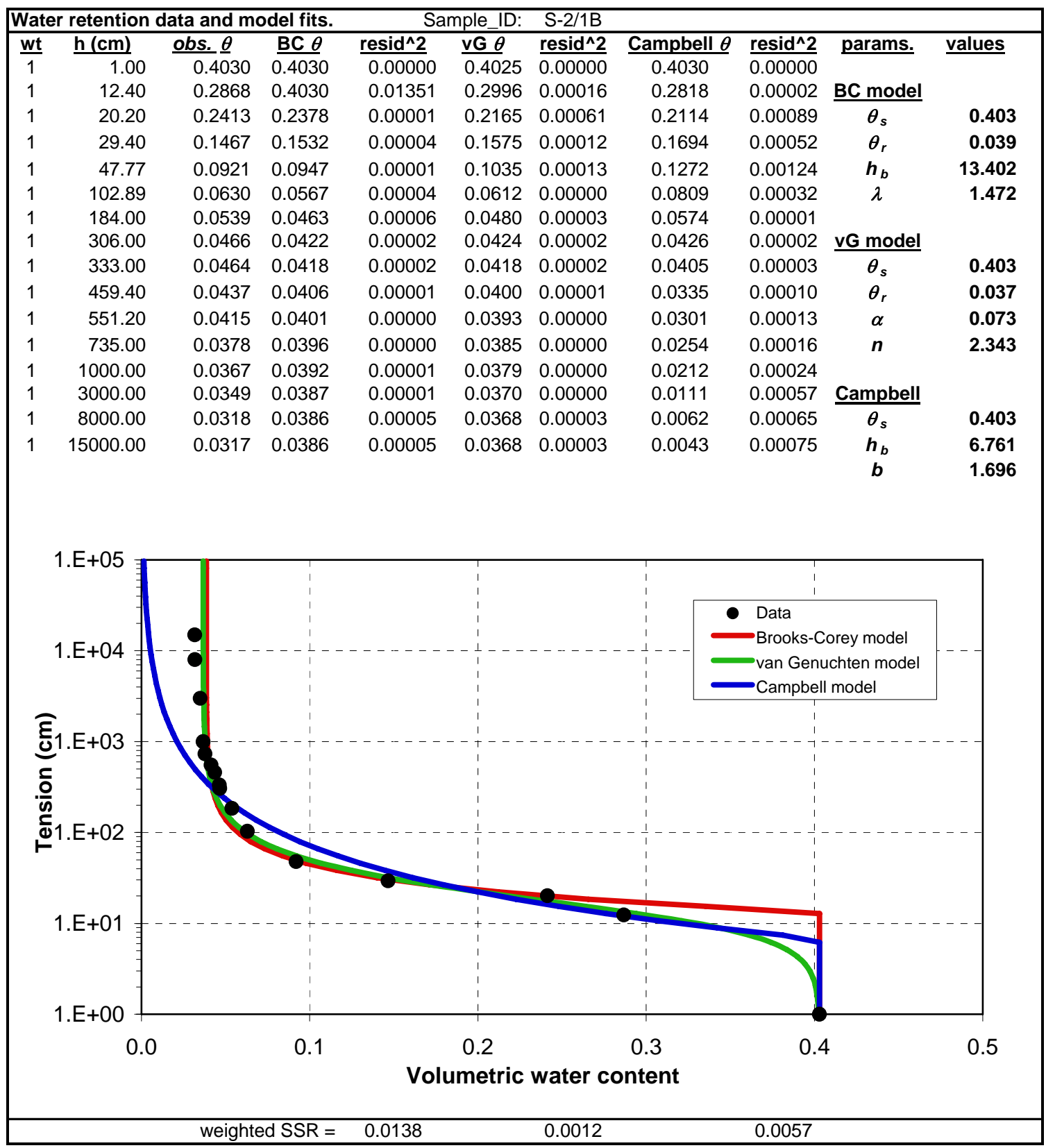

Figure A.29. Water retention data, fitted parameters, and plots showing fits of the van Genuchten (1980), Brooks and Corey (1964) and Campbell (1974) functions for sample S-2/1B from the Sisson and $\mathrm{Lu}(1980)$ field experimental site in the Hanford 200 East Area. 


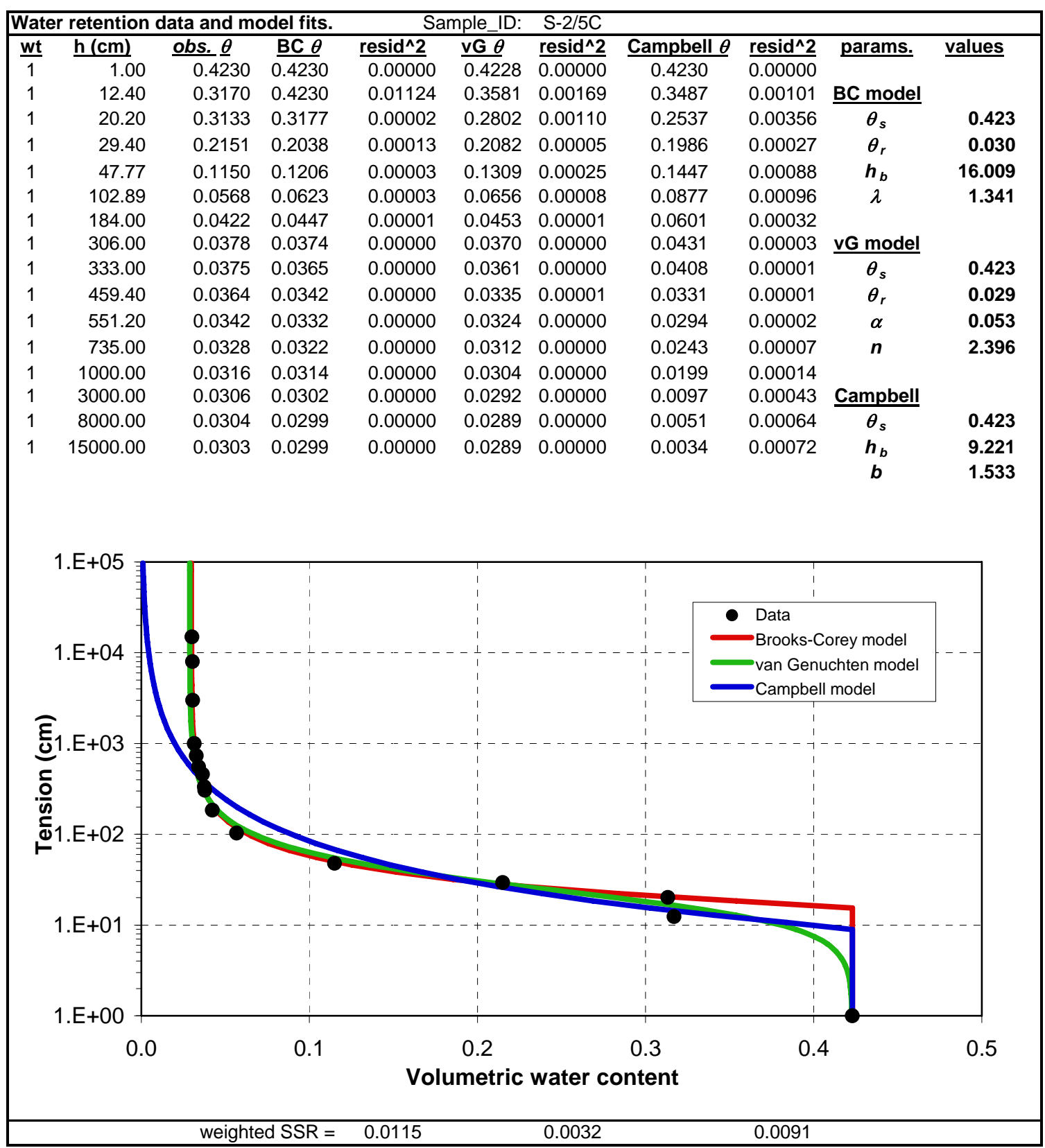

Figure A.30. Water retention data, fitted parameters, and plots showing fits of the van Genuchten (1980), Brooks and Corey (1964) and Campbell (1974) functions for sample S-2/5C from the Sisson and $\mathrm{Lu}$ (1980) field experimental site in the Hanford 200 East Area. 


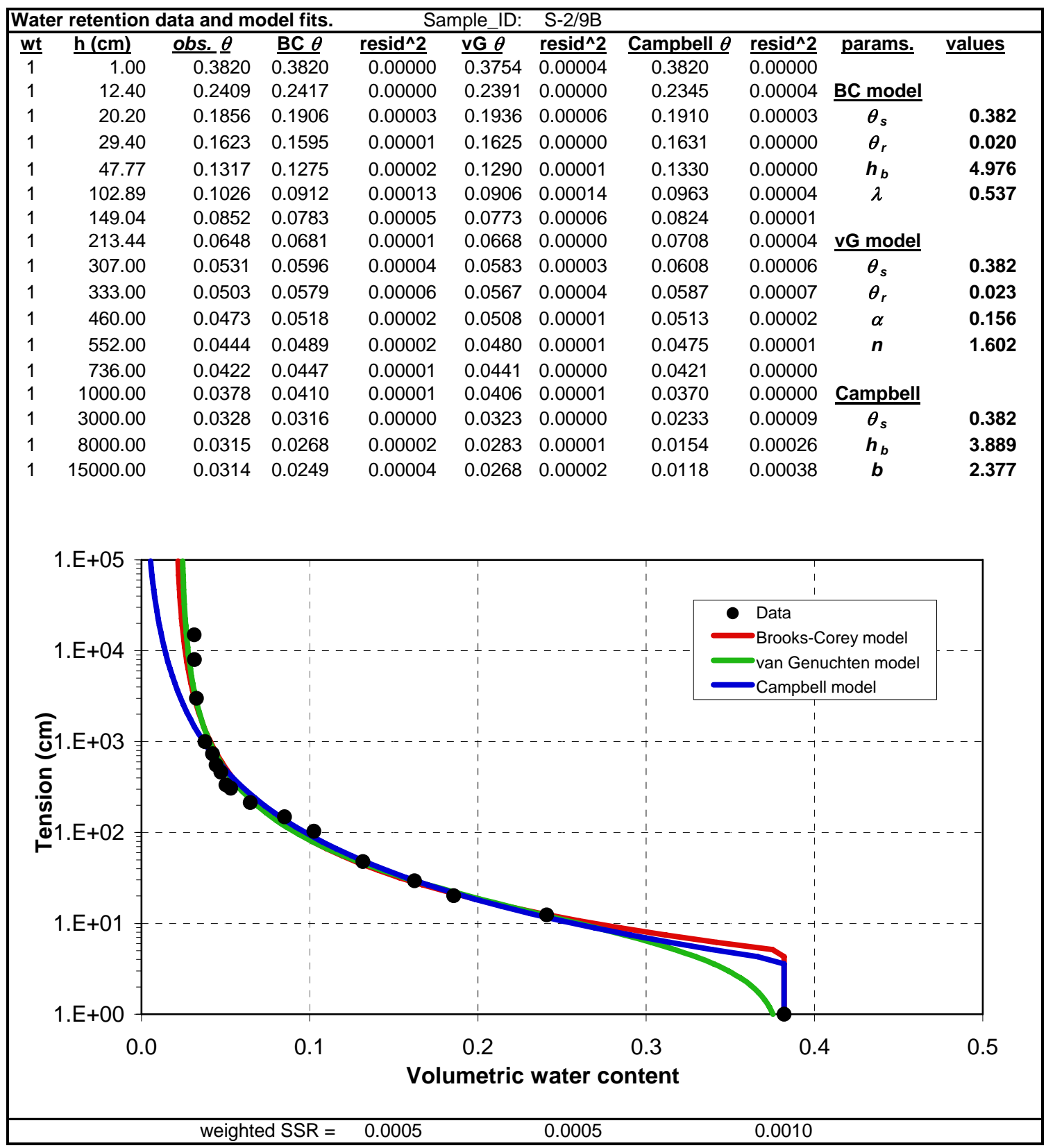

Figure A.31. Water retention data, fitted parameters, and plots showing fits of the van Genuchten (1980), Brooks and Corey (1964) and Campbell (1974) functions for sample S-2/9B from the Sisson and $\mathrm{Lu}$ (1980) field experimental site in the Hanford 200 East Area. 


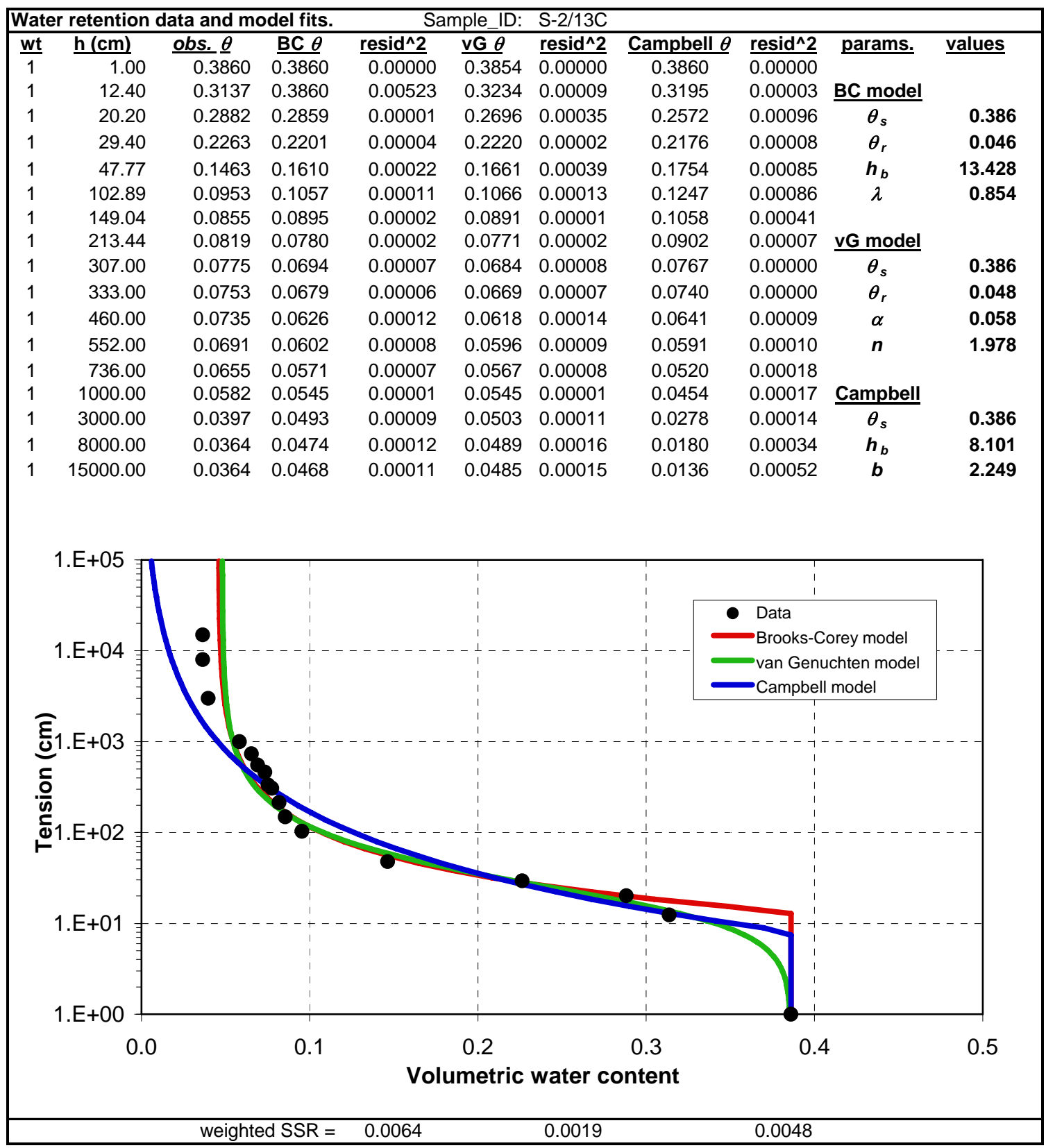

Figure A.32. Water retention data, fitted parameters, and plots showing fits of the van Genuchten (1980), Brooks and Corey (1964) and Campbell (1974) functions for sample S-2/13C from the Sisson and $\mathrm{Lu}$ (1980) field experimental site in the Hanford 200 East Area. 


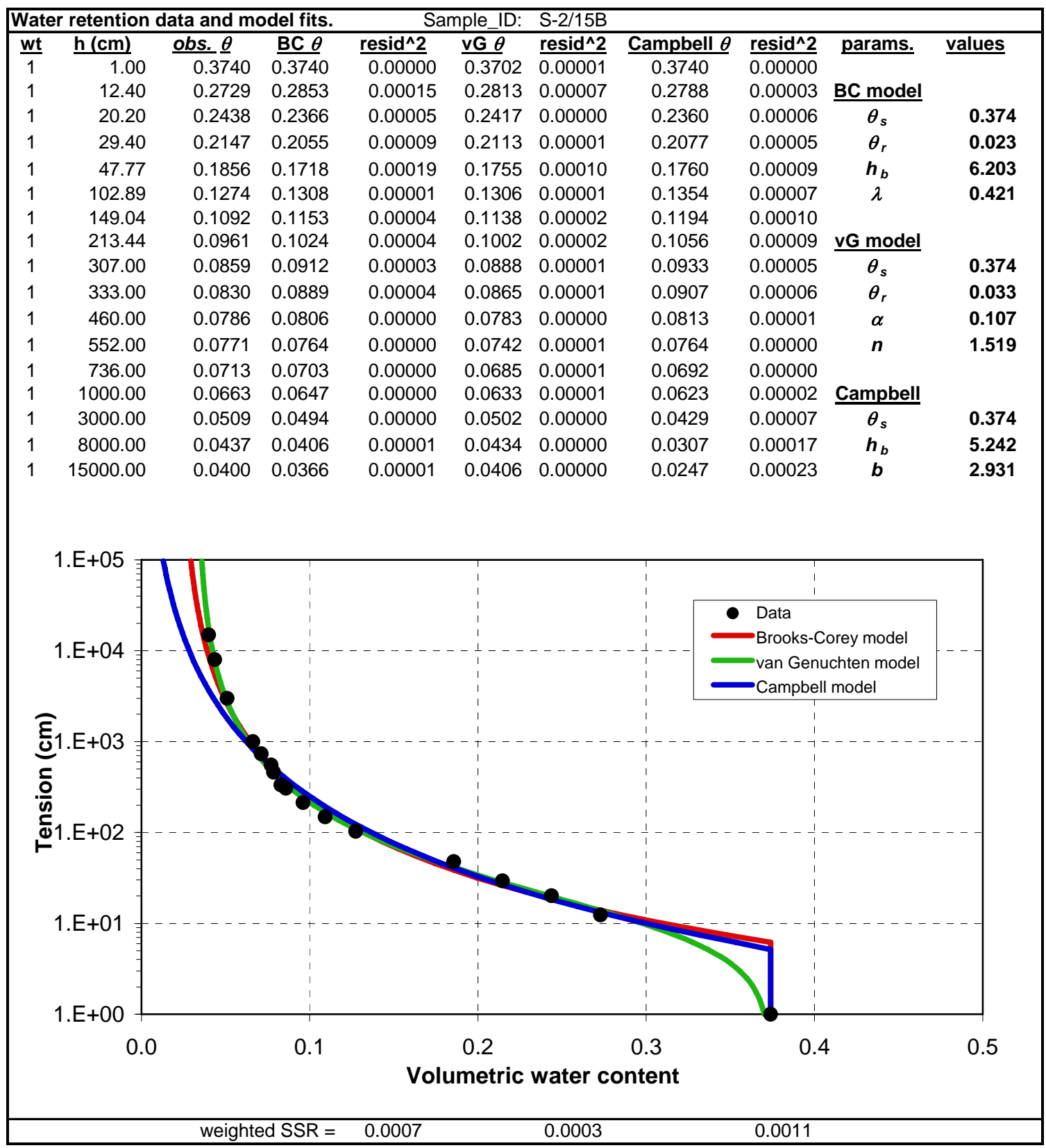

Figure A.33. Water retention data, fitted parameters, and plots showing fits of the van Genuchten (1980), Brooks and Corey (1964) and Campbell (1974) functions for sample S-2/15B from the Sisson and $\mathrm{Lu}$ (1980) field experimental site in the Hanford 200 East Area. 


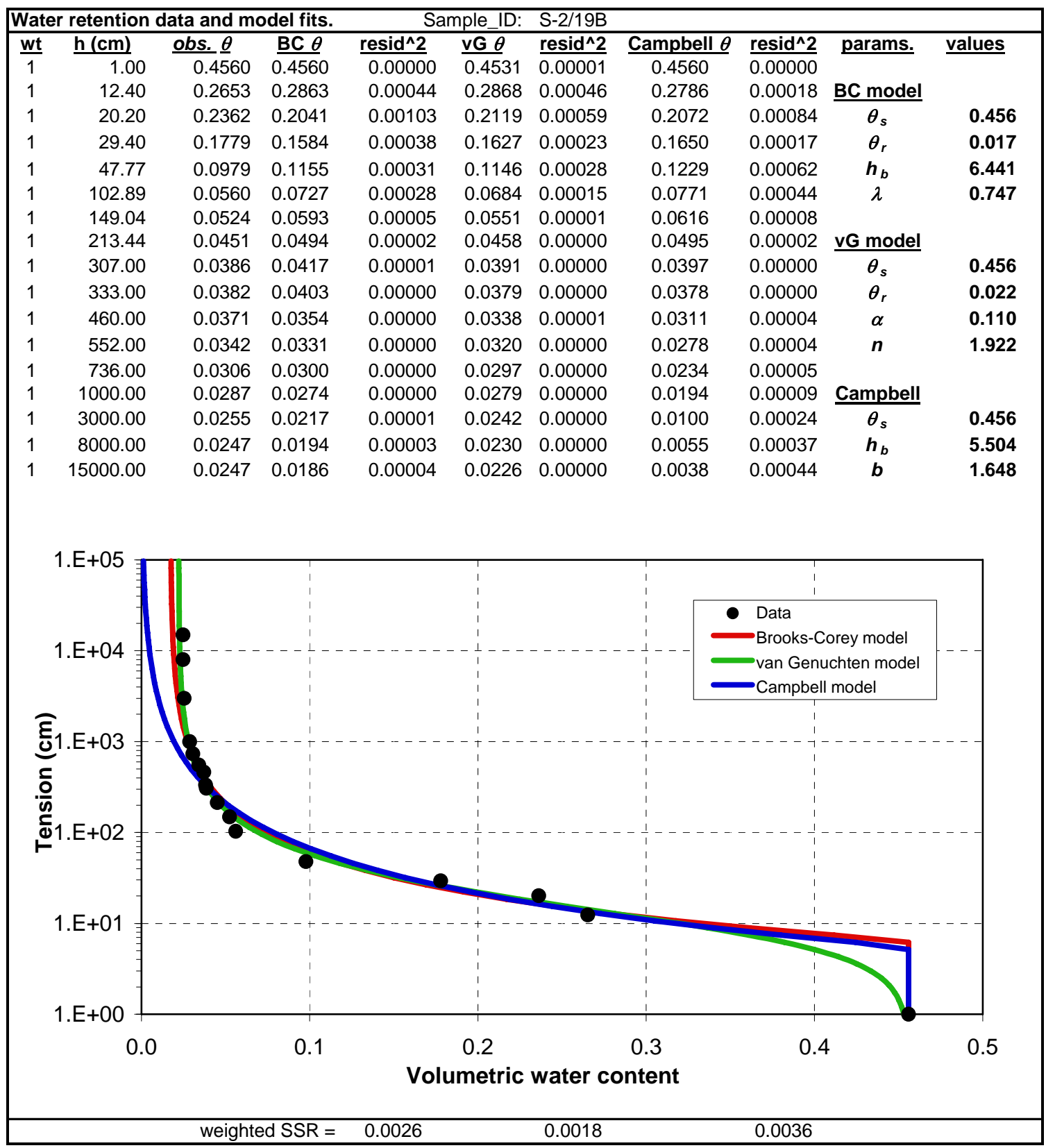

Figure A.34. Water retention data, fitted parameters, and plots showing fits of the van Genuchten (1980), Brooks and Corey (1964) and Campbell (1974) functions for sample S-2/19B from the Sisson and $\mathrm{Lu}$ (1980) field experimental site in the Hanford 200 East Area. 


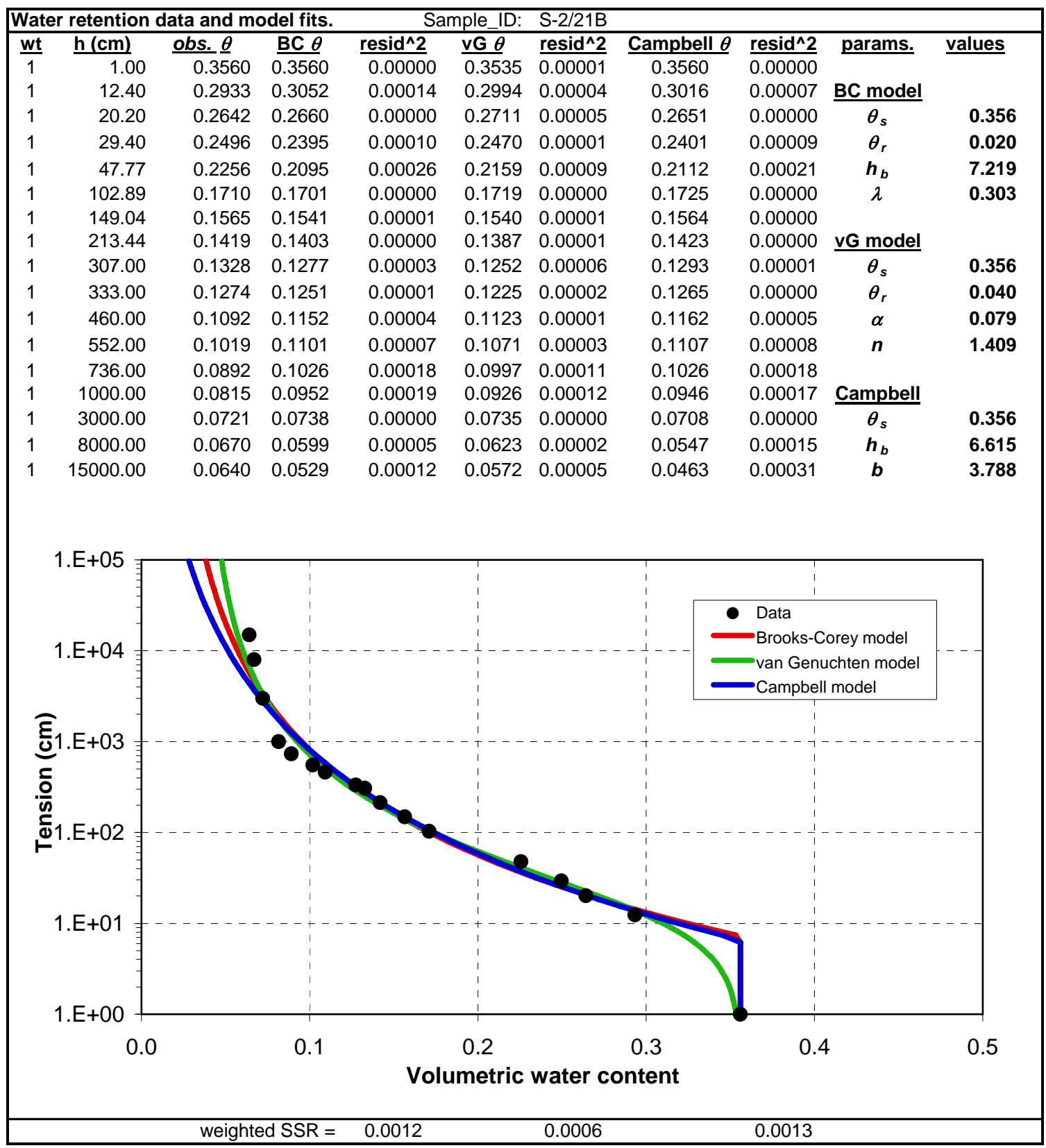

Figure A.35. Water retention data, fitted parameters, and plots showing fits of the van Genuchten (1980), Brooks and Corey (1964) and Campbell (1974) functions for sample S-2/21B from the Sisson and $\mathrm{Lu}$ (1980) field experimental site in the Hanford 200 East Area. 


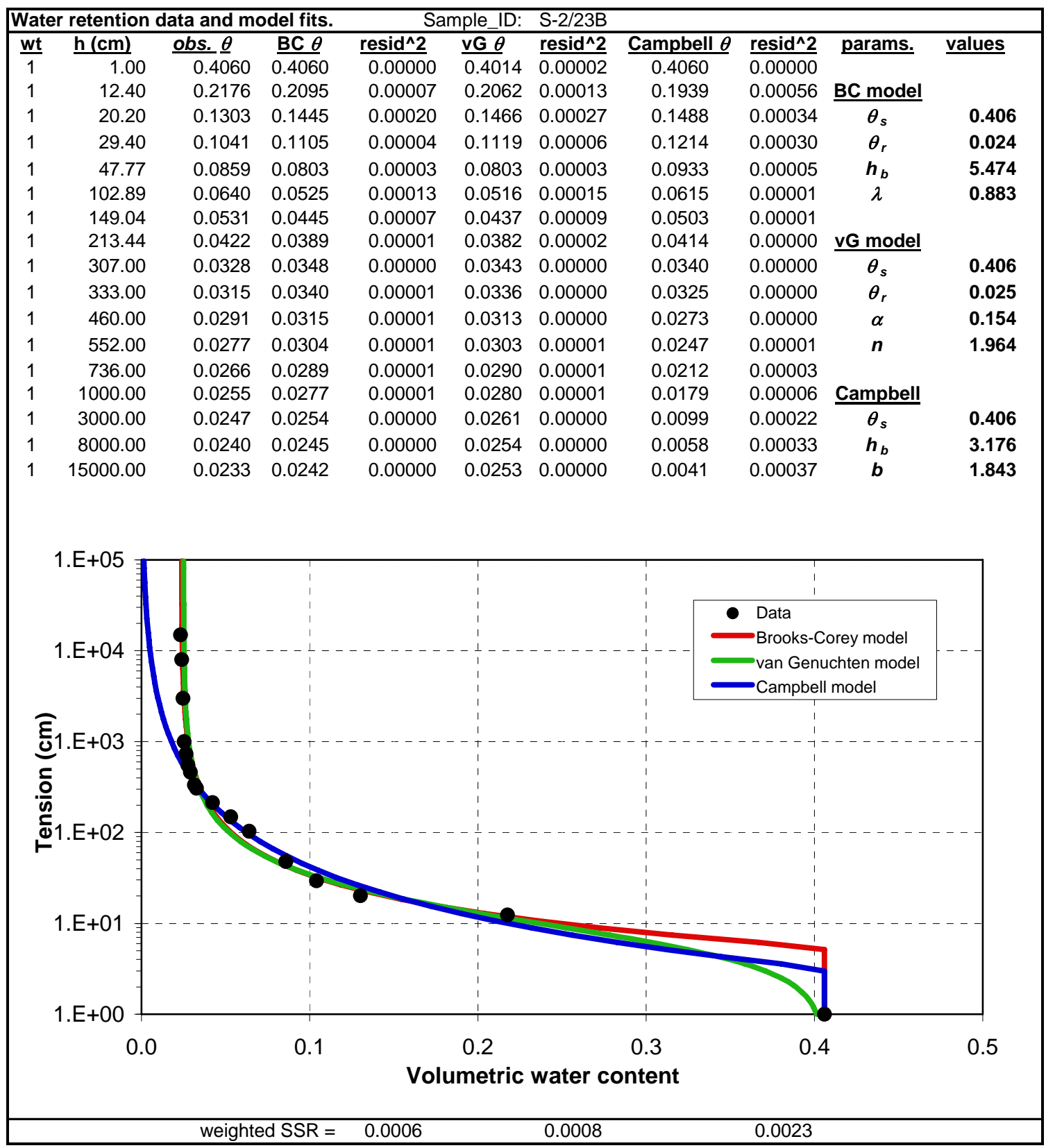

Figure A.36. Water retention data, fitted parameters, and plots showing fits of the van Genuchten (1980), Brooks and Corey (1964) and Campbell (1974) functions for sample S-2/23B from the Sisson and $\mathrm{Lu}$ (1980) field experimental site in the Hanford 200 East Area. 


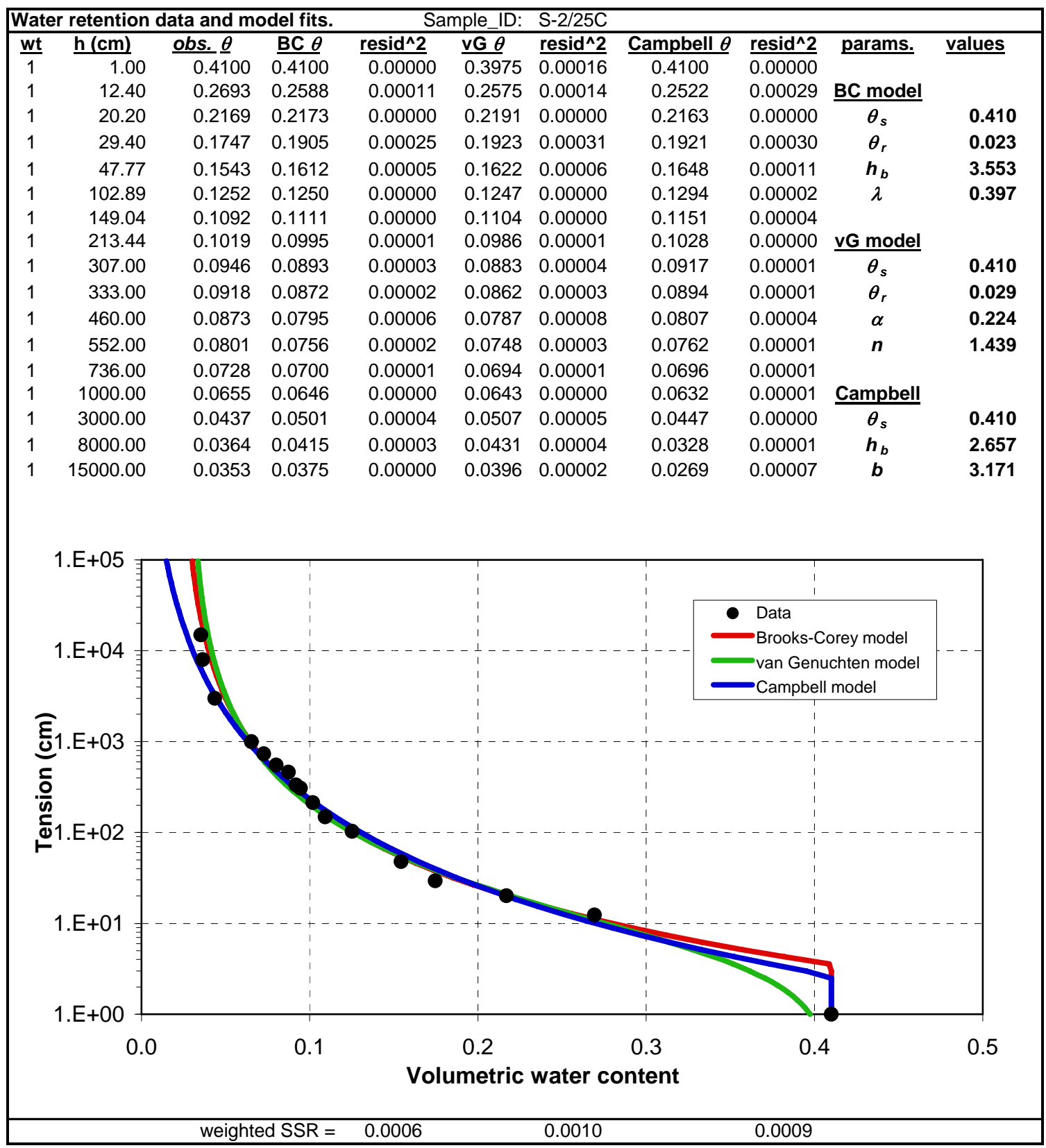

Figure A.37. Water retention data, fitted parameters, and plots showing fits of the van Genuchten (1980), Brooks and Corey (1964) and Campbell (1974) functions for sample S-2/25C from the Sisson and $\mathrm{Lu}$ (1980) field experimental site in the Hanford 200 East Area. 


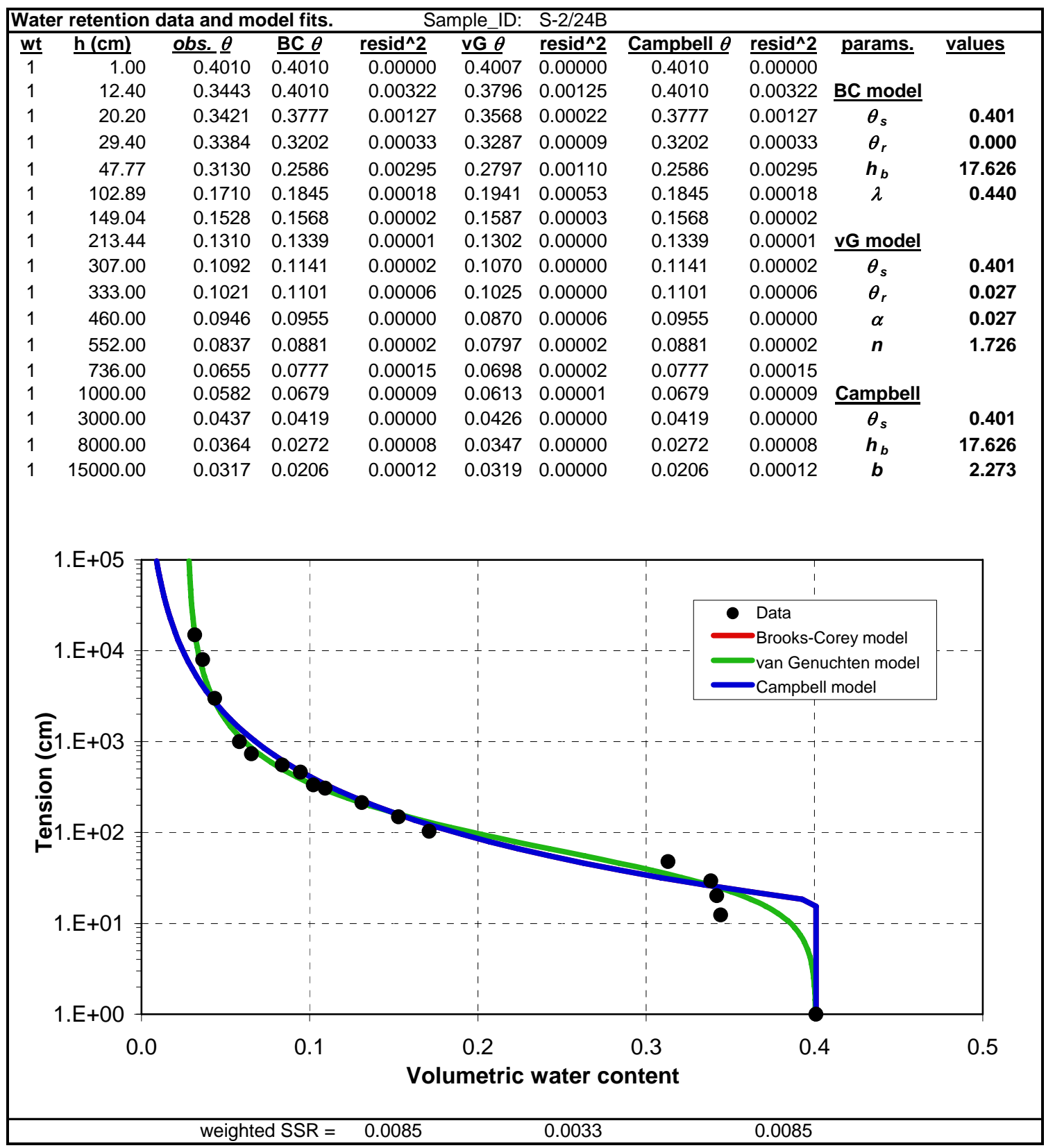

Figure A.38. Water retention data, fitted parameters, and plots showing fits of the van Genuchten (1980), Brooks and Corey (1964) and Campbell (1974) functions for sample S-2/24B from the Sisson and $\mathrm{Lu}$ (1980) field experimental site in the Hanford 200 East Area. 


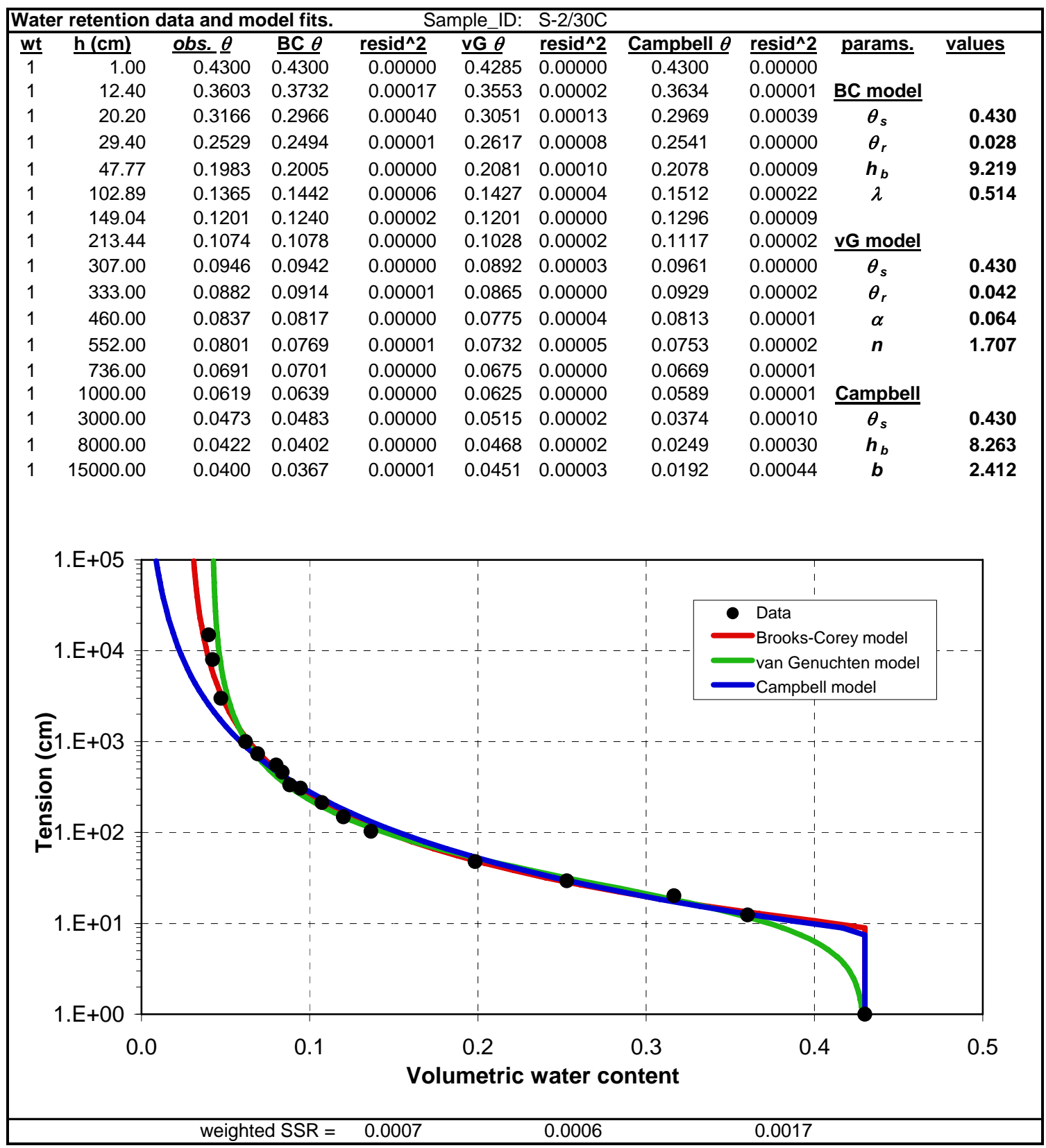

Figure A.39. Water retention data, fitted parameters, and plots showing fits of the van Genuchten (1980), Brooks and Corey (1964) and Campbell (1974) functions for sample S-2/30C from the Sisson and $\mathrm{Lu}$ (1980) field experimental site in the Hanford 200 East Area. 


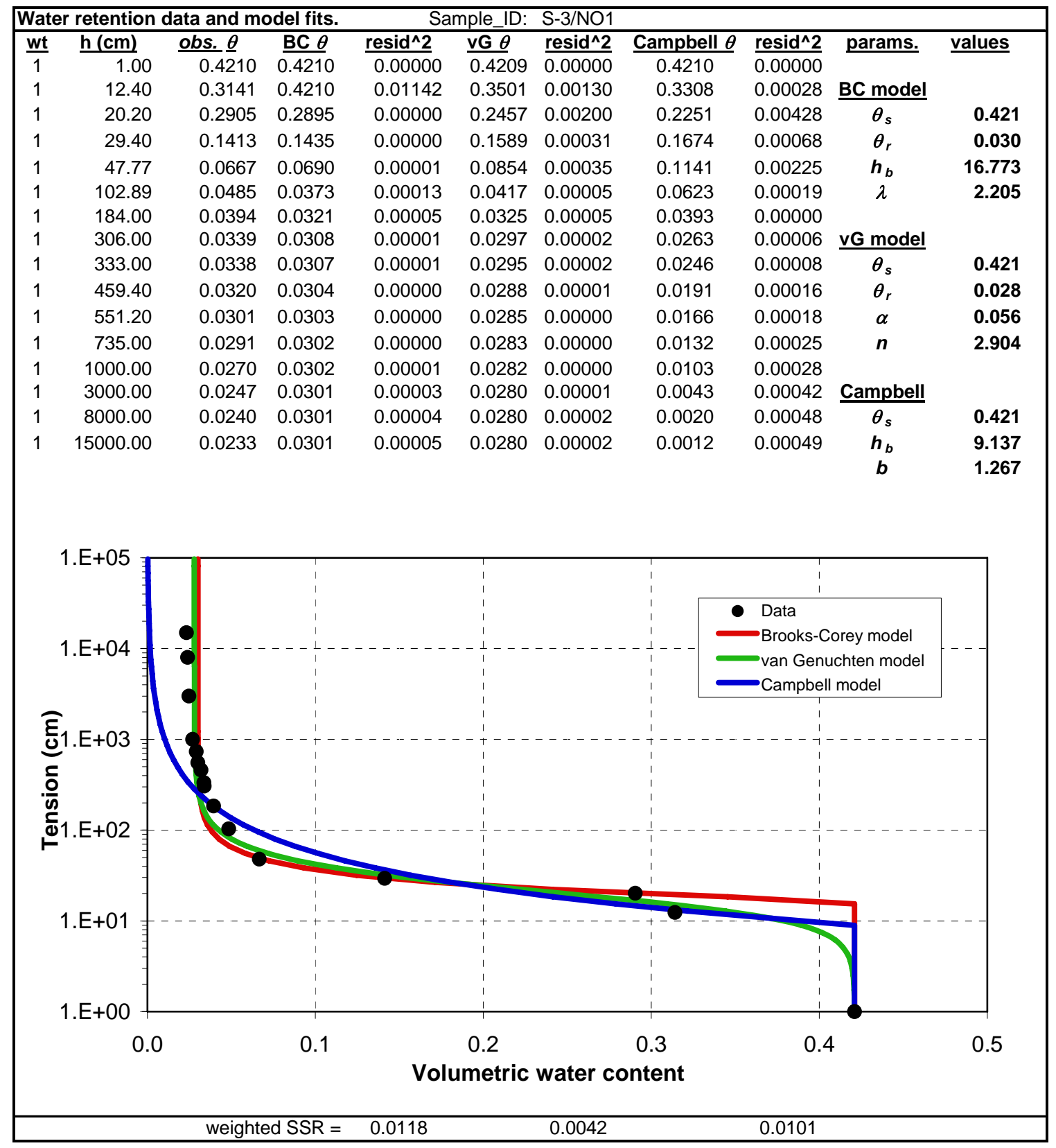

Figure A.40. Water retention data, fitted parameters, and plots showing fits of the van Genuchten (1980), Brooks and Corey (1964) and Campbell (1974) functions for sample S-3/NO1 from the Sisson and $\mathrm{Lu}$ (1980) field experimental site in the Hanford 200 East Area. 


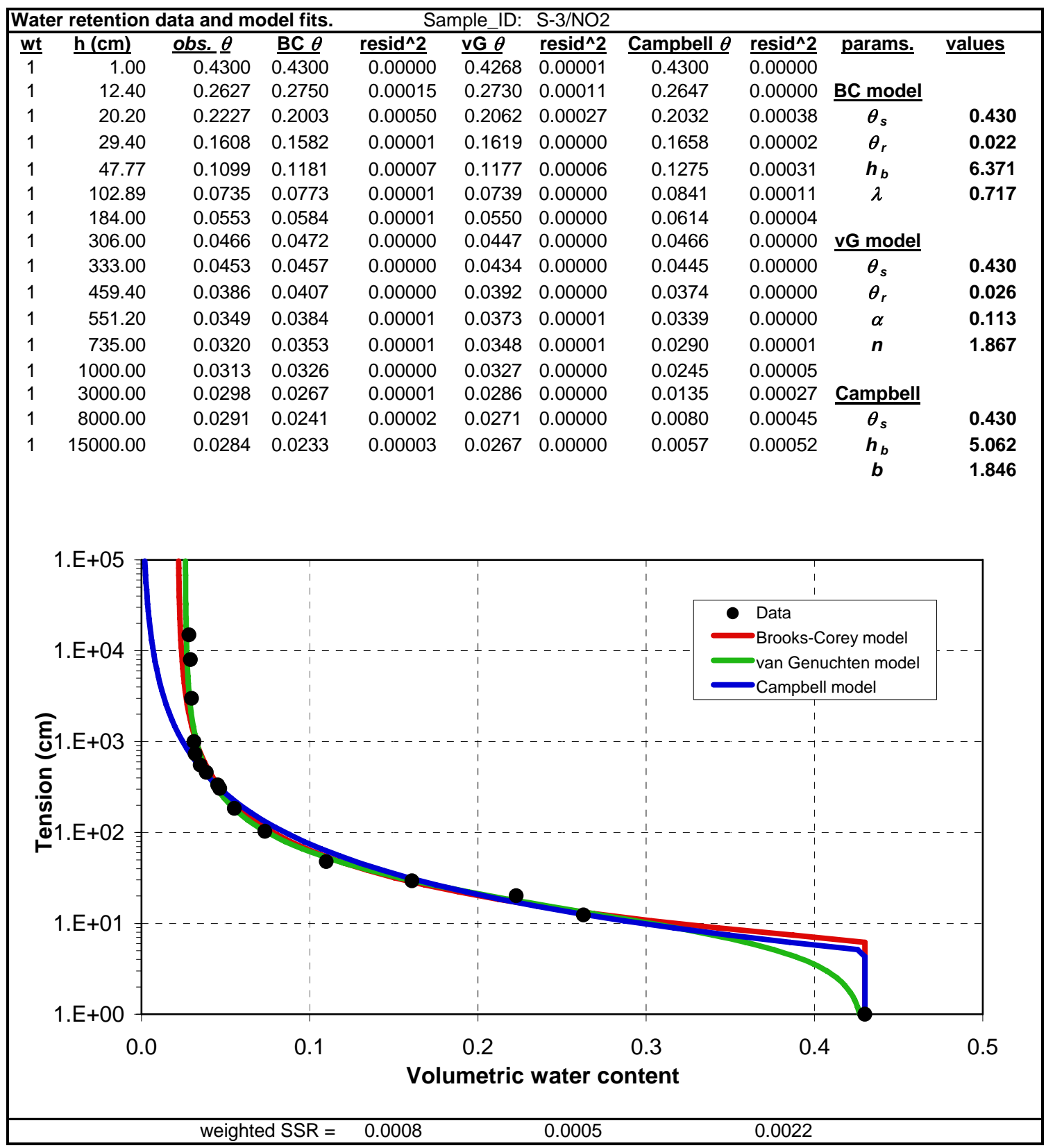

Figure A.41. Water retention data, fitted parameters, and plots showing fits of the van Genuchten (1980), Brooks and Corey (1964) and Campbell (1974) functions for sample S-3/NO2 from the Sisson and $\mathrm{Lu}$ (1980) field experimental site in the Hanford 200 East Area. 


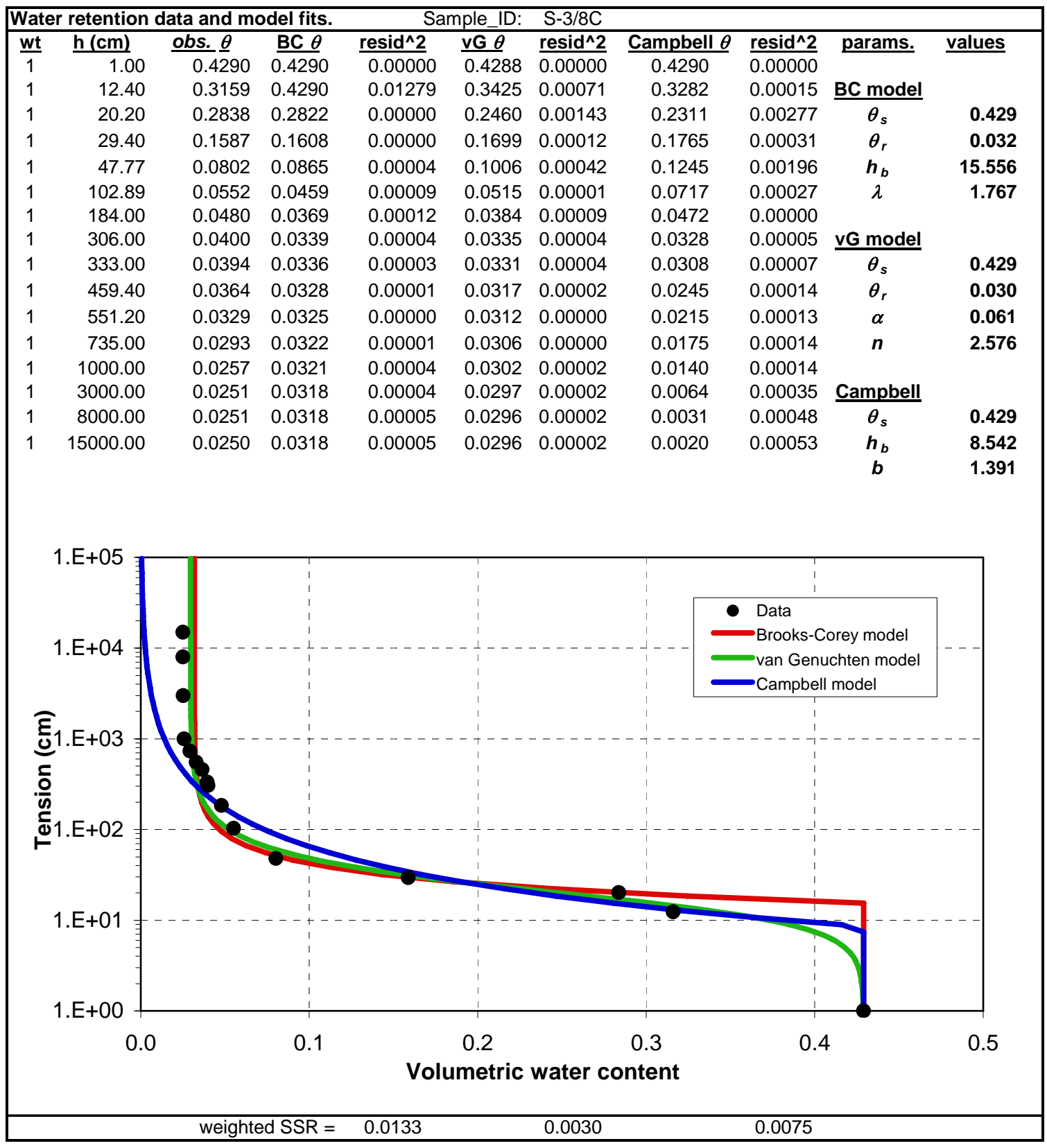

Figure A.42. Water retention data, fitted parameters, and plots showing fits of the van Genuchten (1980), Brooks and Corey (1964) and Campbell (1974) functions for sample S-3/8C from the Sisson and $\mathrm{Lu}$ (1980) field experimental site in the Hanford 200 East Area. 


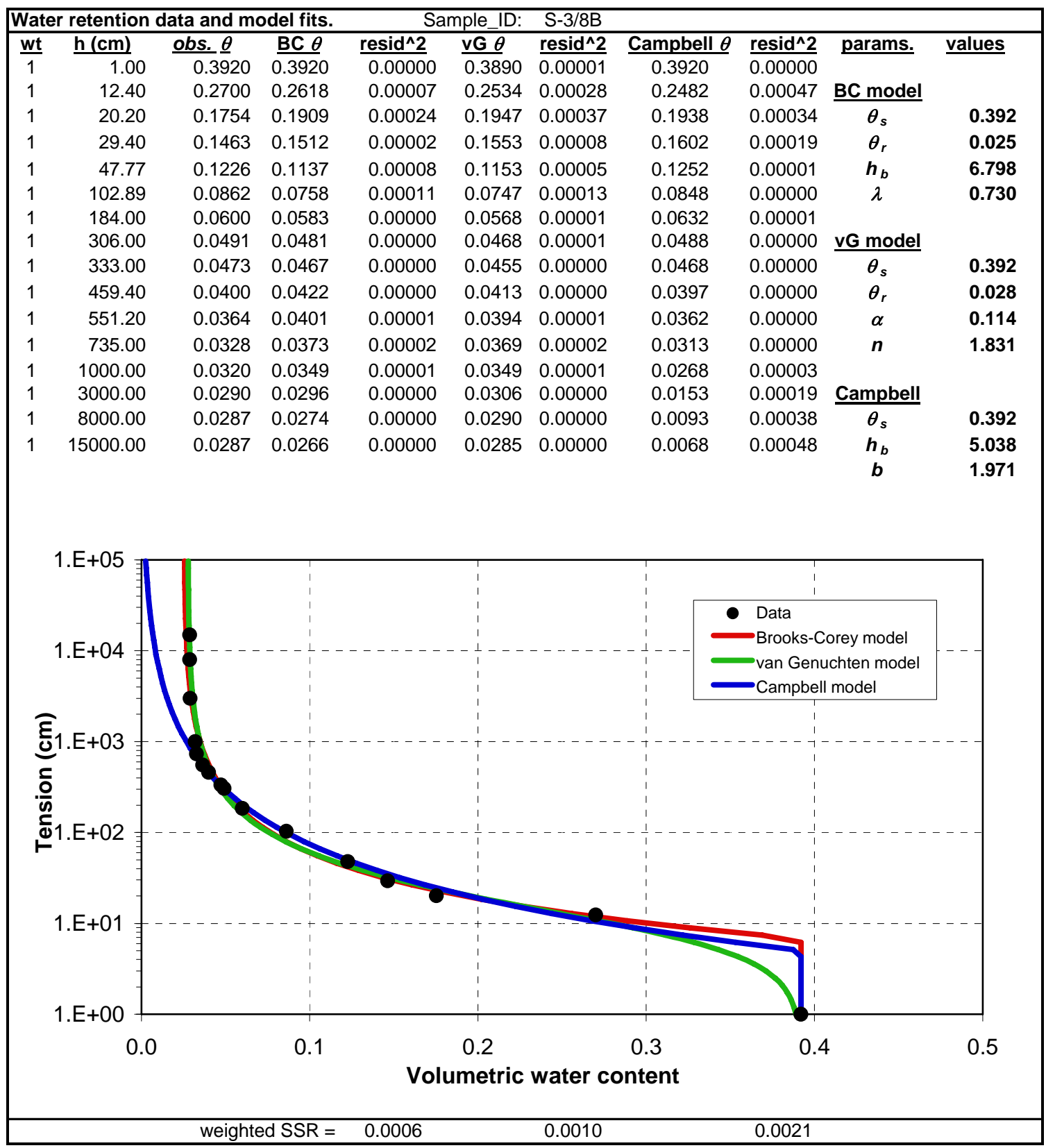

Figure A.43. Water retention data, fitted parameters, and plots showing fits of the van Genuchten (1980), Brooks and Corey (1964) and Campbell (1974) functions for sample S-3/8B from the Sisson and $\mathrm{Lu}$ (1980) field experimental site in the Hanford 200 East Area. 


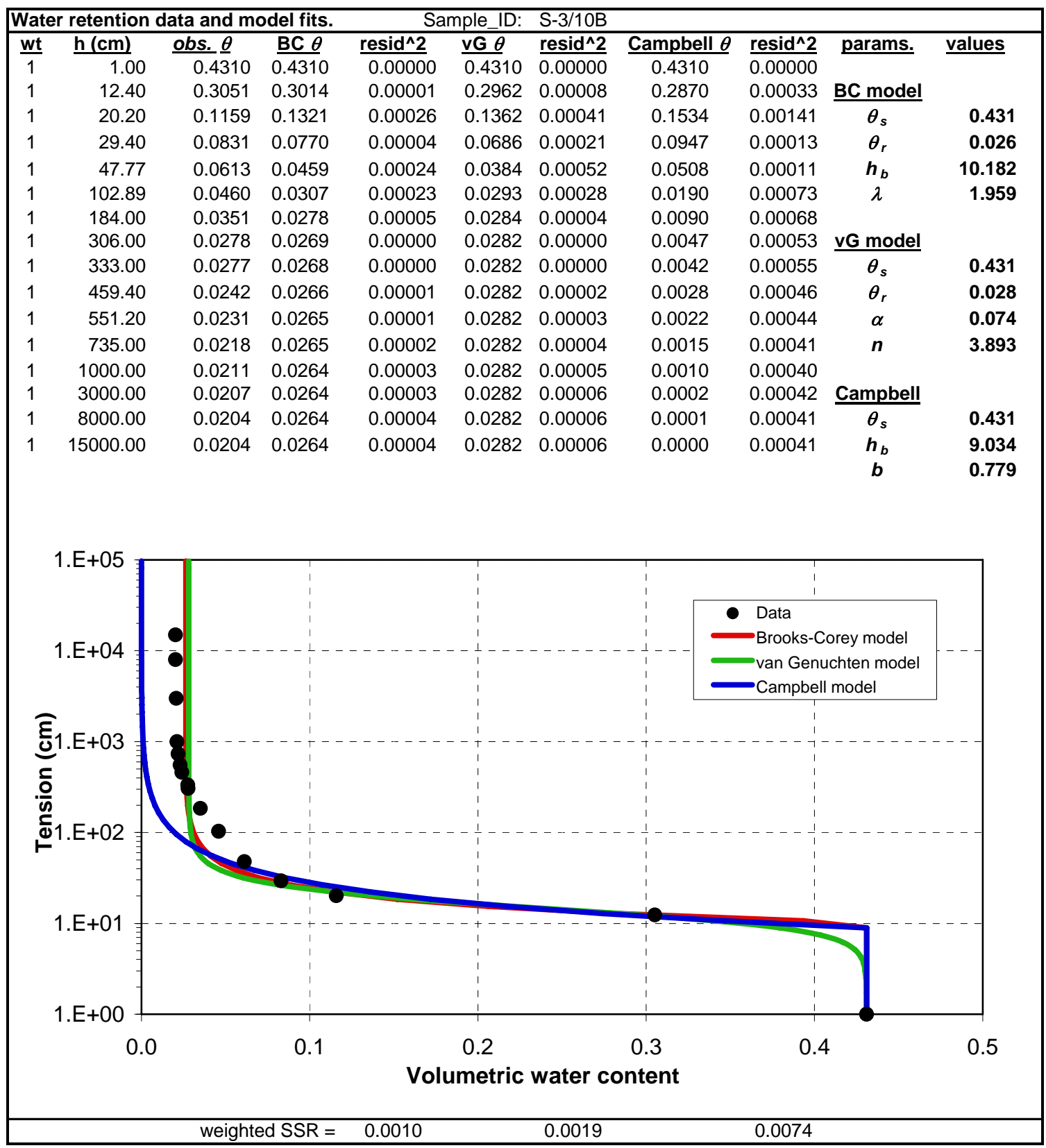

Figure A.44. Water retention data, fitted parameters, and plots showing fits of the van Genuchten (1980), Brooks and Corey (1964) and Campbell (1974) functions for sample S-3/10B from the Sisson and $\mathrm{Lu}(1980)$ field experimental site in the Hanford 200 East Area. 


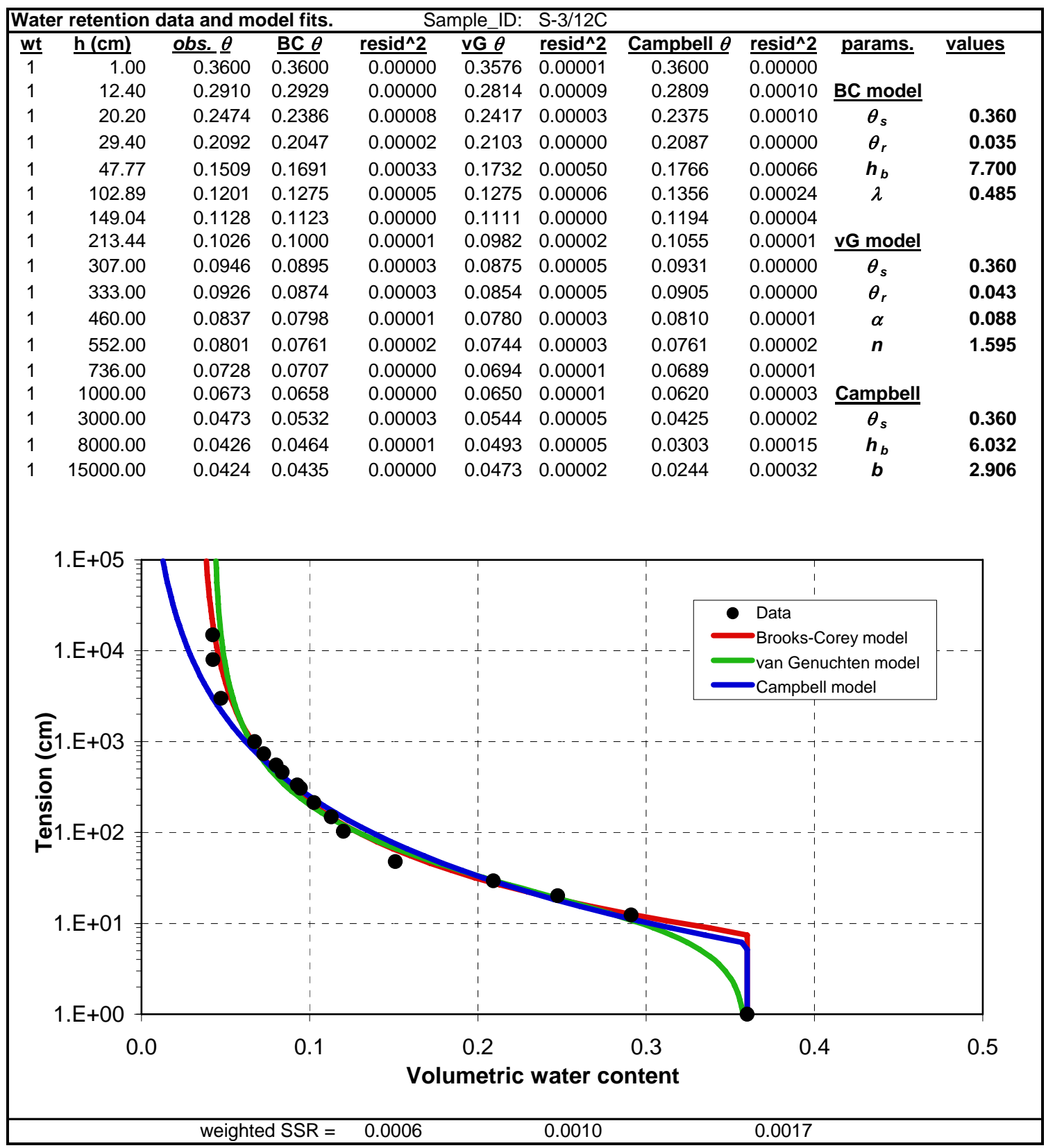

Figure A.45. Water retention data, fitted parameters, and plots showing fits of the van Genuchten (1980), Brooks and Corey (1964) and Campbell (1974) functions for sample S-3/12C from the Sisson and $\mathrm{Lu}$ (1980) field experimental site in the Hanford 200 East Area. 


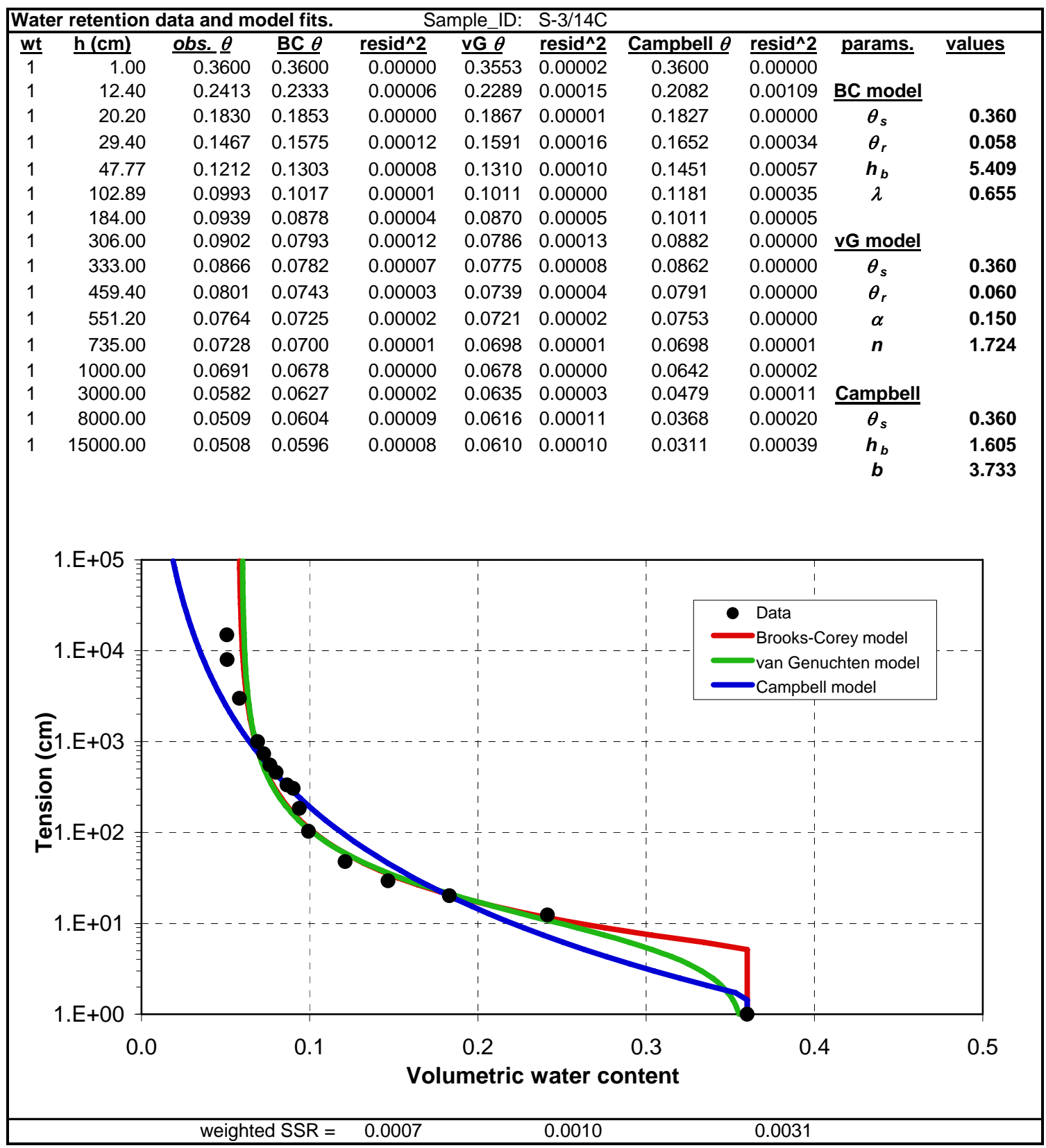

Figure A.46. Water retention data, fitted parameters, and plots showing fits of the van Genuchten (1980), Brooks and Corey (1964) and Campbell (1974) functions for sample S-3/14C from the Sisson and $\mathrm{Lu}$ (1980) field experimental site in the Hanford 200 East Area. 


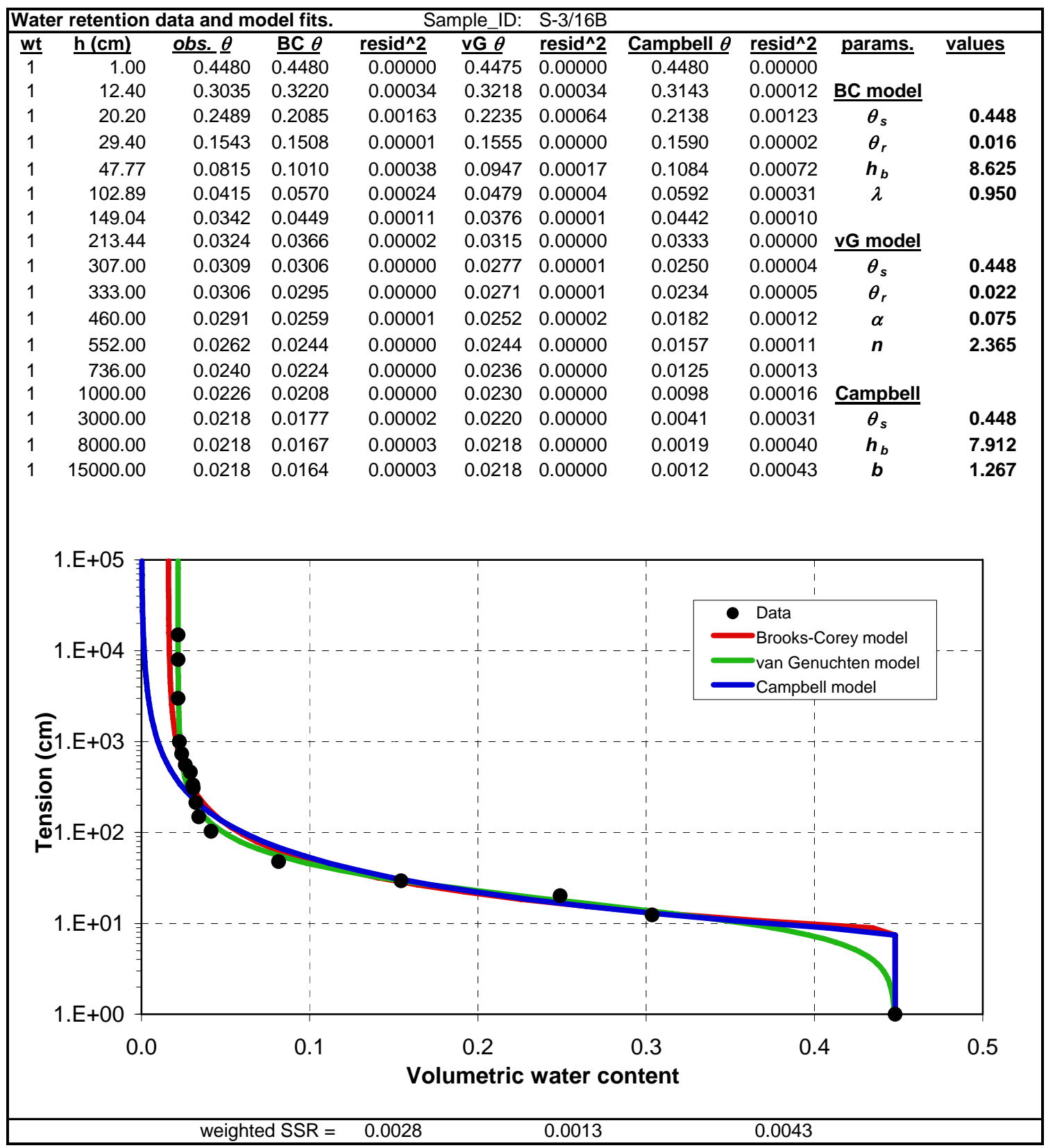

Figure A.47. Water retention data, fitted parameters, and plots showing fits of the van Genuchten (1980), Brooks and Corey (1964) and Campbell (1974) functions for sample S-3/16B from the Sisson and $\mathrm{Lu}$ (1980) field experimental site in the Hanford 200 East Area. 


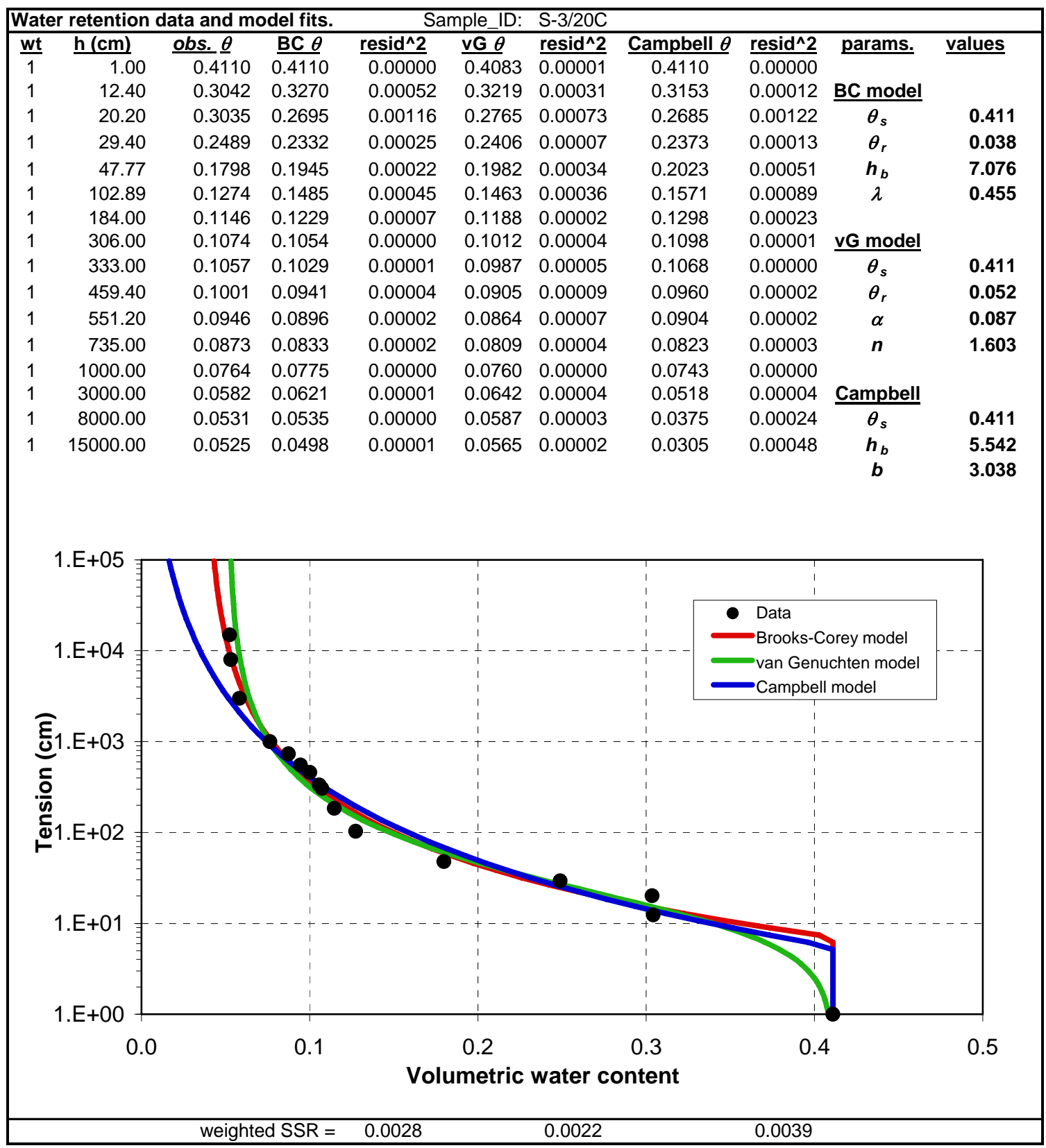

Figure A.48. Water retention data, fitted parameters, and plots showing fits of the van Genuchten (1980), Brooks and Corey (1964) and Campbell (1974) functions for sample S-3/20C from the Sisson and Lu (1980) field experimental site in the Hanford 200 East Area. 


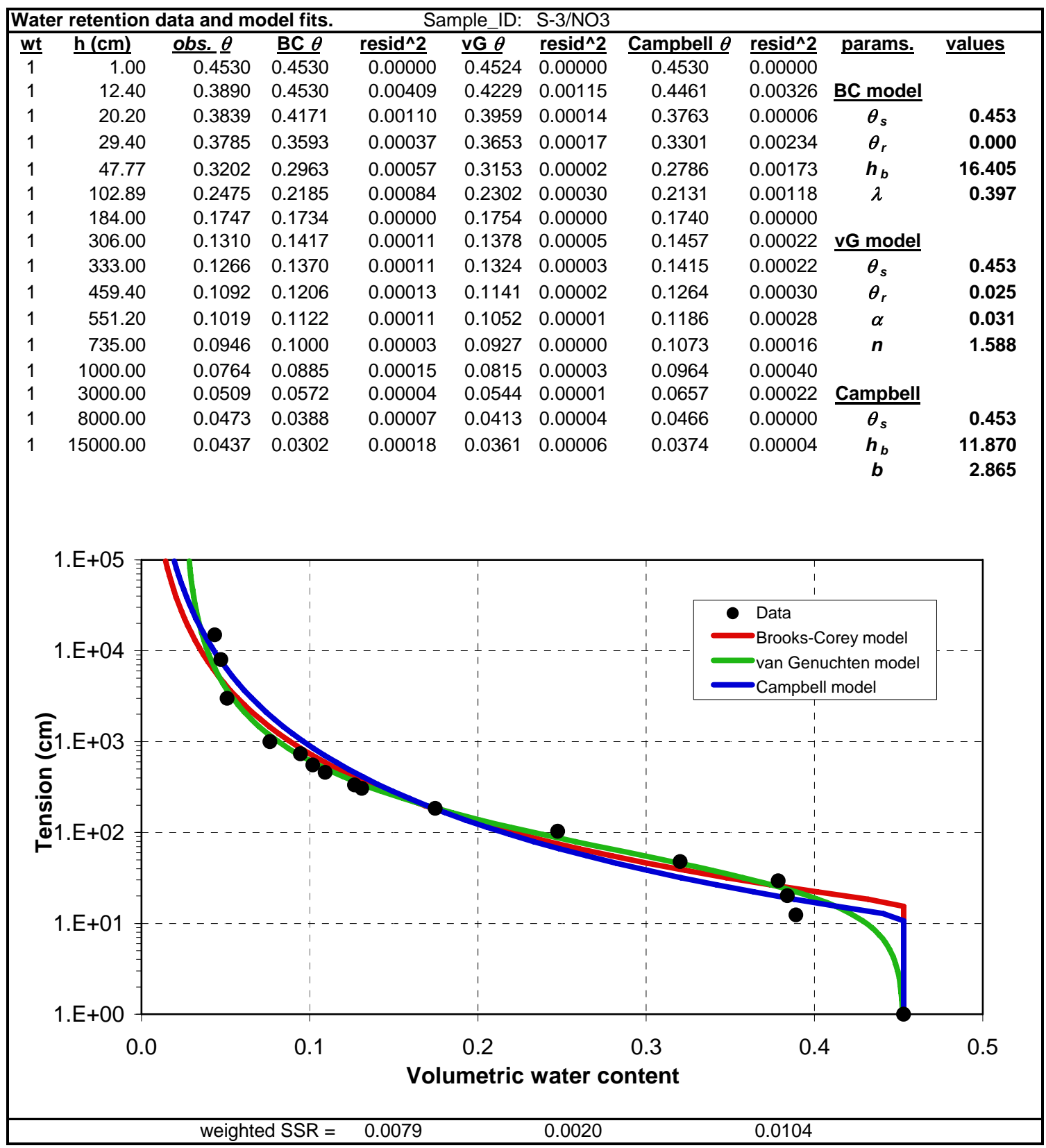

Figure A.49. Water retention data, fitted parameters, and plots showing fits of the van Genuchten (1980), Brooks and Corey (1964) and Campbell (1974) functions for sample S-3/NO3 from the Sisson and $\mathrm{Lu}$ (1980) field experimental site in the Hanford 200 East Area. 


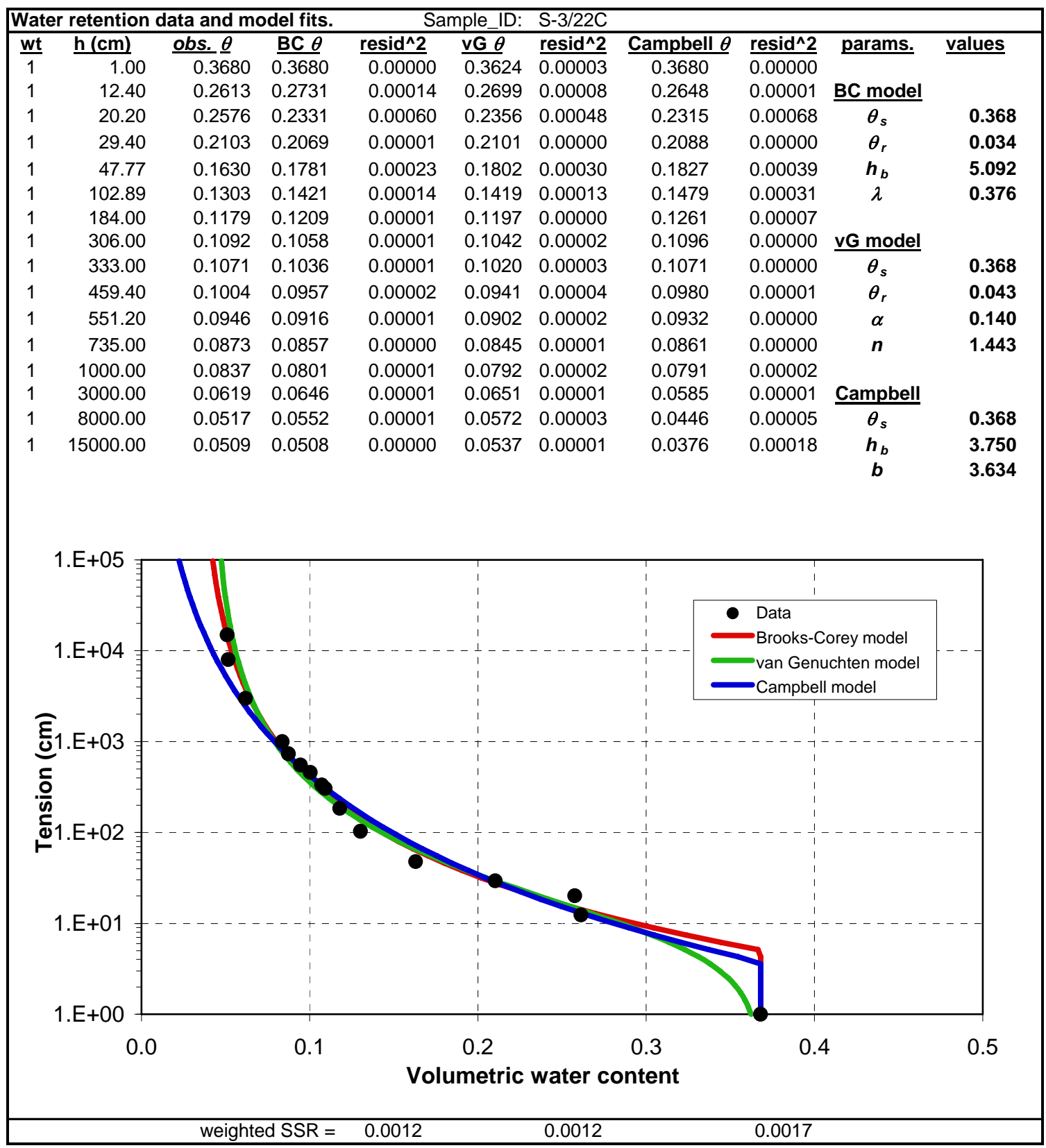

Figure A.50. Water retention data, fitted parameters, and plots showing fits of the van Genuchten (1980), Brooks and Corey (1964) and Campbell (1974) functions for sample S-3/22C from the Sisson and $\mathrm{Lu}$ (1980) field experimental site in the Hanford 200 East Area. 


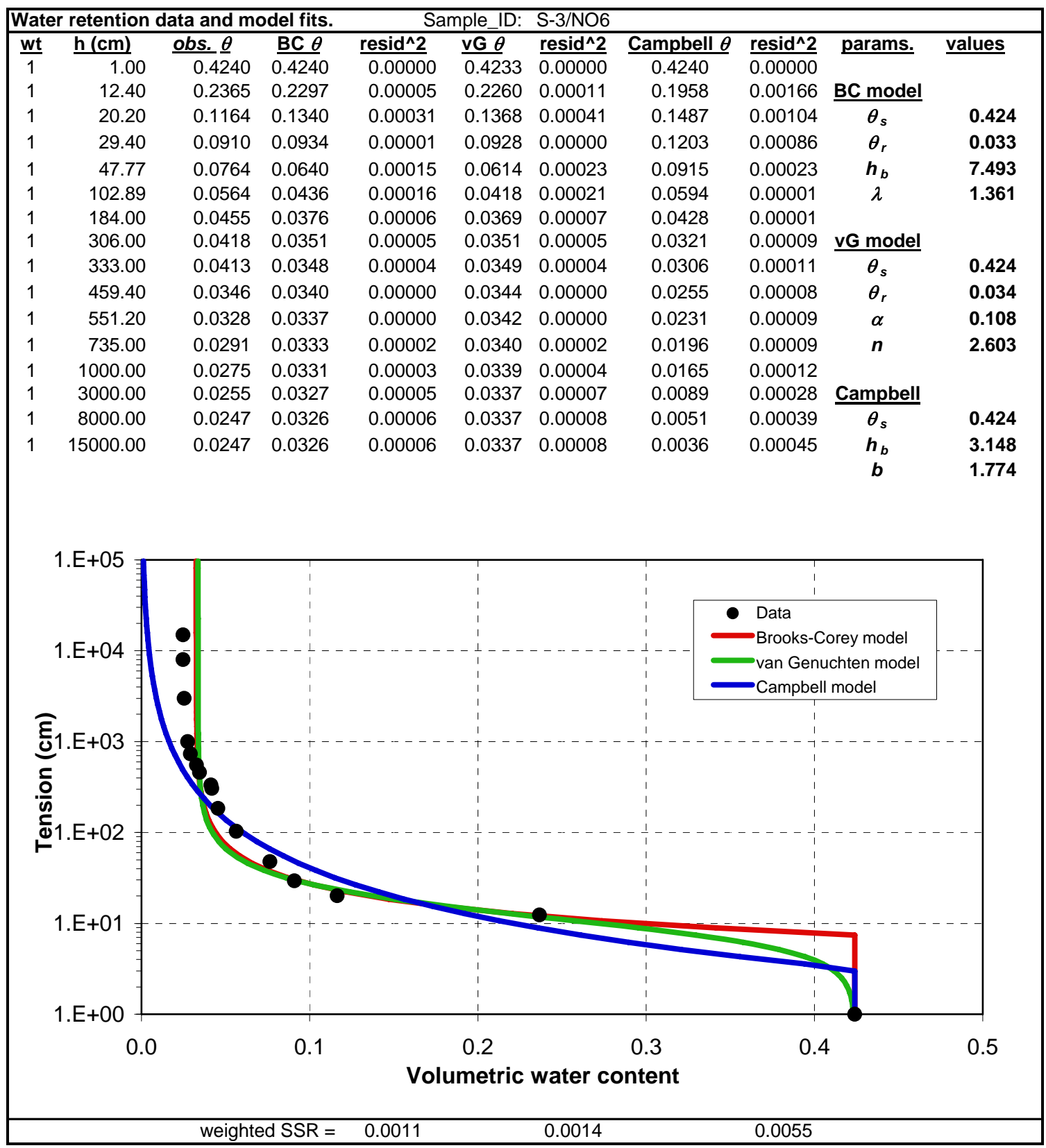

Figure A.51. Water retention data, fitted parameters, and plots showing fits of the van Genuchten (1980), Brooks and Corey (1964) and Campbell (1974) functions for sample S-3/NO6 from the Sisson and $\mathrm{Lu}$ (1980) field experimental site in the Hanford 200 East Area. 


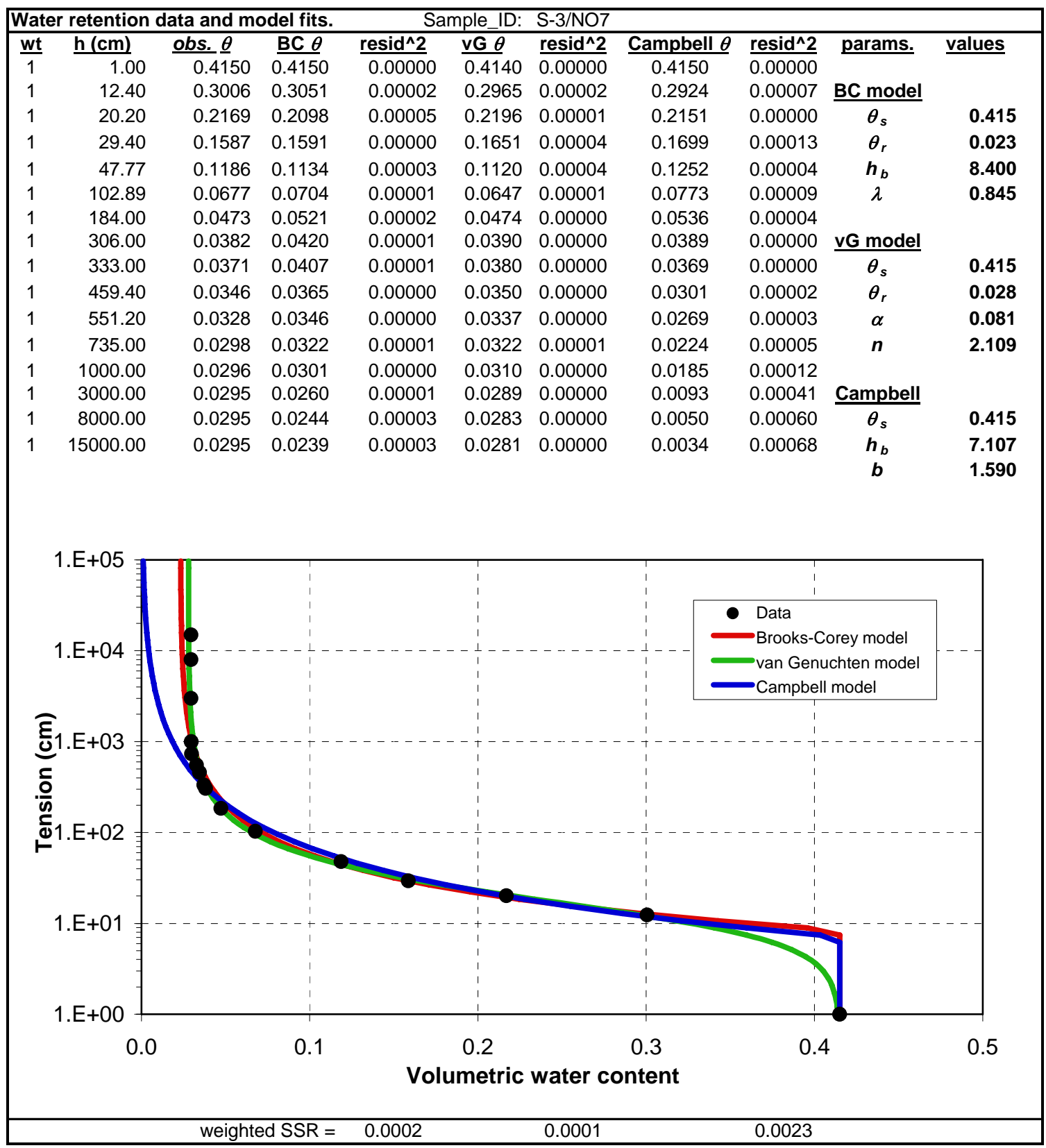

Figure A.52. Water retention data, fitted parameters, and plots showing fits of the van Genuchten (1980), Brooks and Corey (1964) and Campbell (1974) functions for sample S-3/NO7 from the Sisson and $\mathrm{Lu}(1980)$ field experimental site in the Hanford 200 East Area. 


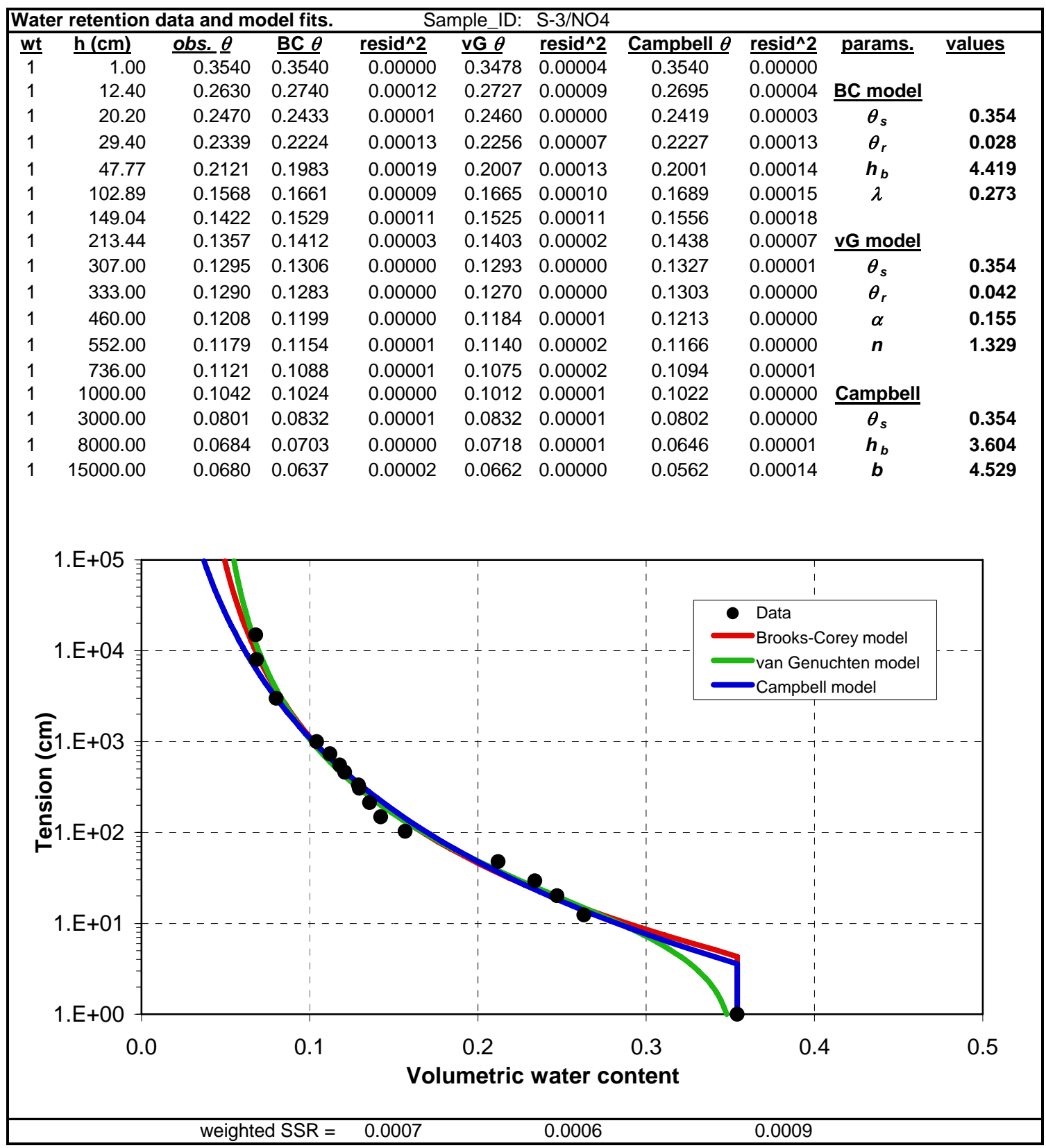

Figure A.53. Water retention data, fitted parameters, and plots showing fits of the van Genuchten (1980), Brooks and Corey (1964) and Campbell (1974) functions for sample S-3/NO4 from the Sisson and $\mathrm{Lu}$ (1980) field experimental site in the Hanford 200 East Area. 



\section{Distribution}

(Issued as electronic copies only - pdf format)

No. of

Copies

1 Fluor Federal Services

$\begin{array}{ll}\text { R. Khaleel R3-50 } & \text { R }\end{array}$

7 CH2M-HILL Plateau Remediation Company, Inc.

B. H. Ford

H8-43

J. D. Hoover

D. E. McKenney

W. J. Mcmahon

W. D. Webber

B. A. Williams

M. I. Wood
H8-43

H8-51

H8- 15

H8-51

H8-51
No. of

\section{Copies}

11 Pacific Northwest National Laboratory

B. N. Bjornstad K6-81

M. J. Fayer K9-33

M. D. Freshley K9-33

G. V. Last K6-81

R. D. Mackley K6-96

C. J. Murray K6-81

M. L. Rockhold K9-33

P. D. Thorne K6-96

Z. F. Zhang K9-33

A. L. Ward K9-33

Information Release Office 




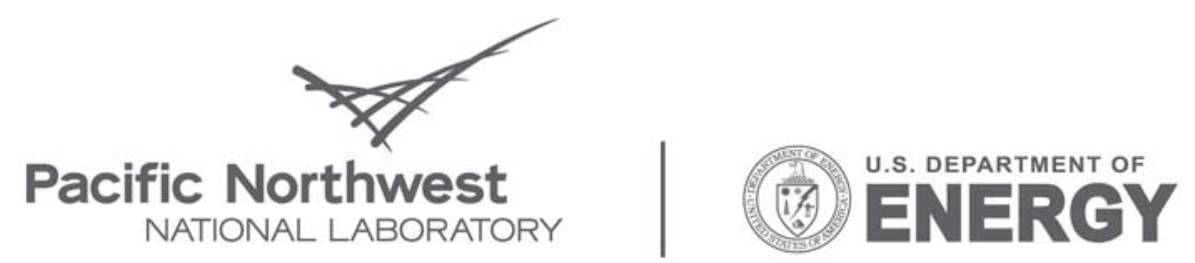

Proudly Operated by Battelle Since 1965

902 Battelle Boulevard

P.O. Box 999

Richland, WA 99352

1-888-375-PNNL (7665)

www.pnl.gov 